UNIVERSIDAD AUTÓNOMA METROPOLITANA IZTAPALAPA

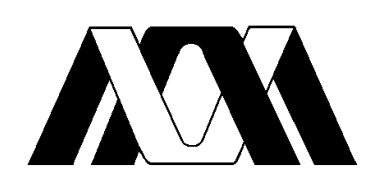

Casa abierta al tiempo

CIENCIAS BIOLÓGICAS Y DE LA SALUD

DEPARTAMENTO DE BIOTECNOLOGÍA

\title{
DIGESTIÓN ANAEROBIA TERMOFÍLICA DE LODOS RESIDUALES SECUNDARIOS
}

\author{
T $\quad \mathbf{E} \quad \mathbf{S} \quad \mathbf{I} \quad \mathbf{S}$
}

QUE PARA OBTENER EL GRADO ACADÉMICO DE:

DOCTOR EN BIOTECNOLOGÍA

P R E S E N T A

M. en B. SERGIO ESTEBAN VIGUERAS CARMONA

Director de tesis:

DR. OSCAR A. MONROY HERMOSILLO

Asesores

DRA.FLORINA RAMÍREZ VIVES

DR. ADALBERTO NOYOLA ROBLES 
A Patricia

Gracias por vivir en esta historia 
Agradezco a mi madre por darme la vida y llenarme de amor, por comprender mi loco andar por la vida.

Agradezco a mi amada Patricia por regalarme su amor durante todo el camino recorrido para llegar a la conclusión de esta tesis, por las largas horas de lectura dominical en el laboratorio $\mathrm{W}$, esperando terminara mi trabajo y por la paciencia para levantarme en todos los momentos que quise claudicar.

Agradezco a Dios por haberme enviado durante este camino, a mi corazón, a mí amada hija Alondra.

Mi agradecimiento a mis amigas Gabriela Zafra, Alejandra Velasco y Patricia Castilla, porque siempre fueron un apoyo en esta empresa. Gracias por sus consejos y cariño.

Agradezco al Dr. Oscar Monroy por su perseverancia para lograr la conclusión de esta tesis y por todo el apoyo durante mi larga estancia en la UAMI.

Gracias, Dra. Florina Ramírez por todos los empujones para lograr el objetivo, agradezco todos sus consejos y palabras de aliento para que siguiera adelante con mi proyecto doctoral.

Agradezco a mis asesores Dr. Adalberto Noyola, Dra. Gabriela Möeller y Dr. Ernesto Favela por su tiempo y consejos para mejorar esta tesis.

Un especial agradecimiento al Dr. Mariano Gutiérrez, por estar siempre dispuesto a ayudarme y por su apoyo para lograr que el borrador del artículo tomara forma.

Agradezco también a mis hermanos: Pepe, Eduardo, Carlos, Laura y Elia por alentarme siempre y a mis sobrinos porque siempre han representado un estímulo para ser mejor.

Gracias a Rafael Torres y César González por su amistad y porque siempre estuvieron dispuestos a escucharme durante las etapas difíciles, que como sabemos fueron innumerables.

Gracias a mis amigos Alejandro Aguilar, Armando Vargas, Angélica Islas, Irma Reséndiz, Angélica Vargas y Alejandro Aguilar Jr., por estar en los momentos más difíciles de esta historia.

Mi agradecimiento a Mary, Paulino, Bety, Javier, Daniel, Maricela, Silvia, Paulita, Ana, Andrés, Gerardo, Marco y Reny por estar siempre cerca de nosotros.

Finalmente agradezco a Patricia Barrera, por dejarme ser parte de su vida y apoyarme siempre a conseguir mis sueños. Te amo de aquí a la luna dos vueltas y de regreso. 
El hombre debe persistir en la creencia de poder explicar los inexplicable de lo contrario no investigaría.

Gothe 
Esta tesis fue realizada en el laboratorio de tratamiento de aguas residuales $y$ microbiología ambiental, del grupo de Ciencia y Tecnología Ambiental de la Universidad Autónoma Metropolitana Unidad Iztapalapa y fue financiado a través de la beca otorgada por el Consejo Nacional de Ciencia y Tecnología.

El doctorado en biotecnología de Universidad Autónoma Metropolitana está incluido en el Padrón Nacional de Posgrado del Consejo Nacional de Ciencia y Tecnología 
Iztapalapa, D.F., a 27 de abril del 2011.

El jurado designado por la División de Ciencias Biológicas y de la Salud de la Universidad Autónoma Metropolitana, aprobó la tesis:

Digestión anaerobia termofílica de lodos residuales secundarios

Que presentó:

M. en B. Sergio Esteban Vigueras Carmona

Comité tutorial:

Dr. Oscar Armando Monroy Hermosillo

Director, UAM-Iztapalapa

Dra. Florina Ramírez Vives

Asesor, UAM-Iztapalapa

Dr. Adalberto Noyola Robles

Asesor, UNAM-Instituto de Ingeniería

Jurado:

Dra. Florina Ramírez Vives

Presidente, UAM-Iztapalapa

Dr. Adalberto Noyola Robles

Secretario, UNAM-Instituto de Ingeniería

Dr. Ernesto Favela Torres

Vocal, UAM-Iztapalapa

Dra. Anne Claire Texier Valentin

Vocal 


\section{DIGESTIÓN ANAEROBIA TERMOFÍLICA DE LODOS RESIDUALES SECUNDARIOS.}

Resumen

Pág.

Abstract

Índice de figuras

$i$

Índice de cuadros

iii

iv

$v i$

1. Introducción 1

1.1.Objetivos

2. Efecto de la carga orgánica en la digestión anaerobia de lodos residuales $\quad 39$ secundarios en un sistema de dos etapas termofílico-mesofílico

2.1. Introducción

2.2. Material y métodos

2.2.1. Recolección de lodos residuales secundarios

2.2.2. Concentración de lodos residuales secundarios

2.2.3. Análisis

2.2.4. Medios de cultivo

2.2.5. Generación del inóculo anaerobio mesofílico y termofílico 12

2.2.6. Lodos residuales secundarios utilizados como sustrato 13

2.2.7 Sistema de dos etapas $\quad 13$

2.3. Resultados y discusión $\quad 14$

2.3.1. Efecto de la carga orgánica sobre la hidrólisis de lodos residuales $\quad 14$ secundarios

2.3.2. Efecto del tiempo de retención de sólidos sobre la velocidad de hidrólisis de 16 sólidos y la producción de metano

2.3.3. Efecto de la carga orgánica sobre la producción de amonio 20

$\begin{array}{lr}2.4 \text {. Conclusiones } & 22\end{array}$

3. Efecto de diferentes pretratamientos sobre la solubilización y 23 biodegradación anaerobia de sólidos suspendidos en lodos residuales secundarios.

3.1. Introducción 24

3.1.1. Pretratamientos térmicos 25

3.1.2. Pretratamientos mecánicos 26

3.1.3 Pretratamientos químicos 27

3.1.4 Pretratamientos combinados $\quad 29$

3.2. Material y métodos 30

3.2.1. Pretratamientos 30

3.2.2. Sustrato 30

3.2.3. Ensayos de biodegradabilidad 31

3.2.4. Cálculo de la energía específica $\quad 32$

3.2.5. Cálculo de la producción de energía por generación de metano 32

3.3. Resultados y discusión 33

3.3.1. Pretratamiento a diferentes temperaturas 33

3.3.2. Pretratamiento por ultrasonido 34

3.3.3. Pretratamiento con álcali 35

3.3.4. Efecto de los diferentes pretratamientos sobre la solubilidad de lodos 36 residuales secundarios

3.3.5. Efecto del pretratamiento sobre la biodegradabilidad anaerobia de los sólidos 37

$\begin{array}{ll}3.4 . & \text { Conclusiones } \\ & 38\end{array}$ 
4. Efecto del pretratamiento termoalcalino sobre la hidrólisis anaerobia de lodos residuales secundarios

4.1. Introducción $\quad 40$

4.2. Materiales y métodos 42

4.2.1. Tratamiento termo alcalino de lodos residuales secundarios 42

4.2.2. Cinéticas de reacción en reactores en lote 43

4.2.2.1. Inóculo 43

4.2.2.2. Sustrato $\quad 43$

4.2.2.3. Cinéticas de hidrólisis de sólidos suspendidos de LRS crudo (SS) y 43 pretratado $\left(\mathrm{SS}_{\mathrm{TA}}\right)$

4.2.2.4.Cálculo de la constante de superficie $\left(\mathrm{K}_{\mathrm{SBK}}\right)$

4.2.2.5. Distribución del tamaño de partícula 45

4.2.3. Cinéticas de hidrólisis de los sólidos disueltos de LRS crudo (SD) y 45 pretratado $\left(\mathrm{SD}_{\mathrm{TA}}\right)$

4.2.4. Cuantificación y composición del biogás 46

4.3. Resultados y discusión 46

4.3.1. Solubilización y biodegradabilidad de los LRS pretratados 46

4.3.2. Evaluación cinética del efecto del pretratamiento termoalcalino 48

4.3.2.1. Distribución del tamaño de partícula 48

4.3.2.2. Cálculo de la constante $\mathrm{K}_{\mathrm{SBK}}$ para los SS y $\mathrm{SS}_{\mathrm{TA}} \quad 48$

4.3.2.3. Cálculo de las constantes $\mathrm{k}_{\mathrm{h}} \mathrm{y} \mathrm{K}_{\mathrm{X}}$ para los $\mathrm{SD}$ y $\mathrm{SD}_{\mathrm{TA}}$

4.3.3. Simulación con reacciones consecutivas de SS y SD a metano 50

4.4. Conclusiones $\quad 51$

5. Conclusiones generales y recomendaciones 53

6. Referencias 57 


\section{Resumen.}

Las sustancias exopoliméricas (SEP) y la membrana celular son los dos principales sustratos que resisten la solubilización durante la digestión anaerobia (DA) mesofílica de lodos residuales secundarios (LRS). Esta resistencia provoca que los tiempos de retención de sólidos en digestores de LRS sean mayores a 15 días, para reducirlos es necesario acelerar la etapa de solubilización/hidrólisis. Es por esto que se deben proponer modificaciones al proceso de estabilización de LR por DA mesofílica. Los cambios deben orientarse principalmente a aumentar la velocidad de desintegración e hidrólisis de los LRS y aumentar la productividad de metano en el proceso. En esta tesis se analizan las variables y procesos que pueden acelerar la digestión anaerobia de lodos residuales secundarios.

En el capítulo 2 se evaluó el efecto de la carga orgánica sobre la digestión anaerobia de lodos residuales secundarios en un sistema de dos etapas termofílicamesofílica y se compara con la digestión anaerobia en una etapa mesofílica y termofílica. La digestión anaerobia de los lodos residuales secundarios se realizó en reactores continuos de tanque agitado. La carga orgánica alimentada varió entre 0.5 y $8.0 \mathrm{~kg} \mathrm{SSV} \cdot \mathrm{m}^{-3} \cdot \mathrm{d}^{-1}$. El reactor termofílico mostró la mejor remoción de sólidos suspendidos volátiles, que fue de $55 \%$ a un TRS de 10 días. Cuando el reactor termofílico presenta alta estabilidad (adecuada remoción de AGV) el sistema termofílico-mesofílico (T2E-M2E) no representa ventajas significativas sobre la operación termofílica de una etapa. En la digestión anaerobia termofílica de LRS existe una relación lineal entre la carga orgánica y la velocidad de producción volumétrica de metano, para cargas de entre 1.0 y $6.0 \mathrm{~kg} \mathrm{SSV} \cdot \mathrm{m}^{-3} \cdot \mathrm{d}^{-1}$. También se encontró que la concentración de amonio no ionizado en los reactores mesofílicos provocó una inhibición en la velocidad de producción de metano.

En el capítulo 3 se evaluó el efecto de los pretratamientos en la digestión anaerobia mesofílica y termofílica de lodos residuales secundarios. Los pretratamientos utilizados fueron: mecánico (ultrasonido), térmico, químico (álcali), ultrasonido-alcalino y térmico-alcalino. Las condiciones de éstos fueron: térmico $\left(120^{\circ} \mathrm{C}, 15 \mathrm{~min}\right)$, alcalino (0.5 g NaOH/g SSV, $1 \mathrm{~h}$ ), térmico-alcalino $\left(0.5 \mathrm{~g} \mathrm{NaOH} / \mathrm{g} \mathrm{SSV}\right.$ y $15 \mathrm{~min}$ a $\left.120{ }^{\circ} \mathrm{C}\right)$, sonicado $(20 \mathrm{kHz}, 1 \mathrm{~h})$, y sonicado-alcalino $(0.5 \mathrm{~g} \mathrm{NaOH} / \mathrm{g} \mathrm{SSV}$ y sonicación a $20 \mathrm{kHz}$, 1h). Todos con agitación constante de 300 rpm.

Para los pretratamientos se determinó la eficiencia de solubilización de los sólidos suspendidos y la biodegradabilidad de la fracción soluble del lodo pretratado. El 
pretratamiento que logró la mayor solubilización fue el ultrasonido-alcalino (75\%). Ninguno de los pretratamientos modifica la biodegradabilidad final del lodo; sin embargo, la producción de metano fue diferente. El lodo pretratado por ultrasonido presentó menor producción de metano.

También se determinó la energía neta producida durante la estabilización anaerobia de lodos pretratados. Todos los pretratamientos tuvieron una energía neta negativa. El pretratamiento que menos energía neta requirió fue el alcalino y el de mayor requerimiento energético fue el ultrasonido-alcalino.

En el capítulo 4 se estudió el efecto del pretratamiento termoalcalino de lodos residuales secundarios en la cinética de hidrólisis anaerobia mesofílica y termofílica de sólidos suspendidos (SS) y disueltos (SD). El pretratamiento termo-alcalino tiene diferente efecto sobre la hidrólisis de sólidos suspendidos y disueltos, por lo que la cinética de la digestión anaerobia de LRS fue estudiada utilizando un modelo de superficie y uno de saturación para encontrar estas diferencias. El pretratamiento termoalcalino incrementa la degradación anaerobia mesofílica y termofílica de sólidos suspendido y tiene efectos negativos sobre la degradación de los sólidos disueltos produciendo una inhibición no competitiva para la digestión anaerobia mesofílica y una inhibición competitiva para la digestión anaerobia termofílica. Una simulación matemática con reacciones consecutivas de SS a SD y a metano, muestra que con un aumento a $4 \%$ en la concentración de sólidos iniciales en los lodos tratados termo alcalinamente, disminuye la inhibición de la hidrólisis de SD en la digestión anaerobia termofílica. 


\begin{abstract}
The effect of alkaline pretreatment of waste-activated sludge, using two models to study the sequential hydrolysis rates of suspended (Sanders' surface model) and dissolved (Goel's saturation model) solids, on the mesophilic and thermophilic anaerobic digestion rate is evaluated. The pretreatment, which reduces the size of the solids, increases the reaction rate by increasing the surface area and the specific surface hydrolysis constant $\left(\mathrm{K}_{\mathrm{SBK}}\right)$; at thermophilic conditions from $0.45 \times 10^{-3} \mathrm{~kg} \mathrm{~m}^{-2} \mathrm{~d}^{-1}$ for the fresh sludge to $0.74 \times 10^{-3} \mathrm{~kg} \cdot \mathrm{m}^{-2} \mathrm{~d}^{-1}$ for the pretreated sludge and at mesophilic conditions these values are $0.28 \times 10^{-3} \mathrm{~kg} \mathrm{~m}^{-2} \mathrm{~d}^{-1}$ and $0.47 \times 10^{-3} \mathrm{~kg} \mathrm{~m}^{-2} \mathrm{~d}^{-1}$ confirming the usefulness of a pretreatment for solids reduction. But for soluble solids, the thermo alkaline pretreatment decreases the reaction rates by inducing a competitive inhibition on the thermophilic anaerobic digestion rate while in the mesophilic range, a noncompetitive inhibition is observed. A mathematical simulation of the consecutive reactions, suspended solids to dissolved solids and to methane in staged anaerobic thermophilic-mesophilic digestion, shows that with $4 \%$ suspended solids concentration it is better not to use a thermo alkaline pretreatment because overall solids reduction and total methane production are not as good as without pretreatment.
\end{abstract}




\section{Índice de figuras}

páginas

Figura 2.1 Dispositivo para la sedimentación de lodos residuales

Figura 2.2 Curva de calibración para determinar la fracción de metano en el biogás

Figura 2.3 Sistemas de una (M1E) y dos etapas (T2E-M2E) para la digestión de lodos residuales secundarios

Figura 2.4 Efecto de la carga orgánica en la concentración de proteínas

solubles durante la digestión anaerobia mesofílica (M1E), termofílica (T2E) y dos etapas termofílica-mesofílica

Figura 2.5 Efecto de la carga orgánica, $\mathrm{CO}$ en la concentración de

carbohidratos solubles durante la digestión anaerobia mesofílica (M1E), termofílica (T2E) y dos etapas termofílica-mesofílica

Figura 2.6 CO, carga orgánica $(\Delta), \mathrm{r}_{\mathrm{SS}}$, velocidad de hidrólisis y $\%$ de hidrólisis: M1E (O), T2E (•); dos etapas (匹).

Figura 2.7. Velocidad de producción volumétrica de metano contra la carga orgánica.

Figura 2.8. Concentración de AGV contra la carga orgánica

Figura 2.9 Concentración de amoniaco a distintas cargas orgánicas. M1E (O), 21 M2E (口), T2E (•).

Figura 3.1 Evolución de la DQO soluble durante el tratamiento térmico de lodo residual secundario a 70,90 y $120^{\circ} \mathrm{C}$ a distintos tiempos de contacto.

Figura 3.2 Perfil tiempo-temperatura durante el tratamiento térmico de lodo 34 residual secundario a 70,90 y $120^{\circ} \mathrm{C}$.

Figura 3.3 Evolución de la DQO soluble durante el tratamiento por ultrasonido de lodo residual secundario a $22 \mathrm{kHz}(\mathrm{O})$ y $44 \mathrm{kHz}(\boldsymbol{\square})$ a distintos tiempos de contacto.

Figura 3.4 Evolución de la DQO soluble durante el tratamiento de lodos 36

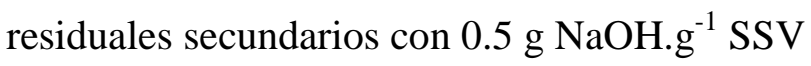

Figura 3.5. Eficiencia de solubilización para lodos residuales secundarios 36 pretratados

Figura 3.6. Biodegradabilidad de los sólidos solubles en lodos residuales 37 pretratados

Figura 4.1 Distribución del tamaño de partícula inicial de $\mathrm{SS}_{\mathrm{S}} \mathrm{SS}_{\mathrm{TA}}$ 
Figura 4.2 Área acumulada de SS y SS

Figura 4.3 Hidrólisis de SS ajustados al modelo de superficie. SS mesofílico

$(\Delta)$, SS termofílico $(\Delta), \mathrm{SS}_{\mathrm{TA}}$ mesofílico $(\circ), \mathrm{SS}_{\mathrm{TA}}$ termofílico $(\bullet)$.

Figura 4.4 Velocidad de producción de metano como función de la DQO

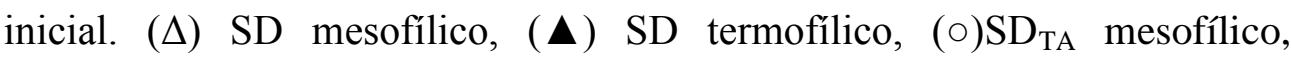
$(\bullet) \mathrm{SD}_{\mathrm{TA}}$ termofílico.

Figura 4.5 Simulación de la digestión anaerobia de LRS usando las

constantes cinéticas de la Cuadro 4.3 y 4.4. SS (०), $\mathrm{CH}_{4}(\Delta)$, DS (口) 


\section{Índice de cuadros.}

Páginas

Cuadro 2.1 Eficiencia de remoción de sólidos suspendidos y producción de metano en la DA mesofílica de LRP y LRS

Cuadro 2.2 Eficiencia de remoción de SSV por digestión anaerobia mesofílica y termofílica

Cuadro 2.3 Sistemas de una y dos etapas para la estabilización de lodos residuales secundarios

Cuadro 2.4 Características de los LRS espesados utilizados como sustrato 13

Cuadro 2.5. Concentración de amonio en los reactores.

Cuadro 3.1 Eficiencia de solubilización de LRS con pretratamiento térmico 26

Cuadro 3.2 Eficiencia de solubilización de LRS con distintos pretratamientos mecánicos.

Cuadro 3.3 Efecto del pretratamiento químico de los LRS en la

solubilización y producción de metano

Cuadro 3.4 Efecto del pretratamiento termoquímico de los LRS en la

solubilización y producción de metano

Cuadro 3.5 Requerimiento energético para los pretratamientos

Cuadro 4.1 Solubilización de LRS por pretratamiento termoalcalino

Cuadro 4.2 Solubilización de LRS por diferentes condiciones de pretratamiento

Cuadro 4.3 Valores de $\mathrm{K}_{\mathrm{SBK}}$ estimados para la hidrólisis de SS

Cuadro 4.4 Constantes del modelo de saturación 
1

INTRODUCCIÓN 


\section{Introducción}

Los lodos residuales (LR) son generados en las plantas de tratamiento de aguas residuales (PTAR). Los lodos generados en la sedimentación primaria se denominan lodos residuales primarios (LRP) y los que resultan de la clarificación secundaria se denominan lodos residuales secundarios (LRS). En México, más del $90 \%$ de ellos no son tratados, lo que implica que alrededor de 3,195 t peso seco/d de lodos residuales sin tratamiento se devuelven al alcantarillado y a las corrientes de agua, lo que representa, sin lugar a duda, un problema ambiental y de salud pública. Este cálculo sólo considera el porcentaje de aguas residuales que se tratan actualmente en el país, $35 \%$ de las municipales y $17 \%$ de las industriales (CNA, 2010).

La importancia de la disposición de lodos se enfatiza aun más cuando se realizan consideraciones económicas. Por ejemplo, los costos de tratamiento y disposición de lodos residuales representan el $60 \%$ del presupuesto anual de operación y mantenimiento de las PTAR (Cacho Rivero y Suidan, 2006).

La norma oficial mexicana (NOM-004-SEMARNAT-2002) establece que se puede utilizar cualquier tecnología que logre dar las características adecuadas a los lodos residuales para ser manejados como biosólidos. Esta Norma clasifica a los biosólidos como tipo excelente o bueno en función del contenido de metales pesados y como clase A, B o C en función del contenido de patógenos. Los biosólidos clasificados como excelentes y clase A pueden ser aprovechados en usos urbanos con contacto público directo durante su aplicación. Los biosólidos tipo excelente o bueno y clase B pueden ser aprovechados en usos urbanos sin contacto público directo durante su aplicación y los de clase $\mathrm{C}$ pueden ser aprovechados en usos forestales, mejoramiento de suelos y usos agrícolas.

Se ha mostrado que la digestibilidad anaerobia de los lodos residuales secundarios (LRS) es considerablemente menor que la de lodos residuales primarios (LRP). La menor biodegradabilidad de los LRS se le ha atribuido a la naturaleza recalcitrante de varios componentes celulares como los exopolímeros y la pared celular (Ghosh, 1991). Debido a esto, la investigación básica y aplicada se ha centrado en este tipo de lodo.

Las características de los LRS varían en función de la tecnología empleada para el tratamiento del agua residual, de las condiciones de operación de la PTAR y de la comunidad que genera el agua residual (rural, urbana, industrial u otras). Por ejemplo, un estudio realizado por Bougrier et al. (2008) indica que las PTAR de tratamiento de agua residual de alta carga, producen LRS de alta biodegradabilidad inicial y que PTAR 
de aireación extendida, tienen una pobre biodegradabilidad inicial, por otro lado, lodos de PTAR de carga media presentan una biodegradabilidad inicial heterogénea, es decir, puede ser de baja biodegradabilidad o alta biodegradabilidad.

Las sustancias exopoliméricas (SEP) y la membrana celular son los dos principales sustratos resistentes a la solubilización durante la digestión anaerobia (DA) mesofílica de los LRS. Esta resistencia provoca que los tiempos de retención de sólidos (TRS) en digestores de LRS sean mayores a 15 días, para reducirlos es necesario acelerar la etapa de solubilización/hidrólisis. Es por esto que se han propuesto modificaciones al proceso de estabilización de LR por DA mesofílica. Los cambios se orientan principalmente a aumentar la velocidad de desintegración e hidrólisis de los LRS y la productividad de metano en el proceso.

Varios procesos nuevos de digestión de lodos residuales han sido discutidos y contrastados con los convencionales de estabilización anaerobia mesofílica, entre los que se destacan: reactores termofílicos, reactores acidogénicos y procesos de dos etapas, en éstos últimos se separan las etapas acidogénica y metanogénica; otros sistemas de dos etapas son los termofílicos-mesofílicos, en ambos se promueve una solo condición de operación en cada etapa, con la intención de aprovechar las ventajas ofrecidas por cada una de ellas.

Algunas de las propiedades particulares de la digestión anaerobia termofílica son: la disminución del tiempo de retención hidráulico, destrucción de patógenos, reducción de la viscosidad de los lodos y bajos volúmenes de residuos generados por la estabilización. Los parámetros a controlar en la DA termofílica son: la alcalinidad y el $\mathrm{pH}$ ya que el metabolismo de las bacterias hidrolíticas es modificado por pequeñas variaciones en la alcalinidad y $\mathrm{pH}$ (Péringen, 1999). Para evitar variaciones en la alcalinidad y el pH, además de contar con un controlador externo (dosis de bicarbonato de sodio $\left(\mathrm{NaHCO}_{3}\right)$, se debe manipular la carga orgánica y el tiempo de retención de sólidos para lograr que las concentraciones de ácidos grasos de cadena larga (AGCL) no inhiban la metanogénesis.

Beneficios adicionales del sistema de dos etapas termofílicos-mesofílicos son: uso de un 35\% menos de polímero aniónico para espesar los biosólidos producidos en estos sistemas, alto contenido de metano en el biogás y bajo de ácido sulfhídrico, proceso estable, aumento de la producción de energía neta, incremento en la destrucción de bacterias entéricas patógenas y virus (Ghosh, 1991). 
Otra forma en que se ha intentado aumentar la velocidad de desintegración del lodo es mediante el uso de pretratamientos, éstos aumentan la disponibilidad de la materia orgánica al hidrolizar los polímeros recalcitrantes y con esto acrecienta la producción de metano. Sin embargo, algunos estudios han demostrado que no hay mejora en la biodegradabilidad anaerobia cuando se aplican pretratamientos termoquímicos (Delgenès et al, 2000) y tampoco mejora la producción de metano (Cacho y Suidan, 2006) cuando los lodos residuales secundarios son pretratados químicamente. Estos resultados aparentemente contrarios, pueden estar relacionados con los criterios utilizados en los cálculos, éstos son expresados en función de la cantidad de SSV alimentados, SSV removidos, DQO alimentado, DQO removido, sólidos suspendidos, sólidos disueltos y sólidos totales; esta heterogeneidad en los cálculos puede llevar a conclusiones erróneas.

Una forma de evaluar el efecto del pretratamiento sobre la digestión anaerobia de LRS es determinando, por separado, la velocidad de hidrólisis de los sólidos suspendidos y la velocidad de hidrólisis de los sólidos disueltos, la primera depende de la superficie disponible para la hidrólisis; la segunda, de la concentración del inóculo y de su actividad metabólica. Este análisis puede realizarse utilizando un modelo matemático que relaciona la velocidad de hidrólisis de los sólidos suspendidos con la superficie disponible para ésta (Sanders et al., 2000) y otro modelo matemático que relaciona la velocidad de hidrólisis de los sólidos disueltos con la concentración del inóculo y su actividad metabólica (Goel et al. 1998). Con este estudio se puede obtener una conclusión sobre el efecto del pretratamiento sobre la digestión anaerobia de lodos residuales secundarios 


\subsection{Objetivo general}

Estudiar las variables y procesos que pueden acelerar la digestión anaerobia de lodos residuales secundarios.

\subsubsection{Objetivos específicos}

1. Evaluar el efecto de la carga orgánica sobre la digestión anaerobia de lodos residuales secundarios en un sistema de dos etapas termofílica-mesofílica.

2. Analizar el efecto de los pretratamientos: mecánico, térmico y alcalino en la digestión anaerobia mesofílica y termofílica de lodos residuales secundarios.

3. Evaluar el efecto del pretratamiento termoquímico de lodos residuales secundarios en la cinética de hidrólisis anaerobia mesofílica y termofílica de sólidos suspendidos y disueltos. 


\section{2}

EFECTO DE LA CARGA ORGÁNICA EN LA DIGESTIÓN ANAEROBIA DE LODOS RESIDUALES SECUNDARIOS EN UN SISTEMA DE DOS ETAPAS TERMOFÍLICO- MESOFÍLICO 


\section{Efecto de la carga orgánica en la digestión anaerobia de lodos residuales secundarios en un sistema de dos etapas termofílico- mesofílico}

\subsection{Introducción}

La digestión anaerobia (DA) de lodos residuales es llevada a cabo por un consorcio microbiano el cual: a) solubiliza los sólidos orgánicos suspendidos, b) hidroliza las proteínas, carbohidratos y lípidos, c) convierte las moléculas orgánicas solubles a ácidos grasos volátiles (AGV), d) convierte los AGV a acetato e hidrógeno y e) finalmente convierte el acetato a bióxido de carbono y metano. La solubilización de los sólidos suspendidos es la etapa que controla el proceso global de la DA de lodos residuales.

Los reactores continuos de tanque agitado (RCTA) a temperatura mesofílica (30$40{ }^{\circ} \mathrm{C}$ ), son los que tradicionalmente se han utilizado para la estabilización anaerobia de lodos residuales (Liu, 1998) porque han mostrado estabilidad a tiempos largos de operación. La digestión anaerobia mesofílica tiene varias ventajas que incluyen la descomposición de la materia orgánica y la producción de biogás con alto poder calórico que puede ser transformado a energía con mayor valor económico y de uso.

En el cuadro 2.1 se aprecia que la DA mesofílica de lodos residuales primarios (LRP) presenta una eficiencia de remoción de sólidos suspendidos volátiles (SSV) entre 55 y $70 \%$, a cargas orgánicas de $1.21 \mathrm{~kg} \mathrm{SSV} \cdot \mathrm{m}^{-3} \cdot \mathrm{d}^{-1}$. En este mismo cuadro se observa que cuando se estabilizan mezclas de LRP y LRS, se aumenta el porcentaje de remoción de SSV, pero esto está en función de la relación LRP:LRS en la mezcla. En consecuencia la mezcla no influye en el grado de destrucción de los sólidos suspendidos de los LRS.

A escala industrial se logra por DA mesofílica una reducción en los LRS de 48 $\%$ de sólidos suspendidos volátiles con una carga orgánica de $1.75 \mathrm{~kg} \cdot \mathrm{SSV} \cdot \mathrm{m}^{-3} \cdot \mathrm{d}^{-1} \mathrm{y}$ producción de metano de $0.462 \mathrm{~kg} \mathrm{CH} 4 \mathrm{~m}^{-3} \cdot \mathrm{d}^{-1}$. Como se observa en el cuadro 2.1 la DA mesofílica de LRS requiere de TRS mayores o iguales a 10 días, consecuentemente las plantas de digestión de lodos requieren de grandes volúmenes de instalación, alta inversión inicial y altos costos de operación y mantenimiento.

Al comparar la productividad de metano en la DA de LRP y LRS la mayor producción de metano se logra durante la estabilización de LRP y también se observa que la mezcla de LRP:LRS no influye en el grado de biodegradabilidad de los LRS. 
Cuadro 2.1 Eficiencia de remoción de sólidos suspendidos y producción de metano en la DA mesofílica de LRP y LRS.

\begin{tabular}{|c|c|c|c|c|c|c|c|}
\hline $\begin{array}{l}\text { Tipo de } \\
\text { reactor }\end{array}$ & $\begin{array}{l}\mathbf{T} \\
\left({ }^{\circ} \mathbf{C}\right)\end{array}$ & Tipo de LR & $\begin{array}{c}\text { TRS } \\
\text { (d) }\end{array}$ & 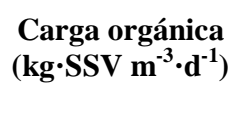 & $\begin{array}{l}\text { Eficiencia de } \\
\text { remoción } \\
\text { (\% de SSV) }\end{array}$ & $\begin{array}{c}\text { Producción de } \\
\text { metano } \\
\left(\mathrm{kg} \mathrm{CH}_{4} \cdot \mathrm{m}^{-3} \cdot \mathrm{d}^{-1}\right)\end{array}$ & Ref. \\
\hline \multirow[t]{3}{*}{ Lote } & 35 & LRS & 27 & 0.54 & 50 & NR & 1 \\
\hline & & LRP & & 1.21 & 70 & & \\
\hline & & LRP:LRS(1:1) & & 0.87 & 60 & & \\
\hline RCTA & 35 & LRS & 20 & 1.75 & 48 & 0.962 & 2 \\
\hline \multirow[t]{2}{*}{ RCTA } & 35 & LRP:LRS & 20 & $1.5-3$ & 49 & 0.588 & 3 \\
\hline & & & 10 & $3-6$ & 47 & 0.525 & \\
\hline \multirow[t]{3}{*}{ RCTA } & 37 & LRP & $15-30$ & 2 & $55-60$ & 0.785 & 4 \\
\hline & & LRS & & & $32-40$ & 0.392 & \\
\hline & & LRS:LRP & & & $40-50$ & 0.714 & \\
\hline
\end{tabular}

Ref: 1. Arnaiz et al., 2006; 2. Killilea, et al., 2000; 3. Metzner y Lemmer (1997); 4. Carrozzi y Steinle (1994)

El tiempo de retención de sólidos (TRS) y la temperatura son dos de los parámetros de diseño más importantes en la DA para la estabilización de lodos residuales (Appels et al., 2008). Elefsiniotis y Oldham (1994) observaron que la distribución de ácidos grasos volátiles (AGV) fue afectada por el cambio en el TRS durante la DA de lodos residuales primarios. El estudio de Miron et al. (2000) reveló que la hidrólisis de lípidos y carbohidratos de lodos primarios se incrementó con el aumento del TRS. De la Rubia et al. (2006) encontraron que el TRS tiene un considerable efecto en la dinámica de la población metanogénica y en el incremento de la concentración de AGV.

La investigación de Mahmoud et al. (2004) mostró que la temperatura tiene influencia significativa en la hidrólisis de proteínas, carbohidratos y lípidos durante la DA de lodos residuales primarios y que la hidrólisis es significativamente mayor a 35 ${ }^{\circ} \mathrm{C}$ que a $25{ }^{\circ} \mathrm{C}$. Por esto, recientemente los RCTA se han utilizado a temperaturas termofílicas $\left(50-60{ }^{\circ} \mathrm{C}\right)$ para cumplir dos objetivos: producir biosólidos clase A e incrementar la velocidad de destrucción de sólidos orgánicos (Buhr y Andrews, 1977; Garber, 1982; Rimkus et al., 1982; Krugel et al., 1998).

Las ventajas de la DA termofílica están relacionadas con el mejoramiento en las propiedades de secado del lodo estabilizado, con la mayor destrucción de patógenos y con el incremento en la velocidad de reacción. Sin embargo, se ha reportado que no existe incremento en la digestión del lodo. Por ejemplo, De la Rubia et al. (2002) mostraron que no existe diferencia en la eficiencia de destrucción de SV entre un reactor mesofílico y uno termofílico (ver Cuadro 2.2) y que en cambio este último presentó una eficiencia de remoción de DQO menor al mesofílico. Las eficiencias de remoción de sólidos para ambos reactores fue de $53 \%$ y la remoción de DQO fue de $52.8 \%$ para el 
mesofílico y $35.3 \%$ para el termofílico. También se observa una disminución en el rendimiento del metano en condiciones termofílicas, alrededor del $50 \%$ con respecto al mesofílico (Cuadro 2.2). En estudio posterior De la Rubia et al. (2006) señalan que en condiciones termofílicas la eficiencia de remoción es independiente del TRS cuando éste es mayor de $15 \mathrm{~d}$. En ese mismo estudio se observa que al disminuir el TRS se genera un aumento en el rendimiento de metano.

Cuadro 2.2 Eficiencia de remoción de SSV por digestión anaerobia mesofílica y termofílica

\begin{tabular}{|c|c|c|c|c|c|c|c|}
\hline $\begin{array}{l}\text { Tipo de } \\
\text { reactor }\end{array}$ & $\begin{array}{l}\mathbf{T} \\
\left({ }^{\circ} \mathbf{C}\right)\end{array}$ & Tipo de LR & $\begin{array}{l}\text { TRS } \\
\text { (d) }\end{array}$ & $\begin{array}{l}\text { Carga orgánica } \\
\left(\mathrm{kg}^{-} \mathrm{SSV} \mathrm{m} \mathrm{m}^{-3} \cdot \mathrm{d}^{-1}\right)\end{array}$ & $\begin{array}{l}\text { Eficiencia de } \\
\text { remoción } \\
(\% \text { de SSV })\end{array}$ & $\begin{array}{c}\text { Producción de } \\
\text { metano } \\
\left(\mathrm{kg} \mathrm{CH}_{4} \cdot \mathrm{m}^{-3} \cdot \mathbf{d}^{-1}\right)\end{array}$ & Ref. \\
\hline RCTA & 55 & LRP:LRS & $\begin{array}{l}15 \\
20 \\
27 \\
40\end{array}$ & $\begin{array}{l}2.3 \\
2.0 \\
1.5 \\
1.0\end{array}$ & $\begin{array}{l}75 \\
55 \\
45 \\
45\end{array}$ & $\begin{array}{l}0.279 \\
0.185 \\
0.150 \\
0.121\end{array}$ & 5 \\
\hline RCTA & $\begin{array}{l}35 \\
55 \\
\end{array}$ & LRP:LRS & 27 & 1.3 & $\begin{array}{l}53 \\
53 \\
\end{array}$ & $\begin{array}{l}0.178 \\
0.143 \\
\end{array}$ & 6 \\
\hline
\end{tabular}

Ref. 5. de la Rubia et al., 2006; 6. de la Rubia et al., 2002

Los sistemas de dos etapas se implementaron con la intención de incrementar la estabilidad de la digestión anaerobia y mejorar la calidad del biosólido producido. En estos sistemas se promueve una sola condición de operación en reactores independientes, que se conectan entre sí, con la intención de aprovechar las ventajas que ofrece cada una de las etapas. Ejemplos de sistemas de dos etapas son reactores acidogénicos- metanogénicos y reactores termofílicos-mesofílicos.

La separación física de las etapas hidrolítica/acidogénica y metanogénica contribuye a la estabilidad de la digestión anaerobia debido a que la sobre carga del reactor metanogénico puede ser prevenida por el control de la etapa acidogénica en el primer reactor. Otras ventajas son el incremento de la actividad específica de producción de metano, incremento en la carga orgánica que puede ser tratada, remoción de compuestos tóxicos para las bacterias metanogénicas y suministro constante de sustrato para las bacterias metanogénicas. Por su parte las desventajas de la separación de las etapas, incluye la acumulación de hidrógeno a concentraciones inhibitorias para la producción de acetato durante la acidogénesis y la eliminación de la interdependencia nutricional entre las bacterias metanogénicas y acidogénicas.

Los sistemas de dos etapas termofílico-mesofílico presentan remociones de SV entre 38 y $45 \%$, para tiempos de retención menores a 15 días y de $58.8 \%$ para TRS mayores a $21 \mathrm{~d}$ (Cuadro 2.3). 
Cuadro 2.3 Sistemas de dos etapas para la estabilización de lodos residuales.

\begin{tabular}{|c|c|c|c|c|c|c|c|}
\hline $\begin{array}{l}\text { Tipo de } \\
\text { reactor }\end{array}$ & $\mathbf{T}\left({ }^{\circ} \mathbf{C}\right)$ & Tipo de LR & TRS (d) & 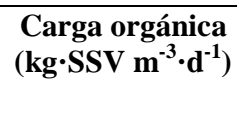 & $\begin{array}{l}\text { Eficiencia de } \\
\text { remoción } \\
(\% \text { de SV) }\end{array}$ & $\begin{array}{c}\text { Producción de } \\
\text { metano } \\
\left(\mathrm{kg} \mathrm{CH}_{4} \cdot \mathrm{m}^{-3} \cdot \mathrm{d}^{-1}\right)\end{array}$ & Ref. \\
\hline $\begin{array}{l}\text { RCTA } \\
\text { dos etapas }\end{array}$ & 55 y 35 & LRS & 2 y 10 & $2.6-3.0$ & 38 & 0.420 & 7 \\
\hline RCTA & 35 & & 25 & $1.2-1.44$ & 42 & 0.210 & \\
\hline RCTA & 35 & LRP:LRS & $\begin{array}{l}24 \\
40\end{array}$ & $\begin{array}{c}1.2-1.4 \\
0.74-0.81\end{array}$ & $\begin{array}{l}32 \\
47\end{array}$ & $\begin{array}{l}0.464 \\
0.275\end{array}$ & 8 \\
\hline $\begin{array}{l}\text { RCTA } \\
\text { dos etapas }\end{array}$ & 55 y 35 & & 4 y 10 & $2.1-2.3$ & 45 & 0.728 & \\
\hline RCTA & 36.8 & LRS & $\begin{array}{c}8 \text { y } 20 \\
3.1(\mathrm{pH} \mathrm{5.6)} \\
9.1(\mathrm{pH} \mathrm{7.7)} \\
\end{array}$ & $\begin{array}{c}1.1-1.2 \\
\left.18.9_{(\mathrm{pH}} 5.6\right) \\
6.2_{(\mathrm{pH} \mathrm{7.7})} \\
\end{array}$ & $\begin{array}{c}50 \\
56.4\end{array}$ & $\begin{array}{l}0.410 \\
0.285\end{array}$ & 9 \\
\hline
\end{tabular}

Ref. 7. García-Heras et al. (1999); 8. Yue H. et al. (1998); 9. Ghosh, (1991)

El objetivo de este estudio es evaluar el efecto del tiempo de retención de sólidos sobre la estabilidad de la digestión anaerobia mesofílica y termofílica de LRS. Además de evaluar la conveniencia de utilizar un sistema mesofílico-termofílico para el tratamiento de lodos residuales secundarios.

\subsection{Material y métodos}

\subsubsection{Recolección de los lodos residuales secundarios}

La recolección de LRS se realizó en la planta de tratamiento de aguas residuales de la UNAM, Ciudad de México, que trata el agua residual del campus, utilizando tres sistemas de tratamiento secundario: lodos activados, discos rotatorios y filtro percolador.

\subsubsection{Concentración de los lodos residuales}

Los lodos residuales se recolectaron mensualmente y se consolidaron por gravedad (figura 2.1) el tiempo de estancia en el sedimentador estuvo en función de la concentración de SST requerida. Posteriormente se almacenaban a $4{ }^{\circ} \mathrm{C}$ en garrafones de polietileno, hasta por 52 días. 


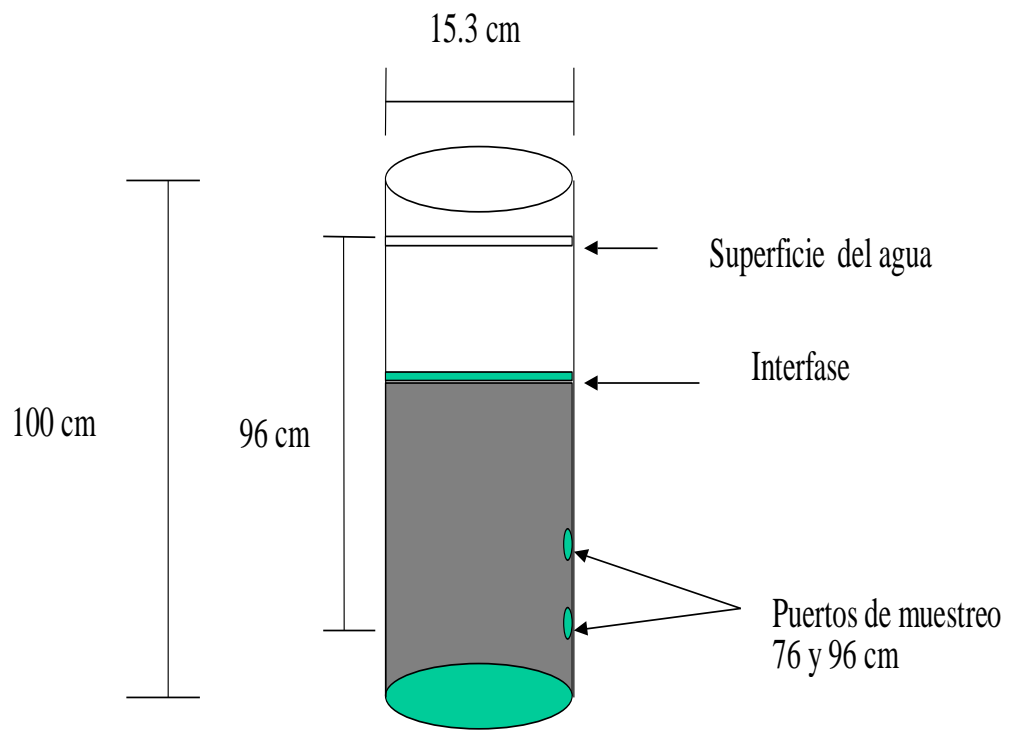

Figura 2.1. Dispositivo para la sedimentación de lodos residuales.

\subsubsection{Análisis}

2.2.3.1 La demanda química de oxigeno total (DQO) y soluble (DQOs), los sólidos suspendidos totales (SST), los sólidos suspendidos volátiles (SSV) y el amonio total se determinaron según APHA, 1998.

2.2.3.2 Los carbohidratos y las proteínas se determinaron por los métodos modificados de Dubois y Lowry respectivamente, según lo descrito por Delgenès et al. (2000).

2.2.3.3 La cuantificación de propionato, butirato y acetato (como representantes de los AGV en la muestra), se realizó por cromatografía de gases.

2.2.3.4 Composición del biogás y cuantificación de metano. La composición del biogás se realizó tomando una muestra del colector de biogás en el reactor y se inyectó $0.1 \mathrm{~mL}$ en un cromatógrafo de gases GOW-MAC con integrador SP-4290 y una columna de acero inoxidable empacada con carbosphere. Las condiciones de operación del cromatógrafo fueron: temperatura del inyector $170{ }^{\circ} \mathrm{C}$, temperatura de la columna $140{ }^{\circ} \mathrm{C}$, temperatura del detector $190{ }^{\circ} \mathrm{C}$, flujo del gas acarreador $(\mathrm{He}) 30 \mathrm{~mL} \cdot \mathrm{min}^{-1}$, corriente de los filamentos $120 \mathrm{~mA}$.

El volumen de metano producido en la digestión de lodos residuales se cuantificó, utilizando la técnica de desplazamiento de una solución salina saturada (300 $\mathrm{g} \mathrm{NaCl} . \mathrm{L}^{-1}$ ), con un $\mathrm{pH}$ de 3.0 , contenida en un tubo de $32 \mathrm{~cm}$ de alto y $3.5 \mathrm{~cm}$ de diámetro interno. Como indicador del cambio de $\mathrm{pH}$, por la disolución del bióxido de 
carbono, se uso rojo de metilo. El volumen de metano se ajusta de acuerdo a las condiciones de $\mathrm{T}$ y $\mathrm{P}$ del experimento.

La fracción de metano en el biogás $\left(\mathrm{f}_{\mathrm{CH} 4}\right)$ se obtuvo a partir de la curva de calibración (figura 2.2) y la ecuación 2.1.

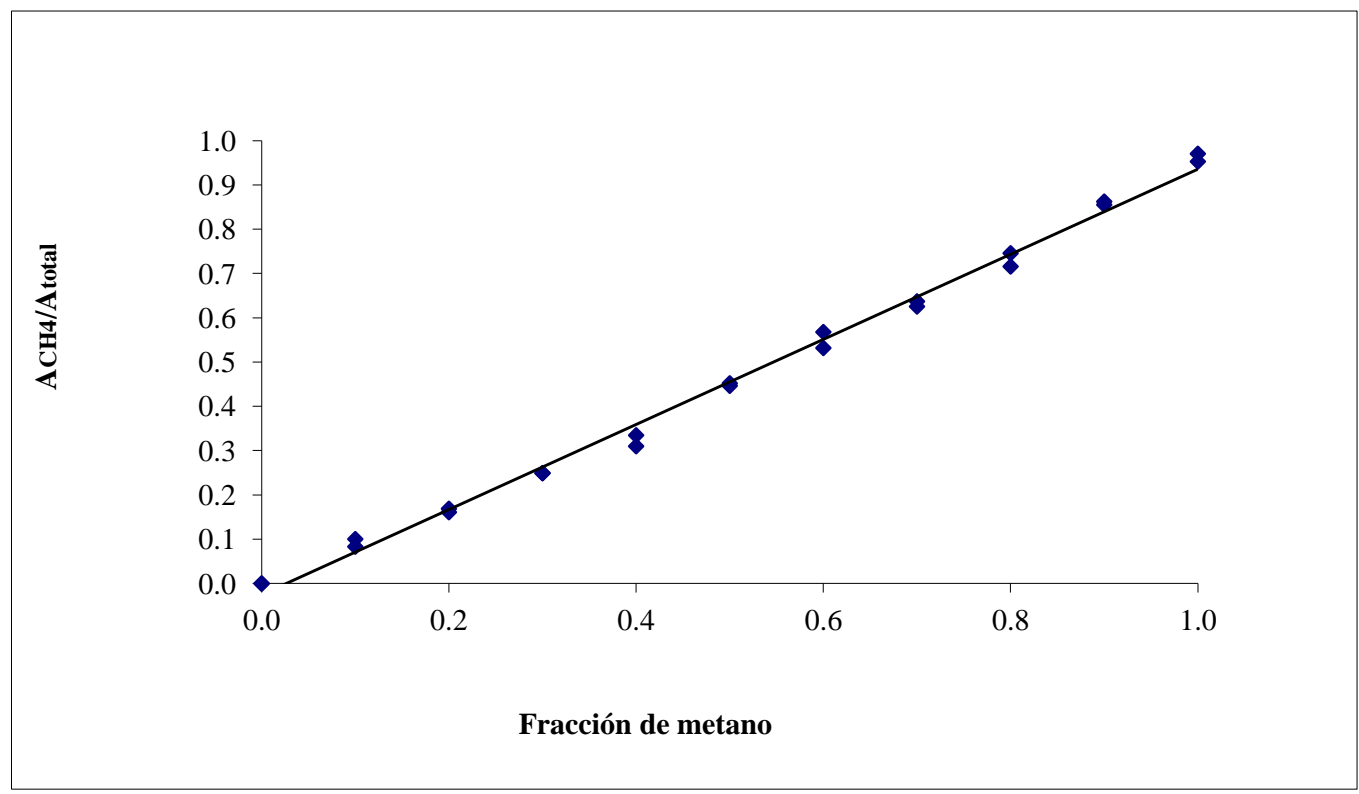

Figura 2.2. Curva de calibración para determinar la fracción de $\mathrm{CH}_{4},\left(\mathrm{f}_{\mathrm{CH} 4}\right)$ en el biogás, $\mathrm{A}_{\mathrm{CH} 4} / \mathrm{A}_{\text {total }}=0.9606 \mathrm{f}_{\mathrm{CH} 4}-0.0248, \mathrm{R}^{2} 0.9951$.

$$
f_{C H 4}=\left(\left(A_{C H 4} / A_{\text {TOTAL }}\right)-0.0248\right)\left(\frac{1}{0.9606}\right)
$$

En donde $\mathrm{A}_{\mathrm{CH} 4}$ es el área de metano y $\mathrm{A}_{\text {TOTAL }}$ es el área total en el cromatógrama.

\subsubsection{Medios de cultivo}

Para realizar las pruebas de biodegradabilidad y las cinéticas de hidrólisis de los sólidos suspendidos y los solubles se utilizó medio mineral anaerobio reducido (RAMM), por sus siglas en inglés, (Shelton y Tiedje, 1984).

\subsubsection{Generación del inóculo anaerobio mesofílico y termofílico}

Tres reactores de tanque agitado, uno de $2 \mathrm{~L}$ de volumen de operación (T2E) y dos con 1 L de volumen de operación (M1E y M2E), fueron llenados con 1.5 L y 0.750 L de LRS consolidados, respectivamente; el lodo contenía $14 \mathrm{~kg} \mathrm{SSV.m}{ }^{-3}$. Posteriormente, fueron sellados herméticamente y purgada la fase gaseosa con nitrógeno, finalmente los reactores M1E y M2E se incubaron a $35^{\circ} \mathrm{C}$ y el reactor T2E a $55^{\circ} \mathrm{C}$. 
Para generar el inóculo anaerobio termofílico y mesofílico estos reactores se operaron con un una carga de alimentación promedio de $0.9 \mathrm{~kg} \mathrm{SSV} . \mathrm{m}^{-3} . \mathrm{d}^{-1}$, para evitar problemas de acidificación (Kim M. et al., 2003). Se consideró que el inóculo tenía una buena actividad cuando la producción de metano llegó a $0.600 \mathrm{~m}^{3} \mathrm{CH}_{4} \cdot \mathrm{kg}^{-1} \mathrm{SSV}_{\text {rem }}$ $\left(0.180 \mathrm{~kg}_{\mathrm{CH} 4} \cdot \mathrm{m}^{-3} \cdot \mathrm{d}^{-1}\right)$, para el reactor mesofílico y $0.400 \mathrm{~m}^{3} \mathrm{CH}_{4} \cdot \mathrm{kg}^{-1} \mathrm{SSV}_{\text {rem }}(0.120$ $\left.\mathrm{kg}_{\mathrm{CH} 4} \cdot \mathrm{m}^{-3} \cdot \mathrm{d}^{-1}\right)$ para el reactor termofílico. El tiempo promedio para la generación de biomasa activa fue de 100 días.

\subsubsection{Lodos residuales secundarios utilizados como sustrato}

Las características de los lodos residuales secundarios utilizados como sustrato se muestran en la Cuadro 2.4.

Cuadro 2.4. Características de los LRS espesados, utilizados como sustrato.

\begin{tabular}{ccc}
\hline & $\begin{array}{c}\text { concentración } \\
\left(\mathrm{kg} \cdot \mathrm{m}^{-3}\right)\end{array}$ & \% en SST \\
\hline SST & $23(6)$ & 100 \\
SSV & $19(5)$ & 83 \\
SSF & $4(2)$ & 17 \\
carbohidratos & $4(1)$ & 17 \\
proteínas & $12(4)$ & 52 \\
\hline DQO & $32(9)$ & $1.68 \mathrm{kgDQO} / \mathrm{kgSSV}$ \\
\hline \multicolumn{2}{l}{ Valor entre paréntesis desviación estándar $\mathrm{n}=10, \mathrm{n}$ es el } \\
número de muestras tomadas.
\end{tabular}

\subsubsection{Sistema de dos etapas}

El sistema de dos etapas fueron dos reactores continuos de tanque agitado (RCTA) conectados en serie, uno con $2 \mathrm{~L}$ de volumen de operación mantenido a $55{ }^{\circ} \mathrm{C}$ en una estufa (T2E) y otro con $1 \mathrm{~L}$ de volumen de operación mantenido a $35^{\circ} \mathrm{C}$ en un cuarto de temperatura controlada (M2E). También se operó otro RMC con 1 L de volumen de operación a $35{ }^{\circ} \mathrm{C}$, utilizado como control (M1E). El sistema se esquematiza en la figura 2.3.

Durante la operación el pH se dejó sin control, monitoreándose cada 24 horas. La alimentación de lodo residual secundario (LRS) fue cada 24 horas, para evitar los problemas relacionados al bombeo de los LRS en reactores de pequeña escala. Los reactores se operaron a distintos tiempos de retención (entre 4 y 25 días). El tiempo de retención de sólidos (TRS) fue reducido por un incremento de la velocidad de 
alimentación. Cuando se ajustó cada TRS se permitió que el reactor llegará al estado estacionario (al menos 3 tiempos de retención).

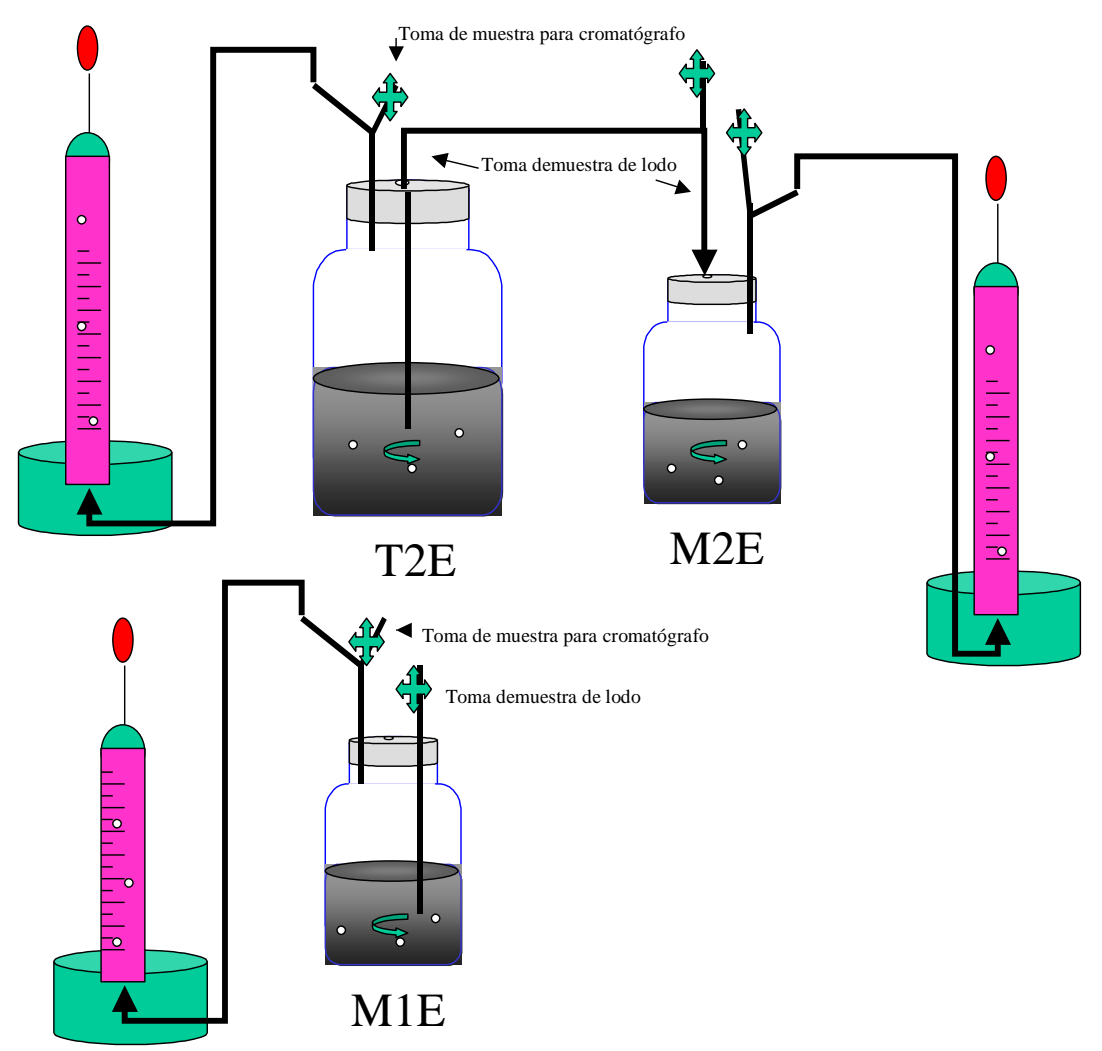

Figura 2.3. Sistemas de una etapa (M1E) y dos etapas (T2E-M2E), para la digestión de lodos residuales secundarios.

\subsection{Resultados y discusión}

\subsubsection{Efecto de la carga orgánica sobre la hidrólisis de lodos residuales secundarios}

Como puede verse en el cuadro 2.4 las proteínas y los carbohidratos son los compuestos orgánicos predominantes en los lodos residuales secundarios, juntos proteínas y carbohidratos representan el $84 \%$ de los sólidos volátiles. El efecto de la carga orgánica $\left(\mathrm{kg} \mathrm{SSV} . \mathrm{m}^{-3} \cdot \mathrm{d}^{-1}\right)$ en la hidrólisis de los lodos residuales secundarios, expresado como la variación de la concentración de proteínas y carbohidratos solubles, se muestra en las Figuras 2.4 y 2.5. 


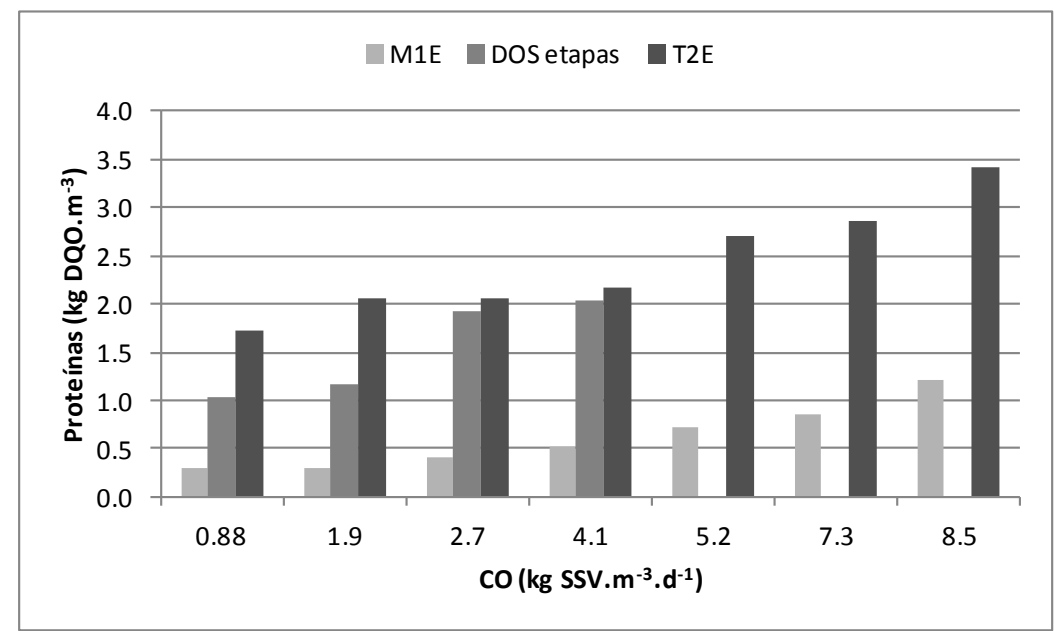

Figura 2.4 Efecto de la carga orgánica, CO, en la concentración de proteínas solubles durante la digestión anaerobia mesofílica (M1E), termofílica (T2E) y dos etapas termofílica-mesofílica.

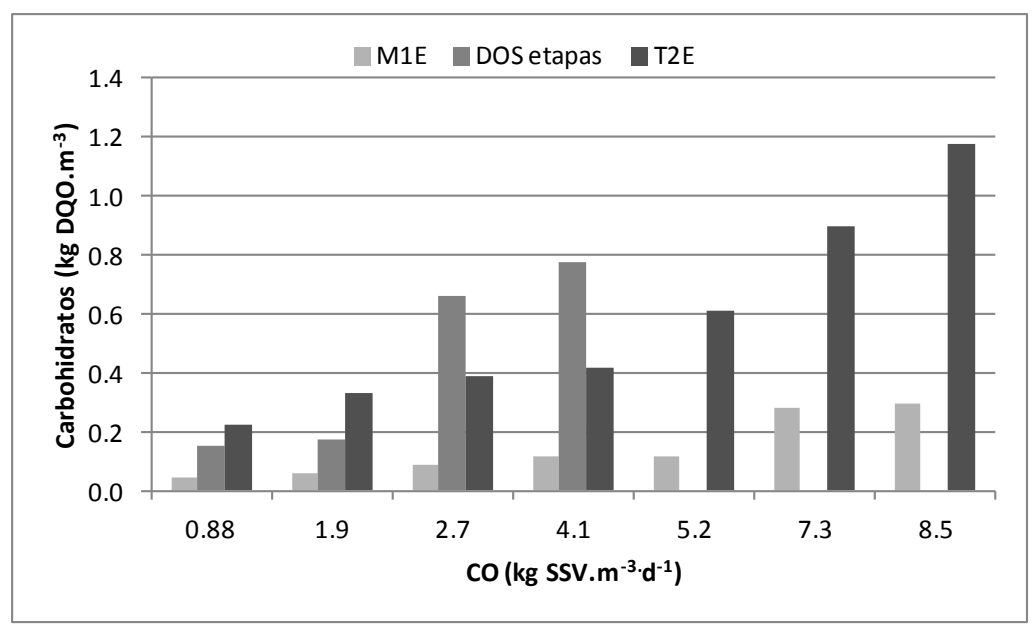

Figura 2.5 Efecto de la carga orgánica, $\mathrm{CO}$, en la concentración de carbohidratos solubles durante la digestión anaerobia mesofílica (M1E), termofílica (T2E) y DOS etapas termofílica-mesofílica.

La concentración de proteínas solubles se incrementa hasta seis veces en el reactor termofílico (T2E) con respecto al mesofílico (M1E); sin embargo, este aumento se reduce conforme aumenta la carga, y llega a ser solo tres veces mayor. En el sistema de dos etapas no se observa una dependencia de la concentración de proteínas soluble con respecto a la carga. Además este análisis muestra que la influencia de la carga orgánica sobre la concentración de proteína soluble puede ser expresada por las ecuaciones 2.2 y 2.3 para mesofilia y termofilia respectivamente.

$$
y_{\text {proteínas }}=0.117 \cdot \mathrm{CO}+0.1073 \quad\left(\mathrm{R}^{2}=0.9442\right)
$$




$$
y_{\text {proteina }}=0.2018 \cdot C O+1.5441 \quad\left(\mathrm{R}^{2}=0.9412\right)
$$

Para los carbohidratos se puede hacer un análisis similar y la influencia de la carga orgánica sobre la concentración de los carbohidratos solubles puede ser expresada por las ecuaciones 2.4 y 2.5 para mesofilia y termofilia respectivamente

$$
\begin{array}{ll}
y_{\text {carb }}=0.035 \cdot C O+0.0099 & \left(\mathrm{R}^{2}=0.9225\right) \\
y_{\text {carb }}=0.1186 \cdot C O+0.0598 & \left(\mathrm{R}^{2}=0.9437\right)
\end{array}
$$

El flóculo en los lodos residuales está formado por exopolímeros excretados por los microorganismos que lo conforman, éstos son principalmente carbohidratos y proteínas. Durante la digestión anaerobia los microorganismos hidrolíticos secretan enzimas que los hidrolizan. Al incrementarse la carga orgánica, la concentración de SSV aumenta y por lo tanto, existe mayor área total de contacto, lo que provoca que mayor cantidad de proteínas y carbohidratos sean solubilizados.

\subsubsection{Efecto del tiempo de retención de sólidos sobre la velocidad de hidrólisis de sólidos y la producción de metano}

La eficiencia de remoción promedio de sólidos suspendidos volátiles (SSV), se muestra en la figura 2.6, el sistema de dos etapas y el reactor termofílico (T2E) son los que muestran la mayor remoción 60 y $50 \%$ respectivamente, pero no hay diferencia entre estos dos sistemas cuando el TRS es menor a 10 días, es decir el reactor mesofílico (M2E) no contribuye en la remoción de SSV. 


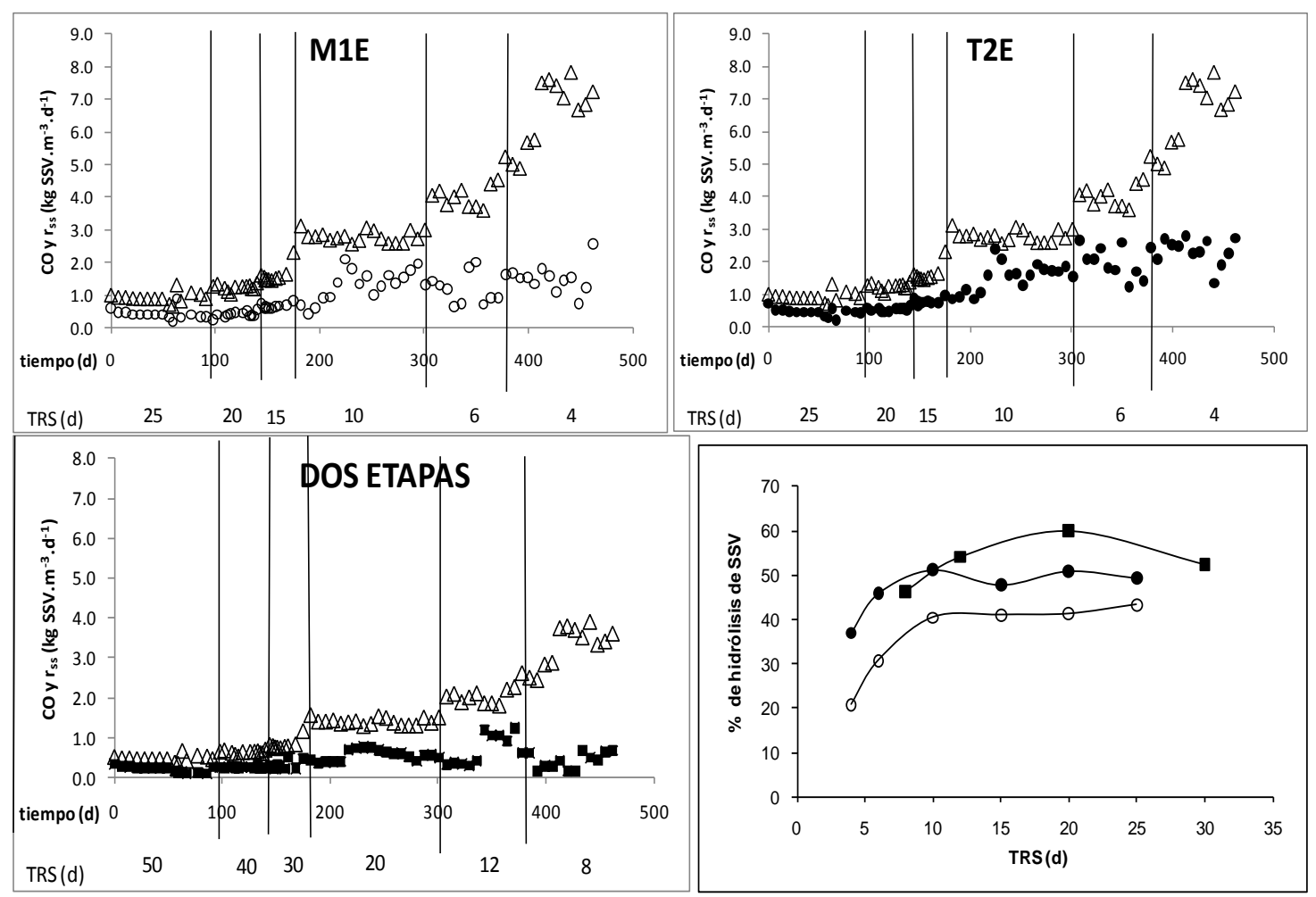

Figura 2.6 CO, carga orgánica $(\Delta), \mathrm{r}_{S S}$, velocidad de hidrólisis y \% de hidrólisis: M1E (O), T2E (•); DOS etapas ( $\bullet)$.

Una importante variable para evaluar la calidad del efluente es la carga orgánica (CO). La figura 2.6 muestra los cambios de la $\mathrm{CO}$ y la velocidad de hidrólisis $\left(\mathrm{r}_{\mathrm{SS}}\right.$ ), a diferentes TRS. Durante el periodo de operación con CO entre 1.0 y $2.0 \mathrm{~kg} \mathrm{SSV} . \mathrm{m}^{-3} . \mathrm{d}^{-1}$ la $\mathrm{r}_{\mathrm{SS}}$ es menor a $1 \mathrm{~kg} \mathrm{SSV} \cdot \mathrm{m}^{-3} \cdot \mathrm{d}^{-1}$, tanto para la DA mesofílica (M1E), la DA termofílica (T2E) y el sistema de dos etapas (T2E-M2E). Para el periodo en donde la CO está entre 2.5 y $7.5 \mathrm{kgSSV} \cdot \mathrm{m}^{-3} \cdot \mathrm{d}^{-1}$, se observa un incremento en la $\mathrm{r}_{\mathrm{SS}}$, llegando a $1.78 \mathrm{~kg} \mathrm{SSV} . \mathrm{m}^{-3} \cdot \mathrm{d}^{-1}$ para la DA mesofílica (M1E) y a $2.42 \mathrm{~kg} \mathrm{SSV} \cdot \mathrm{m}^{-3} \cdot \mathrm{d}^{-1}$ para DA termofílica (T2E), sin embargo se observa menor estabilidad, ya que la dispersión de los valores de la $\mathrm{r}_{\mathrm{SS}}$ es mayor. Por otro lado, el sistema de dos etapas alcanza su mayor $\mathrm{r}_{\mathrm{SS}}$ cuando opera con cargas orgánicas entre 3 y $4 \mathrm{~kg} \mathrm{SSV} \cdot \mathrm{m}^{-3} \cdot \mathrm{d}^{-1}$, siendo ésta 2 veces menor a la máxima $r_{\mathrm{ss}}$ alcanzada en mesofilia y termofilia.

La Figura 2.7 muestra el efecto de la CO sobre la velocidad de producción de metano. Para el digestor anaerobio mesofílica (M1E) el incremento de la velocidad de producción de metano no está directamente relacionado a la $\mathrm{CO}$ ya que se observan dos intervalos bien definidos; uno para CO menores a $2 \mathrm{~kg} \mathrm{SSV} . \mathrm{m}^{-3} \cdot \mathrm{d}^{-1}$ y el otro para CO mayores a $3 \mathrm{~kg} \mathrm{SSV} \cdot \mathrm{m}^{-3} \cdot \mathrm{d}^{-1}$. Los valores promedio de producción de metano coinciden con los reportados por otros autores, por un lado García-Heras et al. (1999) y Song et al. (2004) reportan velocidades de producción de metano de entre $0.178-0.230 \mathrm{~kg}_{\mathrm{CH} 4} \cdot \mathrm{m}^{-3} \cdot \mathrm{d}^{-}$ 
${ }^{1}$ para CO entre 1.21 y $1.44 \mathrm{~kg} \mathrm{SSV} . \mathrm{m}^{-3} . \mathrm{d}^{-1}$ y por su parte Carrozzi y Steinle (1994) y Killilea et al. (2000) reporta valores de producción de metano de entre 0.392 y 0.525 $\mathrm{kg}_{\mathrm{CH} 4} \cdot \mathrm{m}^{-3} \cdot \mathrm{d}^{-1}$ para CO de entre 1.75 y $2 \mathrm{~kg} \mathrm{SSV} \cdot \mathrm{m}^{-3} \cdot \mathrm{d}^{-1}$.

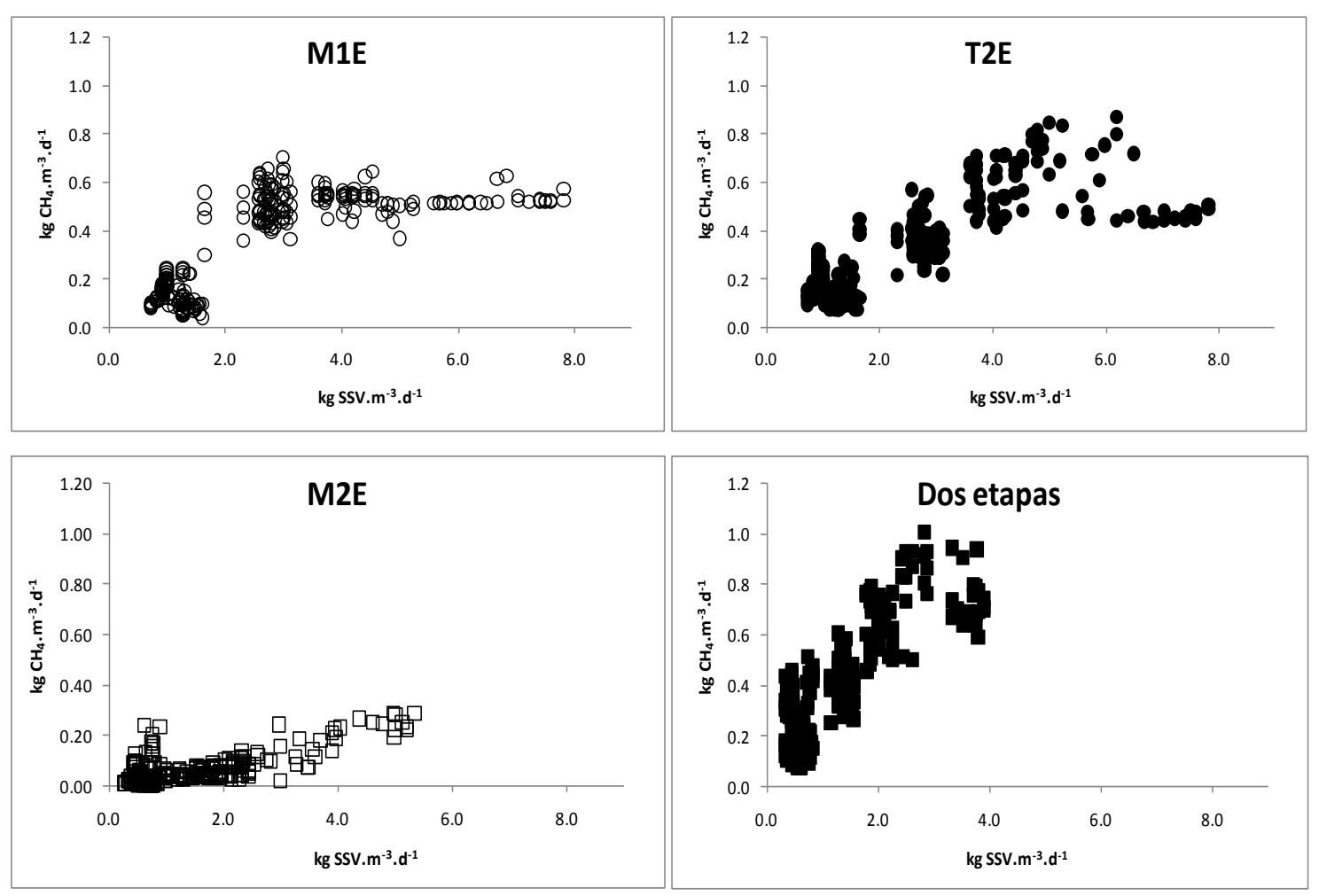

Figura 2.7. Velocidad de producción volumétrica de metano contra la carga orgánica.

Para el digestor anaerobio termofílico (T2E) se observa una relación directa de la carga con la velocidad de producción de metano, cuando la carga es menor a $6 \mathrm{~kg}$ $\mathrm{SSV} . \mathrm{m}^{-3} \cdot \mathrm{d}^{-1}$, esto coincide con el comportamiento observado por de la Rubia et al., (2006) en un reactor anaerobio termofílico que trataba mezclas de LRS:LRP con intervalos de CO de 1.0 a $2.5 \mathrm{~kg} \mathrm{SSV} . \mathrm{m}^{-3} . \mathrm{d}^{-1}$. En la Figura 2.7 también se observa que a CO mayores a $6 \mathrm{~kg} \mathrm{SSV} \cdot \mathrm{m}^{-3} \cdot \mathrm{d}^{-1}$ la velocidad de producción de metano se mantiene constante $\left(0.5 \quad \mathrm{~kg}_{\mathrm{CH} 4} \cdot \mathrm{m}^{-3} \cdot \mathrm{d}^{-1}\right)$, este comportamiento también fue observado por Vandenburgh y Ellis (2002) quienes reportaron una velocidad de producción 1.0 $\mathrm{kg}_{\mathrm{CH} 4} \cdot \mathrm{m}^{-3} \cdot \mathrm{d}^{-1}$ para cargas entre 4.5 y $7.8 \mathrm{~kg} \mathrm{SSV} \cdot \mathrm{m}^{-3} \cdot \mathrm{d}^{-1}$. 


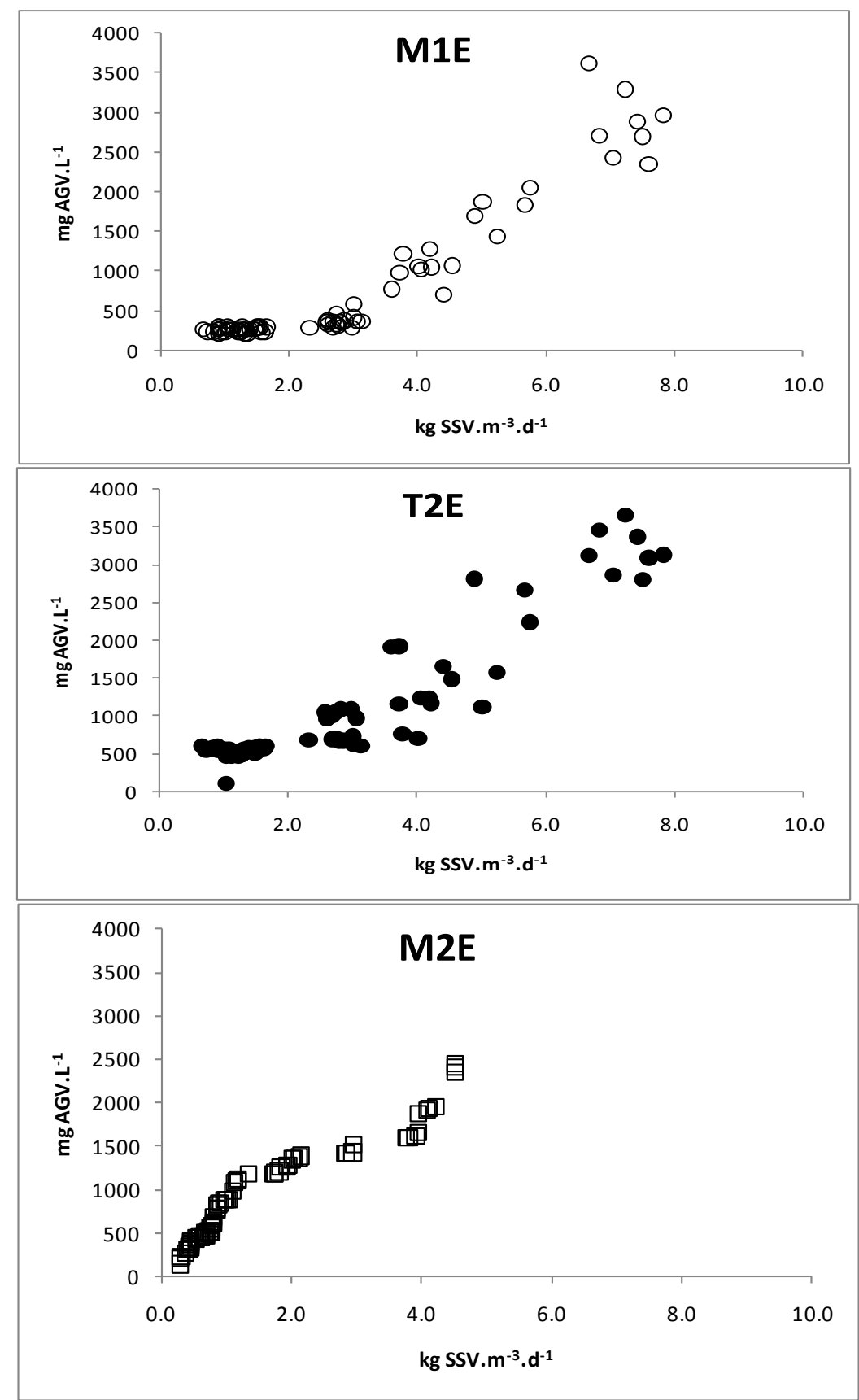

Figura 2.8. Concentración de AGV contra la carga orgánica

La máxima velocidad de producción de metano $\left(0.6 \mathrm{~kg}_{\mathrm{CH} 4} \cdot \mathrm{m}^{-3} \cdot \mathrm{d}^{-1}\right)$ en el reactor M1E, se presentó a las cargas orgánicas más altas, mientras que para T2E, el máximo valor de producción de metano $\left(0.8 \mathrm{~kg}_{\mathrm{CH} 4} \cdot \mathrm{m}^{-3} \cdot \mathrm{d}^{-1}\right)$ se presentó a $\mathrm{CO}$ entre 5 y $6 \mathrm{~kg}$ $\mathrm{SSV} . \mathrm{m}^{-3} \cdot \mathrm{d}^{-1}$, sin embargo a CO mayores a $7 \mathrm{~kg} \mathrm{SSV} \cdot \mathrm{m}^{-3} \cdot \mathrm{d}^{-1}$ la producción de metano cae hasta $0.4 \mathrm{~kg}_{\mathrm{CH} 4} \cdot \mathrm{m}^{-3} \cdot \mathrm{d}^{-1}$, esta disminución en la producción de metano coincide con la acumulación de AGV para ambos reactores (Figura 2.8). 
Para el sistema de dos etapas también se observa una relación lineal entre la carga y la producción de metano para cargas orgánicas menores a $3.5 \mathrm{~kg} \mathrm{SSV} \cdot \mathrm{m}^{-3} \cdot \mathrm{d}^{-1}$, logrando a esta carga la máxima producción de metano $\left(1.0 \mathrm{~kg}_{\mathrm{CH} 4} \cdot \mathrm{m}^{-3} \cdot \mathrm{d}^{-1}\right)$ siendo ésta dos veces mayor que para el reactor termofílico a la misma carga (Figura 2.7).

En los reactores T2E y M1E la concentración de AGV estuvo por debajo de 500 mg DQO.L $\mathrm{L}^{-1}$ cuando se operaron los reactores a TRS mayores a 10 días, Figura 2.8. En esta figura también se observa que la concentración de AGV se incrementa con el

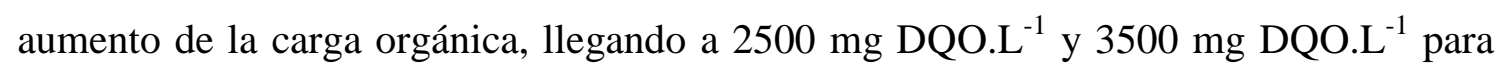
M1E y T2E, respectivamente. Para el reactor M2E, se observa que contribuye mínimamente en la remoción de AGV que recibe del reactor T2E, Figura 2.8.

\subsubsection{Efecto de la carga orgánica sobre la producción de amonio}

En el Cuadro 2.5 se observa la dependencia de la concentración de amonio total con la CO. También se observa que el reactor termofílico (T2E) tiene una mayor concentración de amonio total con respecto al reactor M1E, debido a la mayor eficiencia de hidrólisis de los sólidos volátiles y la consecuente transformación de nitrógeno orgánico a amonio.

Cuadro 2.5. Concentración de amonio en los reactores.

\begin{tabular}{|c|c|c|c|c|c|c|c|}
\hline \multicolumn{3}{|c|}{ M1E } & \multicolumn{2}{|r|}{ T2E } & \multicolumn{3}{|c|}{ M2E } \\
\hline $\begin{array}{l}\text { Carga orgánica } \\
\left(\text { gSSV.L } L^{-1} \cdot d^{-1}\right)\end{array}$ & $\mathrm{pH}$ & $\begin{array}{c}\mathrm{T}-\mathrm{NH}_{3} \\
\left(\mathrm{mg} . \mathrm{L}^{-1}\right)\end{array}$ & $\mathrm{pH}$ & $\begin{array}{c}\mathrm{T}-\mathrm{NH}_{3} \\
\left(\mathrm{mg} . \mathrm{L}^{-1}\right)\end{array}$ & $\begin{array}{l}\text { Carga orgánica } \\
\left(\text { gSSV.L }{ }^{-1} \cdot \mathrm{d}^{-1}\right)\end{array}$ & $\mathrm{pH}$ & $\begin{array}{c}\mathrm{T}-\mathrm{NH}_{3} \\
\left(\mathrm{mg} . \mathrm{L}^{-1}\right)\end{array}$ \\
\hline 0.88 & 7.4 & $1232(297)$ & 7.6 & $2004(665)$ & 0.5 & 7.4 & $2055(541)$ \\
\hline 1.90 & 7.42 & $1306(229)$ & 7.6 & $2108(378)$ & 1.2 & 7.43 & $2177(323)$ \\
\hline 2.70 & 7.5 & $1542(473)$ & 7.7 & $2190(378)$ & 1.9 & 7.54 & 2311 (334) \\
\hline 4.10 & 7.5 & 1549 (281) & 7.7 & 2239 (482) & 2.7 & 7.6 & $2333(233)$ \\
\hline 5.20 & 7.6 & $1783(589)$ & 7.7 & 2554 (712) & 3.4 & 7.6 & $2727(571)$ \\
\hline 7.30 & 7.7 & 1991 (244) & 7.6 & $3456(281)$ & 4.1 & 7.54 & $3229(200)$ \\
\hline 8.50 & 7.8 & 2137 (617) & 7.6 & $3622(136)$ & 4.5 & 7.54 & 3296 (209) \\
\hline
\end{tabular}

La cantidad entre paréntesis representa la desviación estándar de las muestras analizadas.

Para determinar la concentración de amoniaco $\left(\mathrm{NH}_{3}\right)$ a partir de la concentración de amonio total $\left(\mathrm{T}-\mathrm{NH}_{3}\right.$, incluye $\mathrm{NH}_{3}$ y $\mathrm{NH}_{4}{ }^{+}$) se utiliza la ecuación 2.6. 


$$
N H_{3}=K_{a} \frac{\left[T-N N_{3}\right]}{\left[H^{+}\right]}
$$

En donde: $\mathrm{K}_{\mathrm{a}}$ es la constante de equilibrio a $35^{\circ} \mathrm{C}\left(1.13 \times 10^{-9}\right)$ y $55^{\circ} \mathrm{C}\left(3.83 \times 10^{-9}\right)$ respectivamente y $\left[\mathrm{H}^{+}\right]$es la concentración de iones hidrógeno en el reactor.

La figura 2.9 muestra el efecto de la carga orgánica en la concentración de amoniaco, para cada uno de los reactores. Interesante comportamiento presenta el reactor T2E que opera establemente a concentraciones por arriba de $552 \mathrm{mg} . \mathrm{L}^{-1}$, concentración mayor a la reportada como inhibitoria (100 y $150 \mathrm{mg} . \mathrm{L}^{-1}$, temperatura mesofílica, Braun et al, 1981; De Baere et al., 1984). Un comportamiento similar fue reportado por Vandenburgh y Ellis (2002), ellos sugieren que la aparente ausencia de inhibición por amoniaco se debe a que el consorcio anaerobio termofílico puede adaptarse para crecer a altas concentraciones de éste (Angelidaki y Ahring, 1993; Hansen et al., 1998). Al parecer el metabolismo del consorcio anaerobio mesofílico si se ve inhibido por concentraciones de amoniaco mayores a $100 \mathrm{mg} . \mathrm{L}^{-1}$, de aquí que la producción de metano no aumente con el incremento de la carga orgánica en el reactor M1E. La concentración de amoniaco en el reactor M2E, puede explicar porque este reactor mostró una baja velocidad de producción volumétrica de metano (Figura 2.7), contrario a lo esperado.

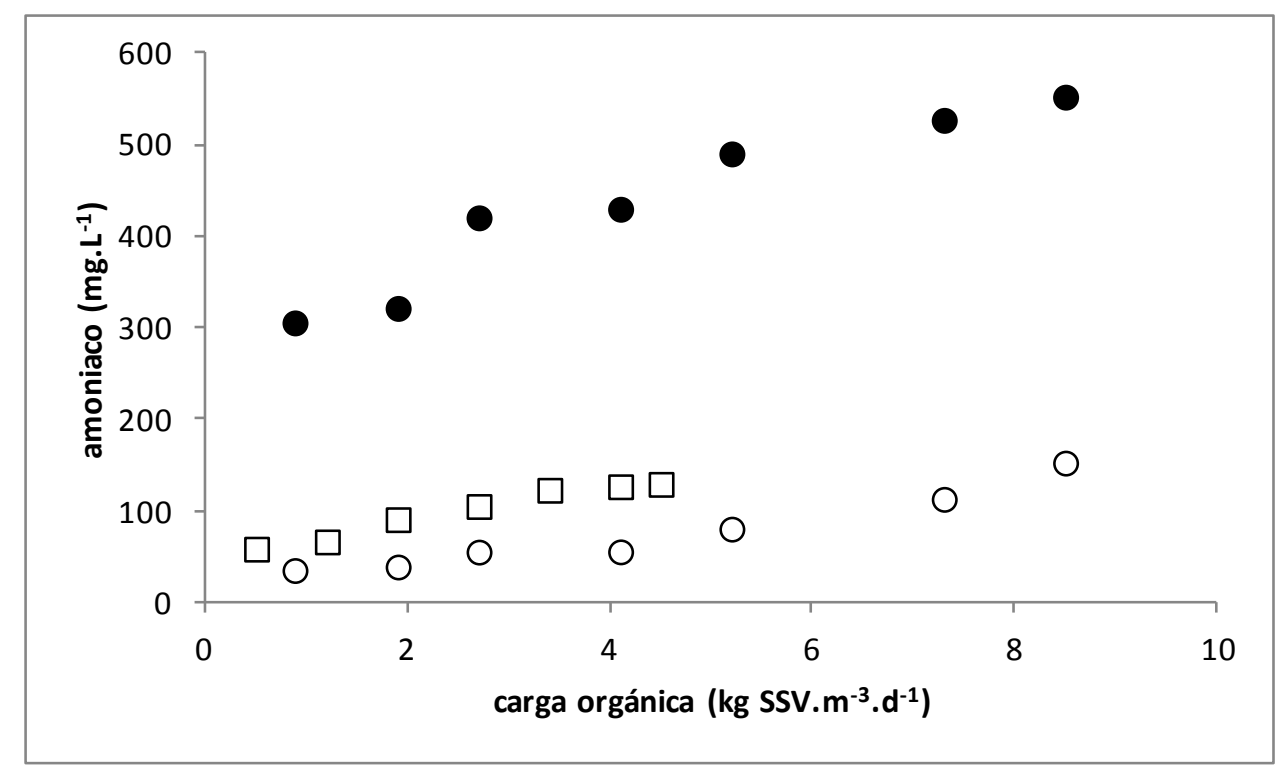

Figura 2.9 Concentración de amoniaco a distintas cargas orgánicas. M1E (O), M2E (口), T2E (•). 


\subsection{Conclusiones}

El sistema de dos etapas (termofílico-mesofílico) tuvo la mayor eficiencia de remoción de sólidos suspendidos volátiles, que fue de $60 \%$ a un TRS de 20 días, pero el reactor termofílico logró una eficiencia de remoción de 50 \% a un TRS de 10 día. Sin embargo, a cargas menores de $1 \mathrm{~kg} \mathrm{SSV} \cdot \mathrm{m}^{-3} \cdot \mathrm{d}^{-1}$ no hay diferencia en la velocidad de hidrólisis $\left(\mathrm{r}_{\mathrm{ss}}\right)$ entre la DA mesofílica, termofílica y en dos etapas. Para cargas de $2 \mathrm{~kg}$ $\mathrm{SSV} . \mathrm{m}^{-3} \cdot \mathrm{d}^{-1}$ el sistema de dos etapas tiene $\mathrm{r}_{\mathrm{ss}}$ dos veces mayor que para la digestión anaerobia mesofílica y termofílica, pero ésta velocidad no cambia a cargas mayores a 2 $\operatorname{kg~SSV~m}{ }^{-3} \cdot \mathrm{d}^{-1}$.

En la digestión anaerobia termofílica de LRS existe una relación lineal entre la carga orgánica y la velocidad de producción volumétrica de metano, para cargas de entre 1.0 y $6.0 \mathrm{~kg} \mathrm{SSV} . \mathrm{m}^{-3} \cdot \mathrm{d}^{-1}$.

El sistema de dos etapas es el más eficiente, con respecto a la producción de metano, logrando generar $1.0 \mathrm{~kg} \mathrm{CH}_{4} \cdot \mathrm{m}^{-3} \cdot \mathrm{d}^{-1}$, cuando la carga orgánica fue de $3 \mathrm{~kg}$ $\mathrm{SSV} \cdot \mathrm{m}^{-3} \cdot \mathrm{d}^{-1}$.

La concentración de amoniaco en los reactores mesofílicos provocó una disminución en la velocidad de producción de metano y el consorcio termofílico fue capaz de adaptarse a altas concentraciones de amoniaco. 


\section{3}

EFECTO DE DIFERENTES

PRETRATAMIENTOS SOBRE LA

SOLUBILIZACIÓN Y BIODEGRADACIÓN ANAEROBIA DE SÓLIDOS SUSPENDIDOS EN LODOS RESIDUALES SECUNDARIOS 
Efecto del pretratamiento sobre la solubilización y biodegradabilidad anaerobia

\section{Efecto de diferentes pretratamientos sobre la solubilización y biodegradación anaerobia de sólidos suspendidos en lodos residuales secundarios}

\subsection{Introducción}

Los lodos residuales secundarios (LRS) están formados principalmente de proteínas, polisacáridos y ácidos húmicos (Frohlund et al., 1996). Los LRS son flóculos compuestos por bacterias, sustancias exopoliméricas (SEP) y cationes multivalentes, como silicatos, óxido de hierro y fosfato de calcio (Salhi, 2003). Las SEP son moléculas producidas por el metabolismo de las bacterias (Urbain et al., 1993). Estas sustancias constituyen del 80 a $90 \%$ de la fracción orgánica de los LRS y el resto son células. Los porcentajes de SEP y biomasa dependen de los tiempos de retención de sólidos en el reactor y de las características del agua residual (Frohlund et al., 1996).

Wilén et al. (2003) caracterizaron siete muestras de LRS de distintas plantas de tratamiento de aguas residuales, encontrando que las SEP contenían de 44 a $55 \%$ de proteínas, de 30 a $33 \%$ de ácidos húmicos y $10 \%$ de carbohidratos. El ácido desoxirribonucleico (ADN) es muy variable y constituye entre el 2 y el $15 \%$ del contenido de las SEP en el lodo (Raszka et al., 2006).

Otra forma útil de caracterizar a los LRS es en función del contenido de sólidos suspendidos (SS) y de la demanda química de oxígeno (DQO). Los SS en los LRS están constituidos por sólidos suspendidos volátiles (SSV), que representa la materia orgánica, y por sólidos suspendidos fijos, que representan el material inorgánico. En muestras de LRS, los SSV representan entre el 60 y $85 \%$ de los sólidos suspendidos (SS). Los SSV están constituidos entre el 30 y $54 \%$ por proteínas, entre 7.7 y $12 \%$ de lípidos y entre 9 y $22 \%$ de carbohidratos (Bougrier et al., 2008; Kyung et al., 1997; Yue et al., 1995; Ghosh, 1991). La DQO en los LRS está constituida por $41 \%$ de proteínas, $25 \%$ de lípidos y $14 \%$ de carbohidratos y el $20 \%$ de otros compuestos no identificados (Tanaka, 1997).

Debido a su alto contenido de materia orgánica los LRS deben ser estabilizados antes de ser colocados en el sitio de disposición, es decir, éstos deben ser tratados para disminuir el volumen a disponer y la concentración de sólidos, además de eliminarles los microorganismos patógenos, virus y parásitos.

La digestión anaerobia (DA) es la tecnología más utilizada para estabilizar LRS, principalmente por la posibilidad de recobrar energía y porque el LRS estabilizado puede en algunos casos ser reutilizado, estos dos aspecto son las principales ventajas de 
la digestión anaerobia mesofílica sobre otras tecnologías. Sin embargo, la estabilización y disposición de los LRS representan el $60 \%$ del presupuesto anual de operación y mantenimiento de las planta de tratamiento de aguas residuales (Cacho Rivero y Suidan, 2006), por lo que sigue representando un reto importante hacer más eficiente esta tecnología.

Cuando se utiliza DA para la estabilización de LRS, la etapa de solubilización/hidrólisis es la limitante, en ella se solubilizan e hidrolizan principalmente proteínas, lípidos y carbohidratos (Batstone, 2002). Los pretratamientos son una alternativa para acelerar esta etapa, éstos aumentan la disponibilidad de los sustratos, debido a que desintegran el flóculo y rompen la membrana celular. Se han propuesto varios métodos para la solubilización de los flóculos de los LRS. Los pretratamientos pueden ser divididos en tres grandes grupos: pretratamientos mecánicos, químicos y térmicos. También se han utilizado pretratamientos combinados: mecánicos-químicos, térmicos-mecánicos y térmicos-químicos.

Otra de las restricciones asociadas al pretratamiento es la sustentabilidad energética en la estabilización del LRS. Olalde (2009) reporta que se necesita 6 veces más energía durante el pretratamiento por ultrasonido con respecto a la requerida para tratar $1 \mathrm{~kg}$ ST de LRS por calor.

\subsubsection{Pretratamientos térmicos}

Los estudios del efecto del pretratamiento térmico sobre la solubilización de LRS y la producción de metano por digestión anaerobia de LRS, reportan temperaturas óptimas entre $160{ }^{\circ} \mathrm{C}$ y $180{ }^{\circ} \mathrm{C}$ con tiempos de tratamiento entre 30 y 60 minutos. Sin embargo, se ha demostrado que el tiempo de tratamiento tiene poco efecto en este rango de temperaturas (Neyens y Baeyens, 2003). Por otra parte, se han realizado pretratamientos térmicos a temperaturas moderadas $\left(70\right.$ a $\left.121{ }^{\circ} \mathrm{C}\right)$ en intervalos de tiempo entre 0.5 y 72 h, en éstos la solubilización varía entre 10 y $38 \%$. La solubilización es dependiente de la temperatura pues en el intervalo de $160{ }^{\circ} \mathrm{C}$ a $180{ }^{\circ} \mathrm{C}$ es donde se obtiene el mayor porcentaje de solubilización, Cuadro 3.1.

Considerando el impacto en la producción de metano, los pretratamientos térmicos pueden ser clasificados en dos grupos: temperaturas moderadas (70 a $121{ }^{\circ} \mathrm{C}$ ) en las que el incremento en la producción de metano fluctúa entre 30 y $50 \%$ y temperaturas altas $\left(160\right.$ a $\left.180{ }^{\circ} \mathrm{C}\right)$ en donde el incremento en la producción de metano está entre 50 y $70 \%$ (Cuadro 3.1). 
Efecto del pretratamiento sobre la solubilización y biodegradabilidad anaerobia

Cuadro 3.1. Eficiencia de solubilización de LRS con pretratamiento térmico.

\begin{tabular}{|c|c|c|c|}
\hline $\begin{array}{l}\text { Características } \\
\text { del pretratamiento }\end{array}$ & $\eta_{s}$ & $\begin{array}{c}\text { Aumento en la producción } \\
\text { de metano }(\%) \\
\text { T, TRS }\end{array}$ & Referencia \\
\hline $\begin{array}{l}\text { Térmico }\left(121^{\circ} \mathrm{C}, 30 \mathrm{~min}\right) \\
14.8 \mathrm{~g} \text { ST.L }{ }^{-1}, 11.24 \mathrm{~g} \\
\text { SV.L }^{-1}\end{array}$ & 19 & $\begin{array}{c}50 \\
35^{\circ} \mathrm{C}, 24 \mathrm{~d}\end{array}$ & 10 \\
\hline $\begin{array}{l}\text { Térmico }\left(121^{\circ} \mathrm{C}, 30 \mathrm{~min}\right) \\
38 \mathrm{~g} \mathrm{ST} . \mathrm{L}^{-1} ; 26 \mathrm{~g} \mathrm{SV} . \mathrm{L}^{-1}\end{array}$ & 10 & $\begin{array}{c}31 \\
37^{\circ} \mathrm{C}, 7 \text { días }\end{array}$ & 11 \\
\hline $\begin{array}{l}\text { Térmico }\left(170^{\circ} \mathrm{C}, 15 \mathrm{~min}\right) \\
20 \mathrm{~g} \mathrm{ST} . \mathrm{L}^{-1}, 15.2 \mathrm{~g} \mathrm{SV} . \mathrm{L}^{-1}\end{array}$ & 40 & $\begin{array}{c}50 \\
35^{\circ} \mathrm{C}, 24 \mathrm{~d}\end{array}$ & 12 \\
\hline Térmico $\left(180^{\circ} \mathrm{C}\right)$ & 30 & $\begin{array}{c}60-70 \\
37^{\circ} \mathrm{C}, 20 \mathrm{~d}\end{array}$ & 13 \\
\hline $\begin{array}{l}\text { Térmico }\left(190^{\circ} \mathrm{C}, 15 \mathrm{~min}\right) \\
20 \mathrm{~g} \mathrm{ST} . \mathrm{L}^{-1}, 15.2 \mathrm{~g} \mathrm{SV} . \mathrm{L}^{-1}\end{array}$ & 49 & $\begin{array}{c}59 \\
35^{\circ} \mathrm{C}, 24 \mathrm{~d}\end{array}$ & 12 \\
\hline
\end{tabular}

\subsubsection{Pretratamientos mecánicos}

Una de las ventajas de los pretratamientos mecánicos es que no es necesario el uso de compuestos químicos y por lo tanto se evita el incremento del contenido de sólidos en el LR (Weemaes y Verstraete, 1998). Los principales pretratamientos mecánicos que se han estudiado son homogeneizadores de alta presión, microondas y ultrasonido, Cuadro 3.2.

El pretratamiento por ultrasonido es un proceso gobernado por la cavitación en la fase líquida, el pretratamiento por ultrasonido es una combinación de diferentes fenómenos: reacción química con radicales libres, pirólisis, combustión y esfuerzos cortantes (Bougrier et al., 2005). Estudios realizados por Wang et al. (2005) concluyeron que la solubilización de los LRS durante la sonicación es debido principalmente a la fuerzas hidromecánicas y a la oxidación por efecto de $\mathrm{OH}^{\bullet}$ y que el porcentaje con el que contribuye cada fenómeno se modifica al aumentar la densidad del ultrasonido $\left(\mathrm{W} \cdot \mathrm{mL}^{-1}\right.$ ). Los mecanismos presentes durante la sonicación de lodos residuales están influenciados por tres variables, energía aplicada, frecuencia del 
Efecto del pretratamiento sobre la solubilización y biodegradabilidad anaerobia

ultrasonido y características del lodo. Estas variables pueden explicar las diferencias en los resultados de solubilización y producción de metano mostradas en el Cuadro 3.2.

Cuadro 3.2. Eficiencia de solubilización de LRS con distintos pretratamientos mecánicos.

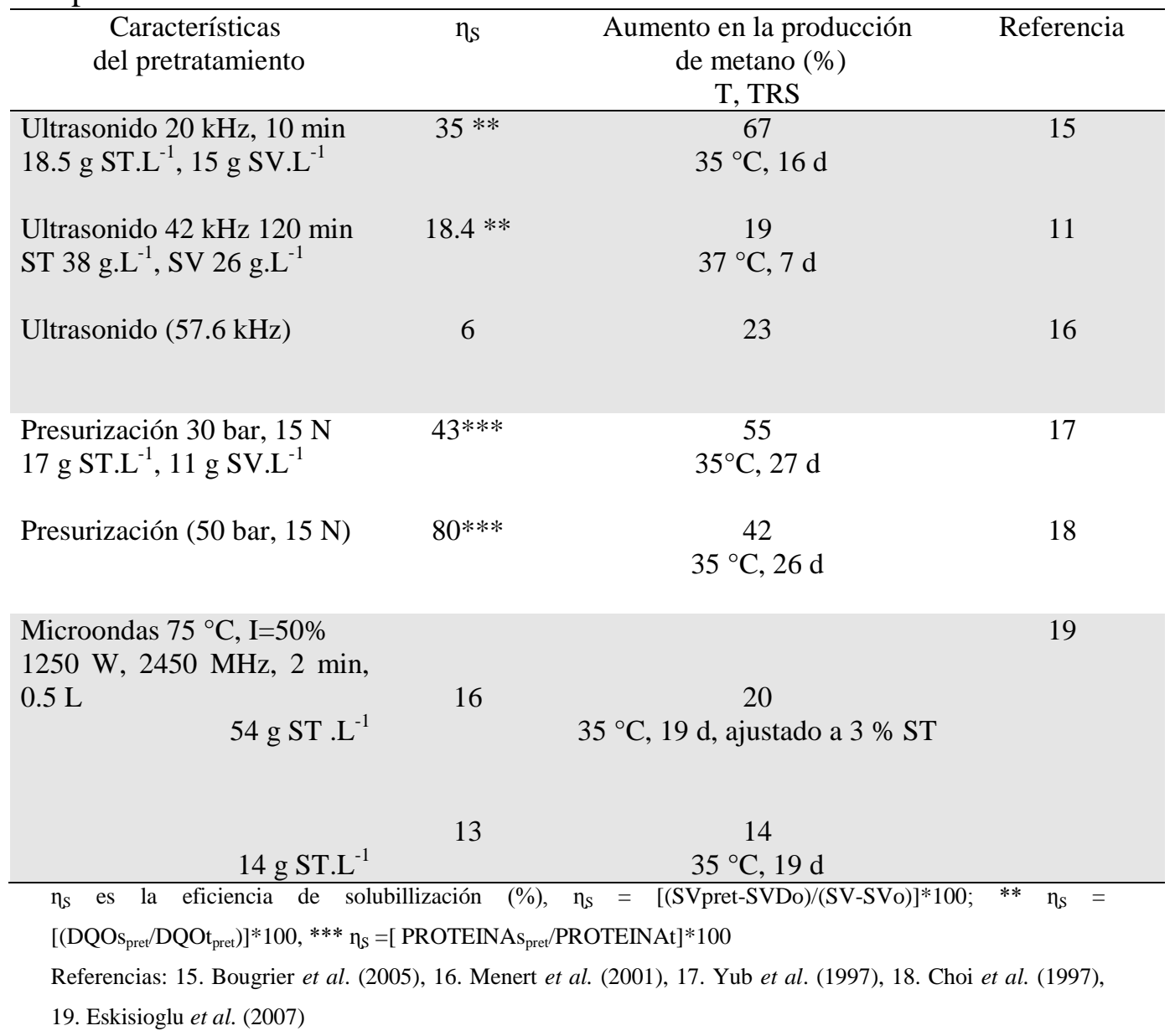

\subsubsection{Pretratamientos químicos}

Los principales pretratamientos químicos estudiados para aumentar la desintegración del flóculo son la oxidación por ozono y por peróxidos y la hidrólisis con álcali.

El pretratamiento con álcali puede ser utilizado para hidrolizar y descomponer lípidos, polisacáridos y proteínas en pequeñas sustancias solubles tales como ácidos alifáticos, carbohidratos de bajo peso molecular y aminoácidos (Chiu et al., 1997). Las reacciones presentes durante la adición del álcali son de saponificación de ácidos urónicos y acetil esteres y de neutralización de diferentes ácidos formados en la degradación de sólidos suspendidos (Kim M. et al., 2003). Los pretratamientos con álcali tienen dos desventajas principales: (1) aumentan el contenido de sólidos totales y 
Efecto del pretratamiento sobre la solubilización y biodegradabilidad anaerobia

(2) debido a que las condiciones de reacción son muy agresivas se deben utilizar materiales con requerimientos especiales para poder instalarse en las plantas de tratamiento de aguas residuales.

El grado de solubilización logrado con distintas bases está en el intervalo de 15 a $40 \%$, el efecto sobre la producción de metano es discreto, se registran incrementos de alrededor del $12 \%$ (Cuadro 3.3).

Cuadro 3.3. Efecto del pretratamiento químico de los LRS en la solubilización y producción de metano.

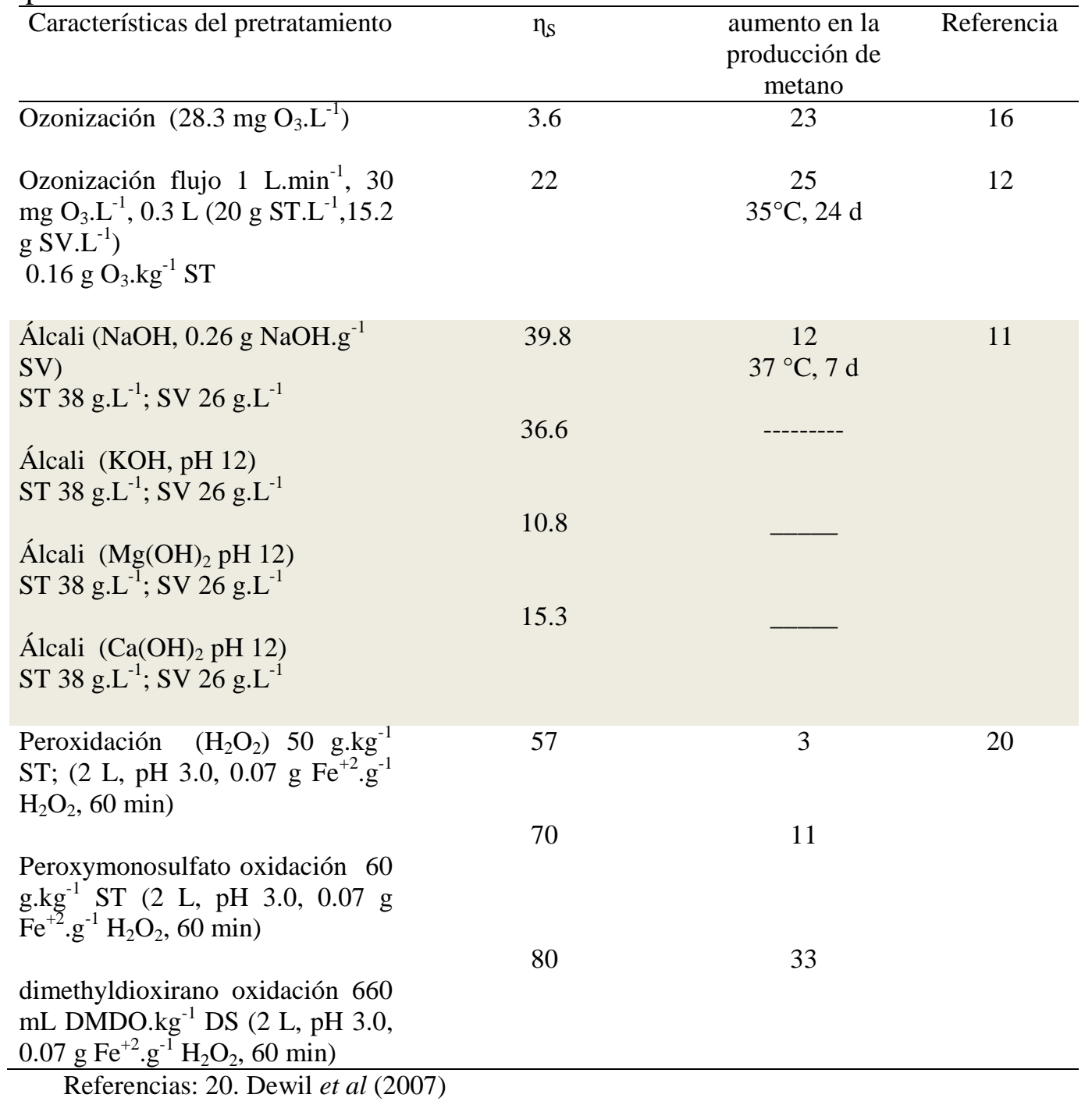

Otro pretratamiento químico utilizado es la oxidación. El pretratamiento con ozono $\left(\mathrm{O}_{3}\right)$ es de especial interés porque no se incrementa la concentración de sólidos totales (Weemaes et al., 2001; Goel et al., 2003). La oxidación con ozono no afecta la remoción de sólidos volátiles y demanda química de oxígeno total (DQOt). El aumento en la producción de metano debido a este pretratamiento es de alrededor de $25 \%$ y la 
Efecto del pretratamiento sobre la solubilización y biodegradabilidad anaerobia

solubilización fluctúa entre 20 y $40 \%$ (Cuadro 3.3). Además, Goel et al. (2003) encontraron que la eliminación de DQO soluble se incrementa de 65 a $80 \%$ en digestores mesofílicos y no observaron mejoría en la digestión anaerobia termofílica, cuando se realizó con LR pretratado con ozono.

Los pretratamiento con peróxidos han recibido recientemente especial atención, ya que se ha demostrado que con el uso de peróxido de hidrógeno, peroximonosulfato y dimetil dioxirano se logra una solubilización de 57, 70 y $80 \%$ respectivamente en los LRS. También se ha observado incrementos de entre 3 y $33 \%$ en la producción de metano (Cuadro 3.3).

\subsubsection{Pretratamientos combinados}

El pretratamiento termoalcalino de LRS, para temperaturas mayores a $130{ }^{\circ} \mathrm{C} \mathrm{y}$ dosis de $\mathrm{NaOH}$ mayores a $0.2 \mathrm{~kg} \cdot \mathrm{kg}^{-1} \mathrm{SV}$, logra eficiencias de solubilización mayores a $70 \%$ (Cuadro 3.4). También se observa que los iones divalentes favorecen la refloculación, ya que la solubilización disminuye con respecto al tratamiento con $\mathrm{NaOH}$ y $\mathrm{KOH}$ hasta en un $35 \%$, cuando el LR es tratado con $\mathrm{Ca}(\mathrm{OH})_{2}$ y $\mathrm{Mg}(\mathrm{OH})_{2}$. Otro de los pretratamientos combinados que logra alta solubilización es el ultrasonido-alcalino, alcanzando valores cercanos al $80 \%$, utilizando dosis de $\mathrm{NaOH}$ menores de $0.1 \mathrm{~kg} \cdot \mathrm{kg}^{-1}$ SV (Cheng-Nan et al., 1997).

Cuadro 3.4. Efecto del pretratamiento termoquímico de los LRS en la solubilización y producción de metano.

\begin{tabular}{|c|c|c|c|c|c|c|c|c|c|}
\hline \multicolumn{6}{|c|}{ Características del pretratamiento } & \multicolumn{3}{|c|}{$\begin{array}{c}\text { Rendimiento } \\
\text { metano }\end{array}$} & \multirow[t]{2}{*}{ Ref. } \\
\hline Dosis & SSV/SST & pH & $\mathbf{T}\left({ }^{\circ} \mathbf{C}\right)$ & $\begin{array}{c}\text { Tiempo de } \\
\text { contacto (h) }\end{array}$ & $\eta_{\mathrm{s}}$ & $\begin{array}{c}\Delta \\
(\%)\end{array}$ & $\begin{array}{c}\mathbf{T} \\
\left({ }^{\circ} \mathbf{C}\right) \\
\end{array}$ & $\begin{array}{c}\mathbf{t} \\
(\mathbf{d})\end{array}$ & \\
\hline $0.3 \mathrm{~g} \mathrm{NaOH} \mathrm{g}^{-1} \mathrm{SSV}$ & 0.87 & 10 & 130 & 0.083 & 70 & 27 & 37 & 10 & 21 \\
\hline $0.6 \mathrm{~g} \mathrm{NaOH} \mathrm{g}^{-1} \mathrm{SSV}$ & 0.95 & 12 & 150 & 0.50 & 70 & -40 & 37 & 20 & 22 \\
\hline $0.5 \mathrm{~g} \mathrm{CaO} \mathrm{g}^{-1} \mathrm{SSV}$ & 0.68 & 11 & 90 & 10 & 45 & 154 & 55 & 15 & 23 \\
\hline $0.26 \mathrm{~g} \mathrm{NaOH} \mathrm{g}^{-1} \mathrm{SV}$ & 0.68 & 12 & 121 & 0.50 & $51.8 * *$ & 34 & 37 & 7 & 11. \\
\hline $0,26 \mathrm{~g} \mathrm{KOH.g}{ }^{-1} \mathrm{SV}$ & & & & & $47.8 * *$ & ----- & & & \\
\hline $0,26 \mathrm{~g} \mathrm{Mg}(\mathrm{OH})_{2} \cdot \mathrm{g}^{-1} \mathrm{SV}$ & & & & & $18.3 * *$ & ----- & & & \\
\hline $0.26 \mathrm{~g}\left(\mathrm{Ca}(\mathrm{OH})_{2} \cdot \mathrm{g}^{-1} \mathrm{SV}\right.$ & & & & & $17.1 * *$ & ---- & & & \\
\hline
\end{tabular}

Los pretratamientos termo-alcalinos y con dimetil dioxirano (DMD) de LRS son los que han reportado mayor solubilización: 70 \% a pH 12 y temperatura mayor a 100 
Efecto del pretratamiento sobre la solubilización y biodegradabilidad anaerobia

${ }^{\circ} \mathrm{C}$ (Tanaka et al., 1997 y Delgenès et al., 2000), y 80 \% con 60 g DMD.kg-1 ST (Dewil et al., 2007). Sin embargo, existen evidencias de que los sólidos disueltos generados debido al pretratamiento termoalcalino tienen una menor biodegradabilidad (Delgenès et al., 2000). Por otro lado, Cacho Rivero y Suidan (2006) no observaron diferencia en la remoción de la DQO por DA de LRS sin pretratamiento con respecto a la DA de LRS pretratados con dosis de $\mathrm{H}_{2} \mathrm{O}_{2}$ de $0.1,0.25$ y 0.5 g.L $\mathrm{L}^{-1}$, a $90{ }^{\circ} \mathrm{C}$ durante $18 \mathrm{~h}$.

En este capítulo se muestran los resultados del efecto de los pretratamientos: alcalino, térmico, termo-alcalino, sonicación y sonicado-alcalino, sobre biodegradabilidad de los sólidos disueltos en lodos residuales secundarios pretratados y se incluye el cálculo de la energía neta requerida para cada uno de los pretratamientos estudiados.

\subsection{Material y métodos}

\subsubsection{Pretratamientos}

$100 \mathrm{~mL}$ de lodos residuales con una concentración de DQO total de 55 g.L $\mathrm{L}^{-1} \mathrm{y}$ concentración de sólidos suspendidos totales (SST) de 35 g.L $\mathrm{L}^{-1}$ y una relación SSV/SST de 0.79 , se sometieron a 3 pretratamientos: térmico $\left(70,90\right.$ y $\left.120^{\circ} \mathrm{C}\right)$, alcalino $(0.5 \mathrm{~g}$ $\mathrm{NaOH} / \mathrm{g} \mathrm{SSV})$, ultrasonido $(20 \mathrm{kHz}$ y $44 \mathrm{kHz}$ ). Todos con agitación constante de 300 rpm.

La eficiencia de solubilización ( $\eta$ ) se determinó para SST, SSV y DQO. Utilizando las ecuaciones 3.1 y 3.2 .

$$
\eta=\frac{[S S]_{0}-[S S]_{P}}{[S S]_{0}} \quad(3.1) ; \quad \eta=\frac{[D Q O s]_{P}-[D Q O s]_{0}}{[D Q O t]_{0}-[D Q O s]_{0}}
$$

En donde: SS son sólidos suspendidos totales y volátiles respectivamente, antes, [ ], y después del pretratamiento, [ ]P, DQOs y DQOt es la demanda química de oxígeno soluble y total respectivamente.

\subsubsection{Sustrato}

El LRS pretratado fue centrifugado a $7000 \mathrm{G}$ durante $15 \mathrm{~min}$ y el sobrenadante fue acondicionado para utilizarse como sustrato en las pruebas de biodegradabilidad. Al sobrenadante se le adicionaron los nutrientes del medio RAMM (ver 2.2.4). 
Efecto del pretratamiento sobre la solubilización y biodegradabilidad anaerobia

\subsubsection{Ensayos de biodegradabilidad}

La biodegradabilidad se determinó según Field et al., (1986). Los ensayos de biodegradabilidad se realizaron en botellas de $250 \mathrm{~mL}$. A cada botella se alimentaron $190 \mathrm{~mL}$ de sustrato e inóculo con una actividad metanogénica de 0.44 g DQO $\mathrm{CH}_{4} . \mathrm{g}^{-}$ ${ }^{1} \mathrm{SSV} . \mathrm{d}^{-1}$. Para el ensayo se adicionó el volumen de inóculo necesario para fijar los SSV en 1.5 g.L $\mathrm{L}^{-1}$. La concentración inicial de $\mathrm{DQO}_{0}$ del sustrato fue de 3.0 g.L $\mathrm{L}^{-1}$. Para evitar descenso del $\mathrm{pH}$ se añadió $1.0 \mathrm{~g} \mathrm{NaHCO} \cdot \mathrm{g}^{-1} \mathrm{DQO}_{0}$. Las botellas se sellaron herméticamente y se purgaron con nitrógeno, posteriormente se incubaron durante 7 días a $35^{\circ} \mathrm{C}$. La botella se conectó a una trampa de gas y ésta a su vez a una columna de $250 \mathrm{~mL}$ con una solución de salmuera para medir el volumen de biogás producido, la composición de éste se determinó por cromatografía de gases (ver 2.2.3.4).

El cálculo de la biodegradabilidad se realizó de la siguiente manera:

1. Se midió el volumen de metano acumulado durante los 7 días de incubación y se convirtió a mg DQO $\mathrm{CH}_{4} \cdot \mathrm{L}^{-1}$ con la ecuación 3.3

$$
\frac{D Q O_{C H 4}}{L}=\frac{V_{C H 4}}{F C} \frac{1}{V}
$$

En donde $\mathrm{V}_{\mathrm{CH} 4}$ es el volumen acumulado de metano (L) en 7 días de digestión, FC es el factor de conversión ( $\mathrm{L} \mathrm{CH}_{4} \cdot \mathrm{g}^{-1} \mathrm{DQO}$ ) a las condiciones de temperatura y presión de operación, V volumen del líquido en el reactor

El valor de FC fue calculado considerando que $0.350 \mathrm{~L}_{\text {de }} \mathrm{CH}_{4} \operatorname{seco}\left(\mathrm{T}=0^{\circ} \mathrm{C}, \mathrm{P}=\right.$ $1 \mathrm{~atm})$ equivale a $1 \mathrm{~g}$ DQO. Este factor es un rendimiento estequimétrico $\left(\mathrm{Y}_{\mathrm{CH} 4}\right)$ de la oxidación del metano

$$
\begin{gathered}
\mathrm{CH}_{4}+2 \mathrm{O}_{2} \rightarrow \mathrm{CO}_{2}+2 \mathrm{H}_{2} \mathrm{O} \\
\frac{22.4 \mathrm{LCH}_{4}(\mathrm{STP})}{1 \mathrm{~mol} \mathrm{CH}_{4}} \cdot \frac{1 \mathrm{~mol} \mathrm{CH}_{4}}{16 \mathrm{~g} \mathrm{CH}} \cdot \frac{16 \mathrm{gCH}_{4}}{64 \mathrm{~g} \mathrm{O}_{2}}=0.350 \frac{\mathrm{LCH}_{4}}{\mathrm{gO}_{2}}
\end{gathered}
$$

entonces:

$$
F C=Y_{C H 4} \frac{273+T_{o p}}{273} \frac{760 m m H g}{P_{o p}} \frac{1}{1-P_{v a p}}
$$

En donde: $\mathrm{T}_{\mathrm{op}}=35^{\circ} \mathrm{C}, \mathrm{P}_{\mathrm{op}} 580 \mathrm{mmHg}$, se consideró que el biogás esta saturado con agua (normalmente de 3 a $4 \%$ en volumen) y la presión de vapor de agua a $35^{\circ} \mathrm{C}\left(\mathrm{P}_{\text {vap}}\right)$ es de 0.0548 atm. Por lo que el FC utilizado es de $547 \mathrm{~mL} \mathrm{CH}_{4} \mathrm{~g}^{-1}$ DQO.

2. La concentración de $\mathrm{AGV}$, al final de la digestión, se determinó según lo descrito en 2.2.3. Posteriormente se calculó la demanda química de oxígeno debida a los $\mathrm{AGV}, \mathrm{DQO}_{\mathrm{AGV}}$ 
3. La biodegradabilidad se calculó con la ecuación 3.4

$$
\% B D=\% M+\% A G V+\% \text { cel }
$$

En donde: \% $\mathrm{M}$ es $100\left(\mathrm{DQO}_{\mathrm{CH} 4} / \mathrm{DQO}_{0}\right), \% \mathrm{AGV}$ es $100\left(\mathrm{DQO}_{\mathrm{AGV}} / \mathrm{DQO}_{0}\right.$ y \%cel es el porcentaje de DQO inicial asimilado por la bacterias metanogénicas (\% cel $_{\mathrm{M}}$ ) y las bacterias acidogénicas $\% \operatorname{cel}_{\mathrm{A}}$.

$$
\begin{gathered}
\% \operatorname{cel}_{M}=\% M \frac{Y_{M}}{1-Y_{M}} \\
\% c e l_{A}=(\% M+\% A G V) \frac{Y_{A}}{1-Y_{A}}
\end{gathered}
$$

En donde $\mathrm{Y}_{\mathrm{M}}$ es el coeficiente de rendimiento celular de baterias metanogénicas $(0.028$ $\left.\mathrm{g} \quad \mathrm{DQO}_{\text {cel }} / \mathrm{gDQO}_{\text {consumida }}\right)$ y $\quad \mathrm{Y}_{\mathrm{A}}$ el de bacterias acidogénicas $(0.196 \mathrm{~g}$ $\left.\mathrm{DQO}_{\text {cel }} / \mathrm{gDQO}_{\text {consumida }}\right)$

\subsubsection{Cálculo de la energía específica}

La energía específica (Es) utilizada en el pretratamiento de los lodos residuales secundarios se expresa como la energía requerida para tratar una masa determinada de LRS. Para el cálculo de la energía específica se empleó la Ec. 3.5.

$$
E_{S}=\frac{(P)(t)}{(V)\left(S T_{0}\right)}
$$

En donde: $\mathrm{E}_{\mathrm{S}}$ es la energía específica $\left(\mathrm{kJ} \mathrm{kg}^{-1}\right)$, $\mathrm{P}$ es la potencia aplicada en cada pretratamiento (W), t es el tiempo de exposición (s), V es el volumen de la muestra (L), $\mathrm{ST}_{0}$ es la concentración inicial de sólidos totales $\left(\mathrm{kg} \mathrm{ST}_{0} \cdot \mathrm{L}^{-1}\right)$.

La potencia $(\mathrm{P})$, para el pretratamiento térmico se definió como la energía necesaria para llevar al LRS de $25{ }^{\circ} \mathrm{C}$ a la temperatura de tratamiento en un lapso de tiempo específico (Olalde, 2009).

El cálculo de la energía específica al utilizar hidróxido de sodio en el pretratamiento se realiza utilizando la energía electrolítica para la producción de $\mathrm{NaOH}$ (19 kW.h.kg- $\left.{ }^{-1} \mathrm{NaOH}\right)$.

\subsubsection{Cálculo de la producción de energía por generación de metano}

Para el cálculo de la energía producida por la combustión del metano, se utilizó la ecuación 3.6

$$
\frac{\mathrm{kJ}}{\mathrm{SSTo}}=\mathrm{f}_{\mathrm{CH} 4} * \mathrm{f}_{\text {solubilización }} * 1.4 * \mathrm{Y}_{\mathrm{CH} 4} * \mathrm{H}_{\mathrm{C}}
$$


En donde $\boldsymbol{f}_{\boldsymbol{C H} \boldsymbol{4}}$ es la fracción de DQO soluble inicial que se transforma a metano $(\% \mathrm{M} / 100), \boldsymbol{f}_{\text {solubilización }}$ es la fracción de solubilización (\%solubilización DQO/100), 1.4 es un factor de conversión en $\mathrm{kg}$ DQO. $\mathrm{kg}^{-1} \mathrm{SST}, \mathrm{Y}_{\mathrm{CH} 4}$ es el rendimiento $\mathrm{m}^{3} \mathrm{CH}_{4}$ (STP). $\mathrm{kg}^{-1}$ DQO, Hc es el calor de combustión del metano $\left(39,597\right.$ kJ.m $\left.{ }^{-3} \mathrm{CH}_{4}\right)$.

\subsection{Resultados y discusión}

\subsubsection{Pretratamiento a diferentes temperaturas}

El efecto del pretratamiento térmico sobre los LRS fue de un incremento en los sólidos disueltos, debido al rompimiento del flóculo y a la hidrólisis de los polímeros orgánicos (proteínas y lípidos), que forman parte del lodo. Al mismo tiempo se destruyeron los microorganismos que forman parte del flóculo y se solubilizaron las proteínas, carbohidratos, lípidos y algunas moléculas de bajo peso molecular, como por ejemplo ácidos grasos volátiles (Li y Noike, 1992). El pretratamiento térmico provocó un aumento en la DQO soluble, y éste dependió de la temperatura, pero independiente del tiempo de tratamiento (Figura 3.1).

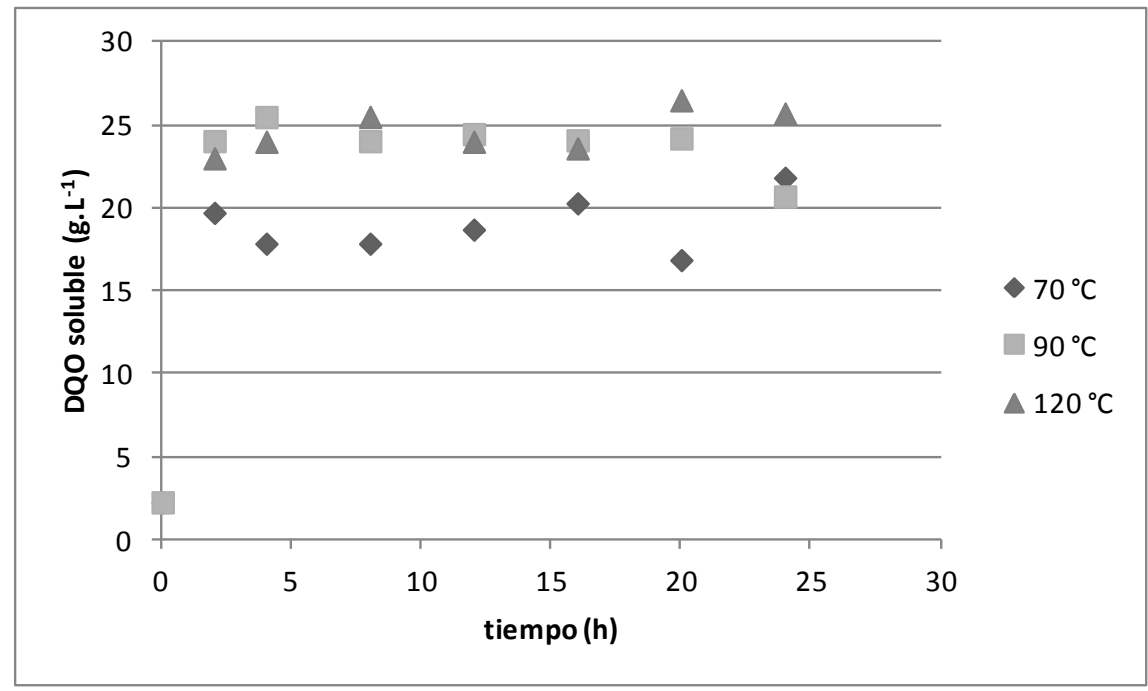

Figura 3.1 Evolución de la DQO soluble durante el tratamiento térmico de lodo residual secundario a 70,90 y $120{ }^{\circ} \mathrm{C}$ a distintos tiempos de contacto.

También se observó que cuando la temperatura fue de $120^{\circ} \mathrm{C}$, no hubo diferencia en la concentración de DQO soluble con respecto al tratamiento a $90{ }^{\circ} \mathrm{C}$. Esto puede deberse al fenómeno de refloculación, dicho comportamiento fue reportado por Gonze et al. (2003) al tratar lodo residual por ultrasonido. La refloculación se ha observado 
cuando hay un incremento en la energía específica aplicada al lodo (Bougrier et al., 2005).

La eficiencia de solubilización de los sólidos suspendidos totales, debido al incremento de la temperatura fue de $22 \%, 40 \%$ y $36 \%$ para 70,90 y $120{ }^{\circ} \mathrm{C}$, respectivamente. No se registró incremento en la solubilización de los SST, con el tiempo de contacto.

El perfil de tiempo temperatura para el pretratamiento térmico se muestra en la Figura 3.2. En la fase de calentamiento se logró el 75\% de la solubilización total de los sólidos suspendidos durante el pretratamiento. Durante la fase de mantenimiento sucedió el resto de la solubilización total.

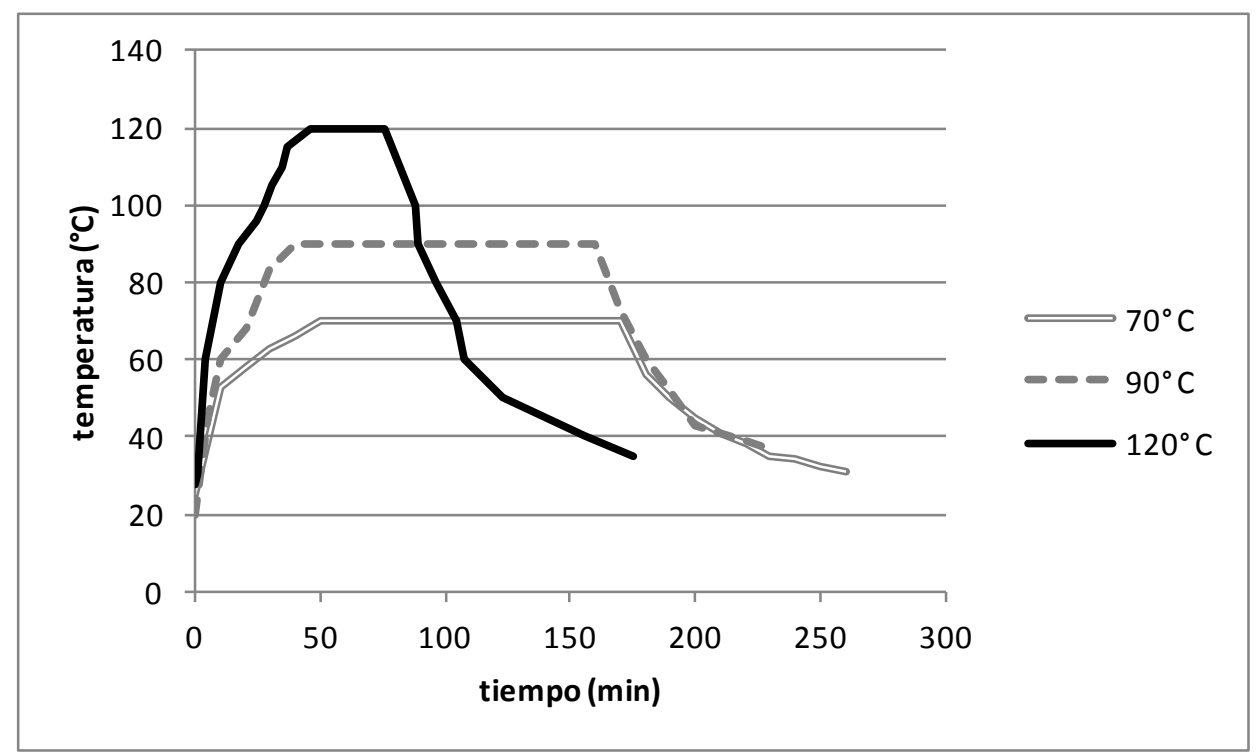

Figura 3.2 Perfil tiempo-temperatura durante el tratamiento térmico de lodo residual secundario a 70,90 y $120^{\circ} \mathrm{C}$.

\subsubsection{Pretratamiento por ultrasonido}

Para las dos frecuencias ensayadas 22 y $44 \mathrm{kHz}$ a cada uno de los tiempos en que se realizó el pretratamiento la DQO total se mantuvo constante, mientras que la DQO soluble se incrementó cuando el tiempo del pretratamiento aumentó, Figura 3.3.

La máxima solubilización alcanzada para una frecuencia de $22 \mathrm{kHz}$ fue de $58.1 \%$ a los 70 minutos de tratamiento. Sin embargo, el aumento de la solubilización ya no fue lineal después de los 50 minutos de tratamiento. Un comportamiento similar tuvo el lodo cuando se trató a $44 \mathrm{kHz}$, observándose una solubilización máxima de $19.3 \%$, y perdiendo su linealidad con el tiempo después de 90 minutos de tratamiento. 
Efecto del pretratamiento sobre la solubilización y biodegradabilidad anaerobia

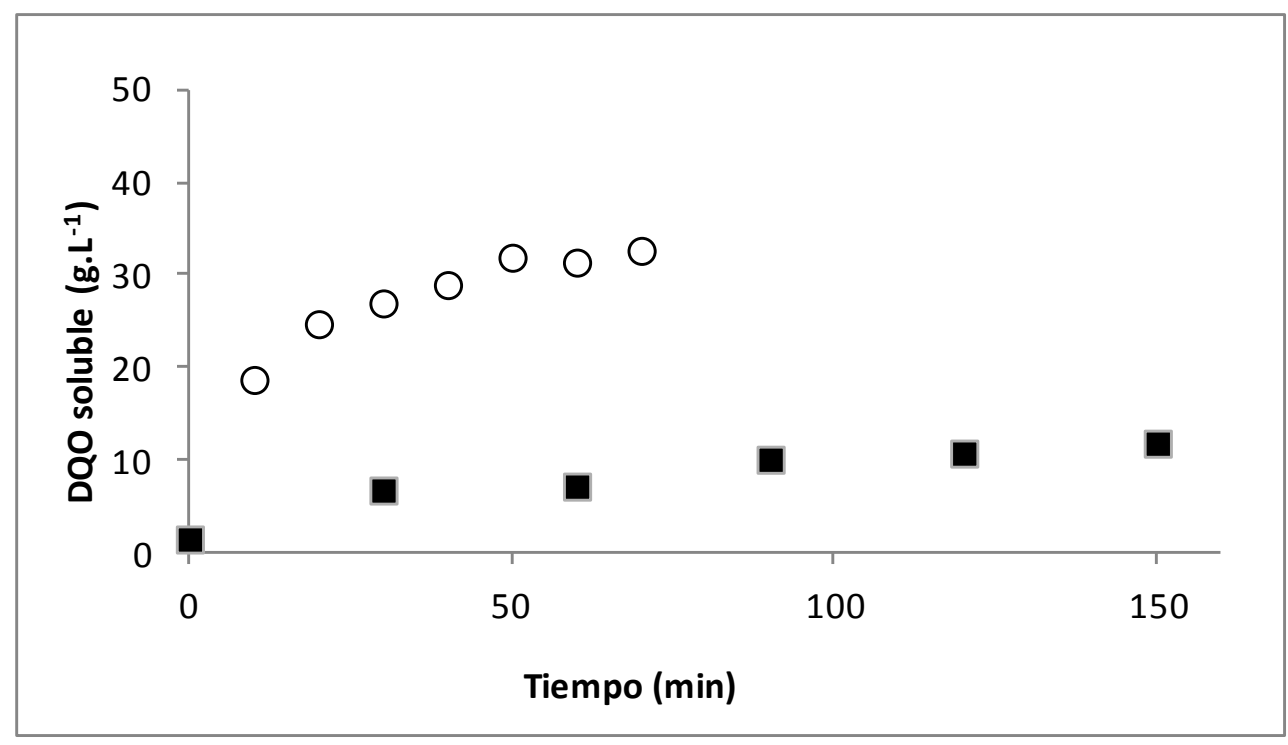

Figura 3.3 Evolución de la DQO soluble durante el tratamiento por ultrasonido de lodo residual secundario a $22 \mathrm{kHz}(\mathrm{O})$ y $44 \mathrm{kHz}$ (匹) a distintos tiempos de contacto.

\subsubsection{Pretratamiento con álcali.}

El efecto del tiempo de contacto del hidróxido de sodio con el LRS sobre la solubilización, se muestra en la Figura 3.4. El grado de solubilización se muestra como un cambio en la concentración de DQO soluble. La dosis empleada es de $0.5 \mathrm{~g} \mathrm{NaOH.g}{ }^{-}$ ${ }^{1} \mathrm{SSV}$, esta dosis provocó un aumento del pH de 6.7 a 12 . El efecto del tiempo de contacto durante el pretratamiento con $\mathrm{NaOH}$ puede ser dividido en dos periodos, una solubilización rápida (primeros 30 minutos) y un periodo de lenta solubilización hasta los 60 minutos. Este efecto también fue observado en estudios similares (Cai et al., 2004; Li et al., 2008). Para periodos más largos (entre 75 y 140 min) no se observa un incremento de la solubilización. En los primeros 20 minutos se logra un $78 \%$ de la solubilización máxima alcanzada. La mayor eficiencia de solubilización (36\%) se da a los 60 minutos de contacto. 
Efecto del pretratamiento sobre la solubilización y biodegradabilidad anaerobia

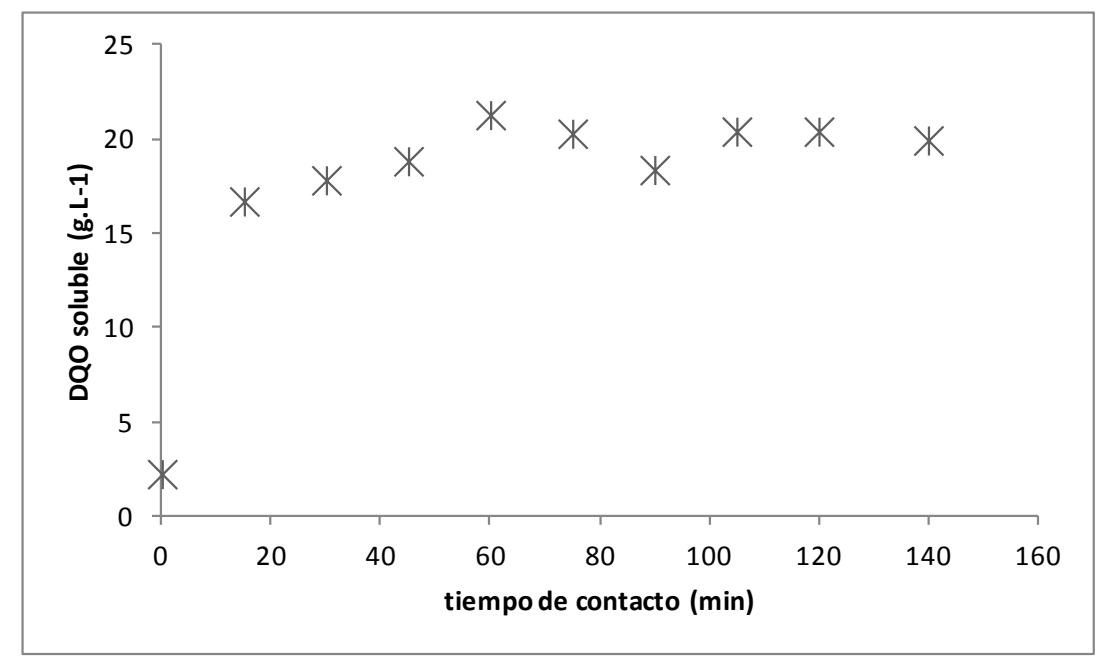

Figura 3.4 Evolución de la DQO soluble durante el tratamiento con álcali a distintos tiempo de contacto

\subsubsection{Efecto de los diferentes pretratamientos sobre la solubilización de lodos residuales secundarios.}

En función de los resultados previos se establecieron los tiempos de contacto para cada pretratamiento y se realizaron los siguientes : $100 \mathrm{~mL}$ de LRS se sometieron a 5 pretratamientos: térmico $\left(120^{\circ} \mathrm{C}, 15 \mathrm{~min}\right)$, alcalino $(0.5 \mathrm{~g} \mathrm{NaOH} / \mathrm{g} \mathrm{SSV}, 1 \mathrm{~h})$, térmicoalcalino $\left(0.5 \mathrm{~g} \mathrm{NaOH} / \mathrm{g} \mathrm{SSV}\right.$ y $15 \mathrm{~min}$ a $\left.120{ }^{\circ} \mathrm{C}\right)$, ultrasonido $(20 \mathrm{kHz}, 1 \mathrm{~h}), \mathrm{y}$ ultrasonido-alcalino (0.5 g NaOH/g SSV y ultrasonido a $20 \mathrm{kHz}, 1 \mathrm{~h})$. Todos con agitación constante de 300 rpm.

El pretratamiento que presentó la mayor eficiencia de solubilización para sólidos suspendidos y demanda química de oxígeno fue el sonicado-alcalino (Son-Alc), Figura 3.5 .

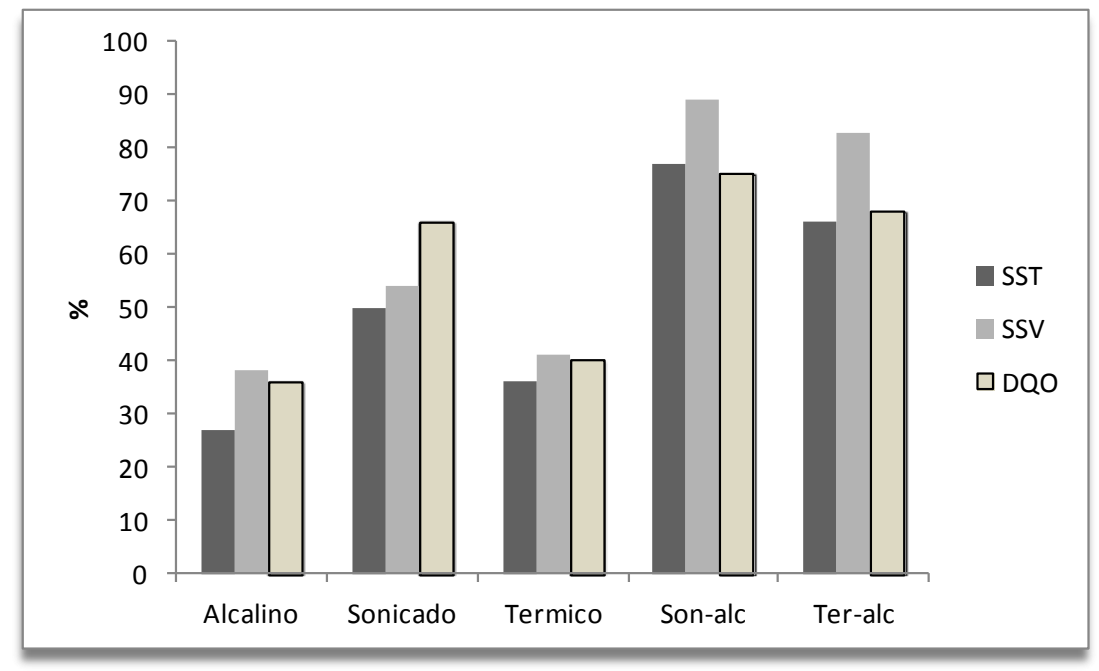

Figura 3.5. Eficiencia de solubilización para lodos residuales secundarios pretratados. 
Efecto del pretratamiento sobre la solubilización y biodegradabilidad anaerobia

\subsubsection{Efecto del pretratamiento sobre al biodegradabilidad anaerobia de los sólidos.}

En la Figura 3.6 se muestran los porcentajes de producción de metano $(\% \mathrm{M})$ y de biodegradabilidad (\%BD) para los cinco pretratamientos. La desviación entandar entre todos los pretratamientos fue de $3 \%$, lo que implica que ninguno de los pretratamientos afectan la biodegradabilidad del lodo.

El pretratamiento por ultrasonido presentó mayor acumulación de $\mathrm{AGV}$, en éste se obtuvo también el mayor porcentaje de propionato, $46 \%$ de los AGV totales. Esta acumulación está asociada a la deficiente eliminación de acetato e hidrógeno por las bacterias metanogénicas, ya que por razones termodinámicas, cuando éstos no son utilizados, el propionato y el butirato no son efectivamente degradados a acetato, bióxido de carbono e hidrógeno (Ahring y Westermann, 1987, 1988).

En el Cuadro 3.5 se muestra los requerimientos energéticos para los 5 pretratamientos. El pretratamiento alcalino produce la mayor energía neta y los pretratamiento sonicado-alcalino y termo-alcalino generan la mayor solubilización con la menor cantidad de energía requerida.

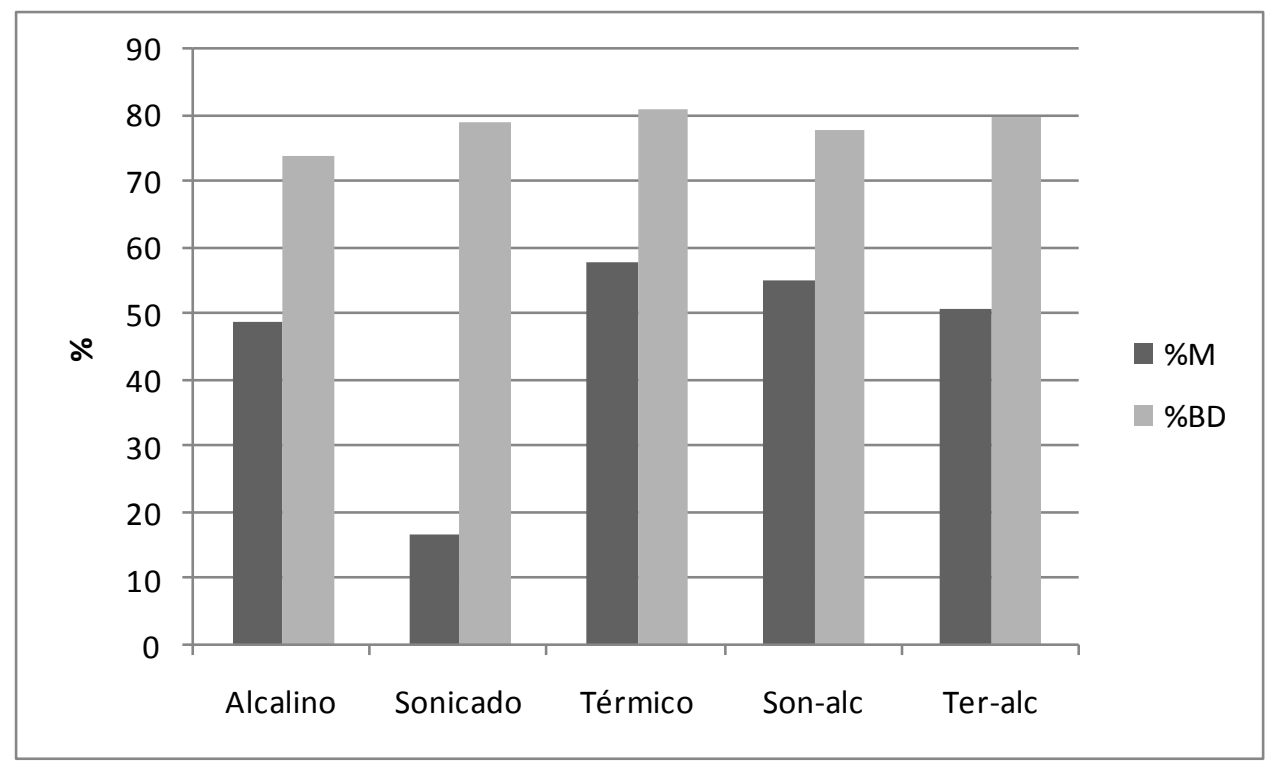

Figura 3.6. Biodegradabilidad de los sólidos solubles en lodos residuales pretratados. 
Efecto del pretratamiento sobre la solubilización y biodegradabilidad anaerobia

Cuadro 3.5. Requerimiento energético para los pretratamientos

\begin{tabular}{cccc}
\hline Pretratamiento & $\begin{array}{c}\text { Gasto de } \\
\text { energía específica } \\
\text { (kJ/kg SSTo) }\end{array}$ & $\begin{array}{c}\text { Solubilización } \\
\mathbf{( \% )}\end{array}$ & $\begin{array}{c}\text { Producción de } \\
\text { energía } \\
\text { específica } \\
\text { (kJ/kg SSTo) }\end{array}$ \\
\hline Alcalino & 2,729 & $47 \pm 10$ & $-1,703$ \\
Sonicado & 100,000 & $66 \pm 6$ & $-259,884$ \\
Térmico & 32,449 & $20 \pm 3$ & $-29,306$ \\
Sonicado-alcalino & 102,729 & $75 \pm 8$ & $-261,379$ \\
Termo-alcalino & 35,178 & $68 \pm 6$ & $-24,623$ \\
\hline
\end{tabular}

El pretratamiento alcalino produce una energía neta positiva. Sin embargo, debido a que el tipo de energía requerida para su producción es eléctrica, se necesita hacer la siguiente consideración: el rendimiento para un sistema de producción de energía eléctrica a partir de la combustión de metano es de $15 \%$ (Weemaes et al., 2001). Por lo que la energía eléctrica generada a partir del metano producido es de $1026 \mathrm{~kJ} . \mathrm{kg}^{-1}$ SSTo. Así que su producción neta de energía es -1703 kJ.kg-1 SSTo.

\subsection{Conclusiones.}

El proceso de hidrólisis de lodos residuales secundarios, utilizando los pretratamientos térmico, ultrasonido y alcalino con hidróxido de sodio presentan dos periodos: en el primero sucede más del $70 \%$ de la solubilización y en el segundo se observa una solubilización lenta y coincide que los periodos de aplicación de energía son menores a 40 minutos, para todos los pretratamientos.

El pretratamiento que dio la mayor solubilización en función de la DQO fue el sonicado-alcalino $75 \%$. Pero también fue el que presentó el menor porcentaje de metanización y mayor requerimiento de energía.

Los pretratamiento combinados generan mayor solubilización, pero el alcalino tiene mayor sustentabilidad energética. 


\section{4}

\section{EFECTO DEL PRETRATAMIENTO \\ TERMOALCALINO SOBRE LA HIDRÓLISIS ANAEROBIA DE LODOS RESIDUALES SECUNDARIOS}

Publicado como: S. E. Vigueras-Carmona, F. Ramírez, A. Noyola and O. Monroy (2011) Effect of thermal alkaline pretreatment on the anaerobic digestion of wasted activated sludge. Water Science \& Technology, Vol. 64, No. 4, pp. 953-959 c IWA Publishing 2011 doi:10.2166/wst.2011.726 
Efecto del pretratamiento sobre la velocidad de hidrólisis

\section{Efecto del pretratamiento termoalcalino sobre la hidrólisis anaerobia de lodos residuales secundarios}

\subsection{Introducción}

La digestión anaerobia (DA) mesofílica es la tecnología que más se utiliza para la estabilización de lodos residuales secundarios (LRS), esto debido a la posibilidad de recobrar energía de la materia orgánica, por reducir la cantidad de sólidos a disponer, por su capacidad de destruir los patógenos y porque se puede controlar la emisión de malos olores.

Los LRS están formados por agregados celulares, formados por sustancias exopoliméricas (SEP) y células que están organizadas en matrices semejantes a un gel (Appels et al., 2008). El $44 \%$ de las SEP son proteínas y sólo alrededor del $30 \%$ de éstas es degradado (Li y Noike, 1992).

Varios autores (Roberts et al. 1999, De la Rubia et al. 2002; Arnaiz et al. 2006) han demostrado que por DA mesofílica se logra remover entre 32 y $56 \%$ de los sólidos volátiles (SV) presentes en los LRS. Los sistemas convencionales de escala industrial, operan con porcentajes de sólidos totales (ST) entre 2 y $4 \%$, tiempos de retención de sólidos (TRS) entre 20 y 30 días y bajas cargas orgánicas entre 0.4 y $2 \mathrm{~kg} \mathrm{SV} \cdot \mathrm{m}^{-3} \cdot \mathrm{d}^{-1}$, con rendimientos de metano alrededor de $0.4 \mathrm{~m}^{3} \mathrm{CH}_{4} \cdot \mathrm{kg}^{-1} \mathrm{SV}$ y remociones de $\mathrm{SV}$ de entre 20 y $40 \%$. Por las condiciones antes mencionadas los volúmenes de los digestores anaerobios utilizados son muy grandes y esto conlleva a una producción negativa de energía neta. Por otro lado, los sistemas no convencionales, como por ejemplo la DA termofílica, con TRS cortos (entre 5 y 10 días) logran un $32 \%$ más de destrucción de SV y un $37 \%$ más de producción de metano, con respecto a los sistemas de DA mesofílica (De la Rubia et al. 2006). Este incremento en la destrucción de SV también se ha observado en los sistemas de dos etapas termofílicos-mesofílicos, en éstos los SV son hidrolizados y fermentados a ácidos grasos volátiles (AGV) en el reactor termofílico, posteriormente los $\mathrm{AGV}$ son transformados a metano y bióxido de carbono en el reactor mesofílico (Yue et al., 1997; Roberts et al. 1999; Zitomer et al., 2008; Kim y Novak, 2011). El digestor termofílico de los sistemas de dos etapas presenta problemas de estabilidad debido a que las bacterias termofílicas son muy sensibles a las fluctuaciones de temperatura lo que hace difícil su control (Appels et al., 2008). 
En los sistemas de DA de LRS, la etapa de hidrólisis es la que limita el proceso de estabilización, la baja velocidad de hidrólisis de los LRS puede ser atribuida a la naturaleza recalcitrante de las SEP y la pared celular, la cual evita la biodegradación de los materiales orgánicos que forman parte de la célula y que son susceptibles de ser utilizados durante la DA. Debido a esto, se han aplicado diversos pretratamientos que promueven la ruptura de la pared celular y mejoran la solubilización de las SEP (Bougrier et al., 2005) incrementando de esta manera la disponibilidad de las proteínas, lípidos, polisacáridos y ácidos nucleicos presentes en los LRS.

El pretratamiento termoalcalino (Chiu et al., 1997), además de tener desventajas prácticas y económicas (Appels et al., 2008), ha generado resultados contradictorios. Mientras que Kim J. et al. (2003) y Vlyssides y Karlis (2004) obtuvieron mayor rendimiento de metano, Delgènes et al., (2000) reportaron que sólo el $20 \%$ de la demanda química de oxígeno (DQO) soluble es transformada a AGV, debido a una baja en la biodegradabilidad de los sólidos disueltos (SD) del LRS pretratado pasando de 58 a $32 \%$. Estos resultados aparentemente contrarios pueden estar vinculados al tipo de análisis realizado. La producción de metano es reportada como función de la concentración inicial de sólidos suspendidos volátiles y la biodegradabilidad es función de la DQO removida.

En el modelo matemático ADM1 (Batstone et al., 2002), la solubilización de los sólidos suspendidos (SS) a carbohidratos, proteínas y lípidos solubles fue incluida principalmente para facilitar el modelado de la digestión anaerobia de lodos residuales. Sin embargo no se contempla que la hidrólisis de los SS y SD se da a diferente velocidad: la velocidad de hidrólisis de los polisacáridos, proteínas y lípidos en suspensión (SS) está en función del tamaño de partícula y del número de sitios de adsorción en la superficie, (Veeken y Hamelers, 1999, Sanders et al., 2000), mientras, que la velocidad de hidrólisis de los polisacáridos, proteínas y lípidos disueltos es función de la concentración de los SD y de la cantidad y actividad del inóculo empleado (Goel et al., 1998).

Sanders et al. (2000) proponen un modelo basado en la superficie de la partícula, este es un modelo determinista, en él se asume que el sólido suspendido está perfectamente unido a la bacteria que secreta la exoenzima hidrolítica que está en exceso respecto a la superficie disponible. Este modelo tiene la ventaja de que la constante de hidrólisis no cambia por unidad de área disponible para la hidrólisis y por lo tanto no varía con el tamaño de partícula, como se aprecia en la Ec. (4.1). 


$$
r_{S S}=\frac{d S S}{d t}=-K_{S B K} A
$$

En donde: $\mathrm{r}_{\mathrm{SS}}$ es la velocidad de hidrólisis de los sólidos suspendidos $\left(\mathrm{kg} \mathrm{m}^{-3} \mathrm{~d}^{-1}\right), \mathrm{K}_{\mathrm{SBK}}$ es la constante de velocidad de hidrólisis basada en la superficie $\left(\mathrm{kg} \mathrm{m}^{-2} \mathrm{~d}^{-1}\right)$, A es el área de la partícula por unidad de volumen de medio $\left(\mathrm{m}^{2} \mathrm{~m}^{-3}\right)$.

Por su parte Goel et al. (1998) proponen un modelo para la hidrólisis de sólidos disueltos, en éste se considera que la relación entre la velocidad de hidrólisis y la concentración de sólidos disueltos es del tipo de saturación, Ec. (4.2).

$$
r_{S D}=k_{h} \frac{S D}{K_{x}+S D}
$$

En donde: $\mathrm{r}_{\mathrm{SD}}$ es la velocidad de hidrólisis de los sólidos disueltos $\left(\mathrm{kg}\right.$ DQO. $\left.\mathrm{m}^{-3} \cdot \mathrm{d}^{-1}\right), \mathrm{SD}$ es la concentración de sólidos disueltos $\left(\mathrm{kg}\right.$ DQO. $\left.\mathrm{m}^{-3}\right) ; \mathrm{k}_{\mathrm{h}}$ es la constante de velocidad máxima de hidrólisis $\left(\mathrm{kg}\right.$ DQO. $\left.\mathrm{m}^{-3} \cdot \mathrm{d}^{-1}\right), \mathrm{K}_{\mathrm{X}}$ es la constante de saturación $\left(\mathrm{kg}\right.$ DQO.m $\left.{ }^{-3}\right)$.

Para usar la ecuación 4.1 es necesario conocer la distribución del tamaño de partícula (DTP). Park et al., (2005) estudiaron el efecto del pretratamiento termoalcalino sobre la DTP. Las muestras de LRS sin pretratamiento, mostraron que el $10 \%$, $50 \%$ y $90 \%$ de las partículas tuvieron diámetros menores a 24, 219 y $450 \mu \mathrm{m}$, respectivamente, mientras que las partículas de los LRS pretratados mostraron un $10 \%$, $50 \%$ y $90 \%$ de partículas con diámetros menores a 2, 29 y $144 \mu \mathrm{m}$, respectivamente. En otro estudio Benabdallah et al., (2007) encontró que la DTP de LRS sin pretratamiento estuvo entre diámetros de partícula de 30 y $50 \mu \mathrm{m}$ y cuando los LRS fueron tratados por ultrasonido la DTP estuvo entre diámetros de 10 a $13 \mu \mathrm{m}$.

El objetivo de esta sección fue evaluar el efecto del pretratamiento termo-alcalino en la velocidad de hidrólisis de los SS y SD de lodos pretratados y sin pretratamiento, utilizando el modelo de superficie y el de saturación para predecir la velocidad a la que los SS y SD respectivamente se convierten a metano, durante la DA mesofílica y termofílica.

\subsection{Material y métodos}

\subsubsection{Tratamiento termo alcalino de los lodos residuales secundarios}

La muestra de LRS se obtuvo de la planta de tratamiento de aguas residuales de Ciudad Universitaria de la Universidad Nacional Autónoma de México, que trata el agua residual del campus y de las unidades habitacionales aledañas. Los LRS se espesaron por gravedad, hasta tener $1 \%$ de sólidos suspendidos totales. La densidad del 
lodo consolidado fue determinada pesando $10 \mathrm{~mL}$ de éste, obteniendo un valor de 1.01 kg. $\mathrm{m}^{-3}$.

El lodo consolidado fue pretratado termo-alcalinamente, ajustando el $\mathrm{pH}$ a 12 con solución $5 \mathrm{~N}$ de hidróxido de sodio, seguido de un incremento de la temperatura hasta $120{ }^{\circ} \mathrm{C}$, mantenido así durante 15 minutos (Delgenès et al., 2000).

A los LRS pretratados y crudos se les determinó la concentración de carbohidratos y proteínas, por los métodos modificados de Dubois y Lowry respectivamente, según lo descrito por Delgenès et al. (2000), y la concentración de DQO total (DQOt) y soluble (DQOs), SST y SSV fue determinada según lo descrito por la APHA (1998). Los sólidos suspendidos (SS) fueron separados de los sólidos disueltos (SD) por centrifugación a $7000 \mathrm{G}$ durante 15 minutos. La DQO de los SS (DQO $\mathrm{SS}$ ) fue determinada por la diferencia entre la DQO en el sobrenadante de una muestra de lodos centrifugada (DQOs) y la DQO en la muestra sin centrifugar (DQOt).

\subsubsection{Cinéticas de reacción en reactores en lote}

\subsubsection{Inóculo}

Lodos anaerobios con $2.4 \%$ de SSV, provenientes de un reactor UASB de $60 \mathrm{~m}^{3}$ que trata agua residuales del campus Iztapalapa de la Universidad Autónoma Metropolitana, fueron usados como inóculo, previa adaptación con medio RAMM (ver 2.2.4) y con $1 \mathrm{~kg}$ DQO. $\mathrm{m}^{-3}$ de acetato de calcio y propionato de calcio (50:50) como fuente de carbono.

\subsubsection{Sustrato}

LRS crudos y pretratados termo-alcalinamente fueron centrifugados a $7000 \mathrm{G}$ durante $15 \mathrm{~min}$. El sobrenadante y el sedimento fueron almacenadas por no más de tres días a $4{ }^{\circ} \mathrm{C}$, hasta que fueron utilizadas.

\subsubsection{Cinéticas de hidrólisis de sólidos suspendidos de LRS crudo (SS) y pretratado $\left(\mathrm{SS}_{\mathrm{TA}}\right)$}

Los $\mathrm{SS}$ y los $\mathrm{SS}_{\mathrm{TA}}$ se suspendieron en $45 \mathrm{~mL}$ de medio RAMM y se inocularon con $5 \mathrm{~mL}$ de lodos anaerobios. La relación sustrato-inoculo se estandarizó en función de los sólidos suspendidos volátiles (SSV) manteniendo la relación 1.0 kg SSV-LRS kg-1 SSV-anaerobio y se incubaron en paralelo a $35^{\circ} \mathrm{C}$ y $55^{\circ} \mathrm{C}$.

Después de la incubación por 28 días, la eficiencia de la hidrólisis ( $)$ fue determinada, Ec. (4.3). 
Efecto del pretratamiento sobre la velocidad de hidrólisis

$$
\eta=\frac{S S_{o}-S S_{t}}{S S_{0}}
$$

en donde $\mathrm{SS}_{\mathrm{o}}$ es la masa inicial de sólidos suspendidos y $\mathrm{SS}_{\mathrm{t}}$ es la masa de sólidos suspendidos al tiempo t.

\subsubsection{Calculo de la constante de superficie $\left(K_{\mathrm{SBK}}\right)$}

La Ec. 4.1 asume que los SS son esferas $\left(A=4 \pi \mathrm{nR}^{2}\right)$ así que la concentración de los SS se puede expresar como:

$$
S S=\frac{4}{3} \pi R^{3} n \rho
$$

Combinando las ecuaciones 4.4 y 4.1 , el decremento del radio medio de la partícula puede ser escrito como:

$$
\begin{aligned}
\frac{d\left(4 / 3 \cdot \pi \cdot R^{3} \cdot n \cdot \rho\right)}{d t} & =-K_{S B K} \cdot\left(4 \pi \cdot n \cdot R^{2}\right) \\
\frac{d R^{3}}{d t} & =-3 \frac{K_{S B K}}{\rho} \cdot R^{2}
\end{aligned}
$$

Derivando

$$
\begin{aligned}
\frac{3 R^{2} d R}{d t} & =-3 \frac{K_{S B K}}{\rho} R^{2} \\
\frac{d R}{d t} & =-\frac{K_{S B K}}{\rho}
\end{aligned}
$$

$\mathrm{Al}$ integrar

$$
\begin{aligned}
& \int d R=-\frac{K_{S B K}}{\rho} \int d t \\
& R=R_{0}-\left(\frac{K_{S B K}}{\rho} \cdot t\right)
\end{aligned}
$$

Definiendo la eficiencia de la hidrólisis $(\eta)$

$$
\eta=\frac{S S_{0}-S S}{S S_{0}}=1-\frac{S S}{S S_{0}}
$$

Sustituyendo SS como una función de R

$$
\eta=1-\frac{4 / 3 \cdot \rho \pi \cdot R^{3} \cdot n}{4 / 3 \cdot \rho \pi \cdot R_{0}^{3} \cdot n}=1-\frac{R^{3}}{R_{0}^{3}}
$$


Considerando los diferentes tamaños de partículas en los SS podemos escribir la Ec. 4.6 como

$$
\eta=\sum_{0}^{n}\left[1-\frac{\left(R_{o}-\frac{K_{S B K} * t}{\rho}\right)^{3}}{R_{o}^{3}} \frac{A_{o}^{j}}{A_{o}}\right]
$$

En donde $\mathrm{A}_{\mathrm{o}}{ }^{\mathrm{j}} / \mathrm{A}_{\mathrm{o}}$ es la fracción de área de los SS de tamaño j en los SS iniciales y $\mathrm{R}_{0}$ es el radio inicial de los SS de tamaño j, ambos basados en la distribución del tamaño de partícula. $\rho$ es la densidad del LRS.

\subsubsection{Distribución del tamaño de partícula}

Para determinar la distribución del tamaño de partícula de los SS y de los $\mathrm{SS}_{\mathrm{TA}}$, se tomaron ocho alícuotas de $50 \mu \mathrm{L}$ de cada muestra y se depositaron por separado en discos de papel filtro de $0.22 \mu \mathrm{m}$ y las partículas fueron fotografiadas con una cámara Capture Kit 128 acoplada a un microscopio Olimpus BX50 usando el objetivo 40X. De las imágenes bidimencionales digitalizadas se obtuvo el diámetro de partícula utilizando el software Imagen Pro-Plus 4.1, y este diámetro fue utilizado para calcular el área, considerando que la partícula es una esfera. El área fue obtenida por la integración de las áreas de cada tamaño de partícula $\left(\sum_{0}^{100 \mu m} \pi d^{2} C_{p}\right)$ en donde d y $\mathrm{C}_{\mathrm{p}}$ son el diámetro y la concentración de la partícula, respectivamente.

\subsubsection{Cinéticas de hidrólisis de los sólidos disueltos de LRS crudo (SD) y pretratado $\left(\mathrm{SD}_{\mathrm{TA}}\right)$}

Del sobrenadante (ver 4.2.2.2), se tomaron $45 \mathrm{~mL}$ de $\mathrm{SD}$ y $\mathrm{SD}_{\mathrm{TA}}$, las muestras se complementaron con las sales del medio RAMM y se inocularon con $5 \mathrm{~mL}$ de lodos anaerobios, incubándose en paralelo a $35^{\circ} \mathrm{C}$ y $55^{\circ} \mathrm{C}$. La determinación de la velocidad de hidrólisis se realizó a 6 distintas concentraciones de DQO inicial: 126, 271, 727, 1133, 1301, $1960 \mathrm{mg} / \mathrm{L}$ para $\mathrm{SD}_{\mathrm{TA}}$ y 4 distintas concentraciones de DQO inicial: 126, $271,839,1030 \mathrm{mg} . \mathrm{L}^{-1}$ para SD. Para cada concentración se determinó por quintuplicado la velocidad de hidrólisis con la Ec. (4.8).

$$
r_{S D}=\frac{Q_{C H 4}}{\Delta t} \cdot \frac{1}{\left(Y_{C H 4}\right)}
$$


En donde $\mathrm{r}_{\mathrm{SD}}$ es la velocidad de hidrólisis de SD $\left(\mathrm{kg}\right.$ DQO. $\left.\mathrm{m}^{-3} \cdot \mathrm{d}^{-1}\right), \mathrm{Q}_{\mathrm{CH} 4}$ es el metano acumulado $\left(\mathrm{m}^{3} \cdot \mathrm{m}^{-3}\right), \Delta \mathrm{t}$ es el intervalo de tiempo de la digestión (d) y $\mathrm{Y}_{\mathrm{CH} 4}$ es el factor de conversión $0.350 \mathrm{~m}^{3} \mathrm{CH}_{4} \cdot \mathrm{kg}^{-1}$ DQO.

El inverso de la ecuación 4.2 fue utilizada para calcular las constantes del modelo de saturación (Goel et al., 1998), ecuación (4.9).

$$
\frac{1}{r_{S D}}=\frac{K_{X}}{k_{h}} \frac{1}{S D}+\frac{1}{k_{h}}
$$

\subsubsection{Cuantificación y composición del biogás}

La producción del biogás fue medida por desplazamiento de una solución de salmuera (para evitar la solubilización del biogás). Un volumen de $0.1 \mathrm{~mL}$ de biogás de cada columna de desplazamiento fue analizado en un cromatografo de gases de conductividad térmica (ver 2.2.3.4)

\subsection{Resultados y discusión}

\subsubsection{Solubilización y biodegradabilidad de los LRS pretratados}

La caracterización de los LRS crudos y los pretratados se muestran en la Cuadro 4.1. Debido al pretratamiento termoalcalino, la solubilización de los SS, expresada como DQOs/DQOt, estuvo por arriba del $51 \%$ que es un valor próximo al reportado para condiciones similares (Cuadro 4.2). Los datos también sugieren que la solubilización puede ser evaluada midiendo cualquiera de los compuestos orgánicos en los LRS, ya que la desviación estándar de la solubilización, utilizando sólidos suspendidos, carbohidratos, proteínas o DQO, fue del $6.5 \%$.

El pretratamiento termo-alcalino tiene ventajas en términos energéticos con respecto a otros pretratamientos que requieren mayor energía (Cuadro 4.2). Menert et al. (2001) encontraron que el tratamiento por ultrasonido es el que mayor cantidad de energía utiliza. Con ozono y calor se requiere el $51 \%$ y $25 \%$ de la energía utilizada en el ultrasonido. Aunque aplicando mayor cantidad de energía (por ejemplo pH 11 y 90 ${ }^{\circ} \mathrm{C}$, durante $10 \mathrm{~h}$ ) se puede obtener mayor solubilización, el gasto energético no es justificado. 
Efecto del pretratamiento sobre la velocidad de hidrólisis

Cuadro 4.1. Solubilización de LRS por pretratamiento termo-alcalino (TA).

\begin{tabular}{|c|c|c|c|}
\hline & LRS & $\mathrm{LRS}_{\mathrm{TA}}$ & Solubilización \\
\hline Parámetro & \multicolumn{2}{|c|}{ Concentración (kg.m $\left.{ }^{-3}\right)$} & $\%$ \\
\hline SST & 9.9 & 4.5 & -54.5 \\
\hline SSF & 2.0 & 2.0 & \\
\hline SSV & 7.9 & 2.5 & -68.4 \\
\hline $\mathrm{CHO}_{\mathrm{t}}$ & 1.41 & & \\
\hline $\mathrm{CHO}_{\mathrm{s}}$ & 0.047 & 0.69 & 49 \\
\hline $\mathrm{CHO}_{\mathrm{ss}}$ & 1.36 & 0.72 & -47 \\
\hline $\operatorname{Prot}_{t}$ & 6.9 & & \\
\hline $\operatorname{Prot}_{\mathrm{s}}$ & 0.33 & 4.2 & 61 \\
\hline $\operatorname{Prot}_{\mathrm{ss}}$ & 6.6 & 2.7 & -59 \\
\hline $\mathrm{DQO}_{\mathrm{t}}$ & 14.7 & 13.5 & --- \\
\hline DQOs & 1.2 & 7.6 & 51.3 \\
\hline DQOss & 13.5 & 5.9 & -55.7 \\
\hline $\mathrm{DQO}_{\mathrm{t}} / \mathrm{SSV}$ & 1.9 & 5.9 & --- \\
\hline SSV/SST & 0.8 & 0.55 & --- \\
\hline
\end{tabular}

Parámetro de solubilización = $\left(\right.$ Parámetro $_{\mathrm{TA}}-$ Parámetro $\left._{\mathrm{LRS}}\right) /\left(\right.$ Parámetro $\left._{\mathrm{LRS}}\right)$

Parámetros: $\mathrm{CHO}=$ carbohidratos, $\mathrm{Prot}=$ proteínas, $\mathrm{SS}=$ sólidos suspendido

Cuadro 4.2. Solubilización de LRS por diferentes condiciones de pretratamiento.

\begin{tabular}{|c|c|c|c|c|}
\hline $\begin{array}{c}\text { LRS } \\
\left(\mathrm{kg} \mathrm{TS} \mathrm{m}^{-3}\right)\end{array}$ & Pretratamiento & $\begin{array}{c}\text { solubilización } \\
\mathrm{DQO}_{\mathrm{s}} / \mathrm{DQO}_{\mathrm{t}}(\%)\end{array}$ & $\begin{array}{c}\text { Es } \\
\left(\mathrm{kJ}^{-\mathrm{kg}^{-1}} \mathrm{TS}_{0}\right)\end{array}$ & Referencia \\
\hline 9.23 & $\begin{array}{l}\text { ultrasonido }(250 \mathrm{~W}, 25 \\
\mathrm{kHz}, 15 \text { min })\end{array}$ & 67.0 & 180,000 & $\begin{array}{c}\text { Guangming et al. } \\
\text { (2007) }\end{array}$ \\
\hline 9.9 & $\begin{array}{l}\text { Termo-alcalino (pH } 12 \\
\left.\text { y } 15 \text { min } @ 120^{\circ} \mathrm{C}\right)\end{array}$ & 51.3 & 50,086 & Este trabajo \\
\hline $25(\mathrm{SV})$ & $\begin{array}{l}\text { Térmico } 45 \text { min @ } 121 \\
{ }^{\circ} \mathrm{C}\end{array}$ & 56.7 & 60,000 & Este trabajo \\
\hline 10.0 & $\begin{array}{l}\text { ultrasonido }(300 \mathrm{~W}, 20 \\
\mathrm{kHz}, 30 \mathrm{~min})\end{array}$ & 35.0 & 69,053 & $\begin{array}{l}\text { Wang et al. } \\
\text { (2005) }\end{array}$ \\
\hline 18.5 & $\begin{array}{l}\text { ultrasonido }(20 \mathrm{kHz} \text {, } \\
225 \mathrm{~W}, 10 \mathrm{~min})\end{array}$ & 33.0 & 15,000 & $\begin{array}{l}\text { Bougrier et al, } \\
\text { (2005) }\end{array}$ \\
\hline 38 & $\begin{array}{l}\text { Termo-alcalino (pH } 12 \text { y } \\
\left.15 \text { min @ } 121^{\circ} \mathrm{C}\right)\end{array}$ & 52.0 & 13,203 & $\begin{array}{l}\text { Kim J. et al. } \\
\text { (2003) }\end{array}$ \\
\hline 39 & $\begin{array}{l}\text { Termo-alcalino }(\mathrm{pH} 12 \mathrm{y} \\
\left.30 \text { min @ } 150^{\circ} \mathrm{C}\right)\end{array}$ & 70.0 & 15,841 & $\begin{array}{l}\text { Delgenès et al. } \\
\quad(2000)\end{array}$ \\
\hline \multirow[t]{4}{*}{68} & $\begin{array}{l}\text { Termo-alcalino (pH 11, } \\
90^{\circ} \mathrm{C} \text { y: }\end{array}$ & & & $\begin{array}{l}\text { Vlyssides \& } \\
\text { Karlis (2004) }\end{array}$ \\
\hline & $10 \mathrm{~h}$ & 94.0 & 116,087 & \\
\hline & $7 \mathrm{~h}$ & 68.0 & 81,261 & \\
\hline & $4 \mathrm{~h})$ & 41.0 & 46,435 & \\
\hline$E_{S}=\frac{P \cdot t}{V \cdot T S_{O}}:$ & Dnomá & kJ.kg $\left.{ }^{-1} \mathrm{STo}\right]$ & ], $\mathrm{t}=[\mathrm{s}]$, & {$\left[\mathrm{m}^{3}\right]$, STo $[\mathrm{kg}$} \\
\hline
\end{tabular}




\subsubsection{Evaluación cinética del efecto del pretratamiento termo alcalino}

\subsubsection{Distribución del tamaño de partícula}

La Figura 4.1 muestra la distribución del tamaño de partícula de los SS y $\mathrm{SS}_{\mathrm{TA}}$ de las ocho muestras analizadas (un total de 1694 partículas de los SS y 4726 partículas de los $\mathrm{SS}_{\mathrm{TA}}$ fueron obtenidas). Un análisis estadístico binomial de la curva, muestra que aunque los diámetros medios (y la desviación estándar) son similares, $36.56 \mu \mathrm{m}$ (17.6) para SS y $33.25 \mu \mathrm{m}$ (14.21) para $\mathrm{SS}_{\mathrm{TA}}$, la concentración de partículas y área total disponible aumentaron en más de tres veces (Figura 4.2) para los $\mathrm{SS}_{\mathrm{TA}}$ con respecto a los SS.

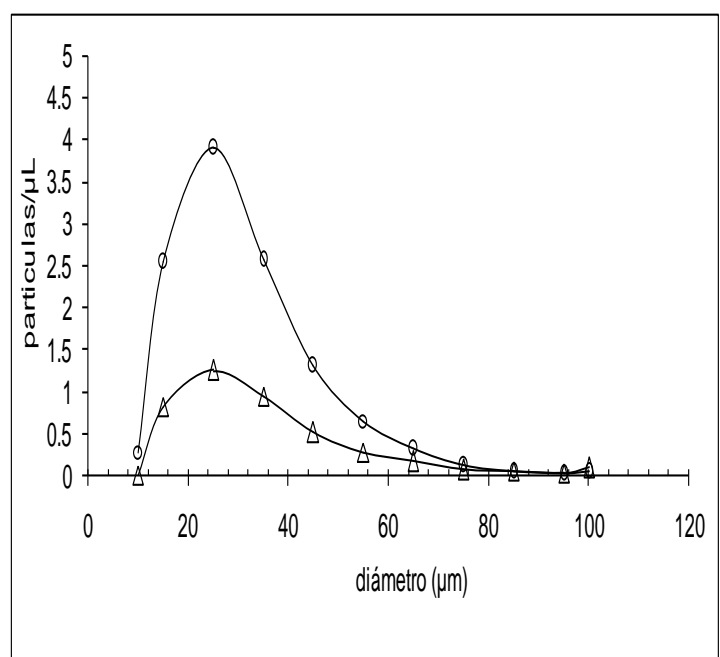

Figura 4.1. Distribución del tamaño de partícula inicial de $\mathrm{SS}(\Delta)$ y $\mathrm{SS}_{\mathrm{TA}}(\mathrm{o})$.

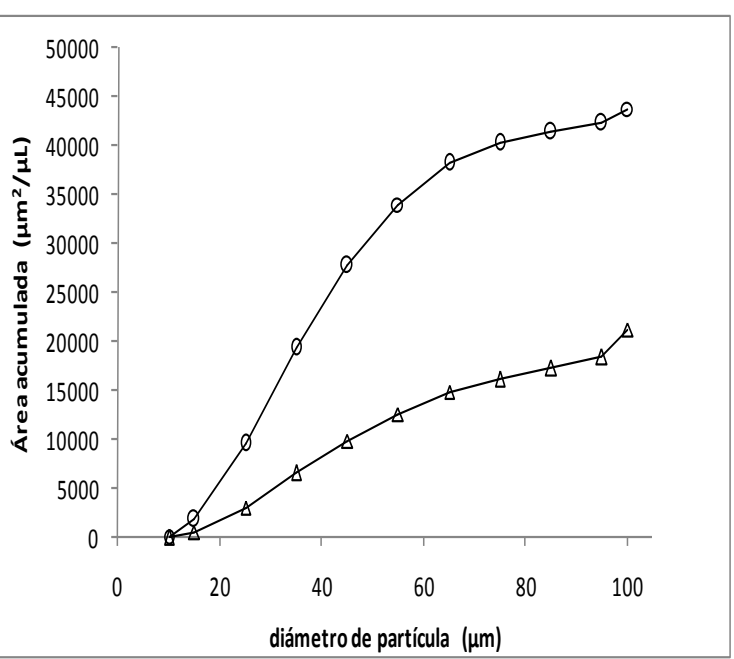

Figura 4.2. Área acumulada de $\mathrm{SS}(\Delta)$ y $\mathrm{SS}_{\mathrm{TA}}$ (o).

\subsubsection{Cálculo de la constante $\mathrm{K}_{\mathrm{SBK}}$ para los $\mathrm{SS}$ y $\mathrm{SS}_{\mathrm{TA}}$}

El Cuadro 4.3 muestra los valores calculados de $\mathrm{K}_{\mathrm{SBK}}$ utilizando los datos experimentales de la figura 4.2 (la fracción de área $\mathrm{A}_{0}{ }^{\mathrm{J}} / \mathrm{A}_{0}$ de cada tamaño de partícula en la ecuación 4.7) y ajustando los valores experimentales de las eficiencias de hidrólisis.

La Figura 4.3 muestra que el pretratamiento termo-alcalino mejora tanto la hidrólisis anaerobia mesofílica y termofílica de SS, en 67 y 64 por ciento respectivamente.

Cuadro 4.3. Valores de $\mathrm{K}_{\mathrm{SBK}}$ estimados para la hidrólisis de SS.

\begin{tabular}{l|lc|cc}
\hline & \multicolumn{2}{|c|}{ Mesofílico } & \multicolumn{2}{c}{ Termofílico } \\
& $\mathrm{kg} \cdot \mathrm{m}^{-2} \cdot \mathrm{d}^{-1}$ & $\mathrm{r}^{2}$ & $\mathrm{~kg} \cdot \mathrm{m}^{-2} \cdot \mathrm{d}^{-1}$ & $\mathrm{r}^{2}$ \\
\hline $\mathrm{SS}$ & $0.28 \times 10^{-3}$ & 0.980 & $0.45 \times 10^{-3}$ & 0.992 \\
$\mathrm{SS}_{\mathrm{TA}}$ & $0.47 \times 10^{-3}$ & 0.994 & $0.74 \times 10^{-3}$ & 0.994 \\
\hline
\end{tabular}




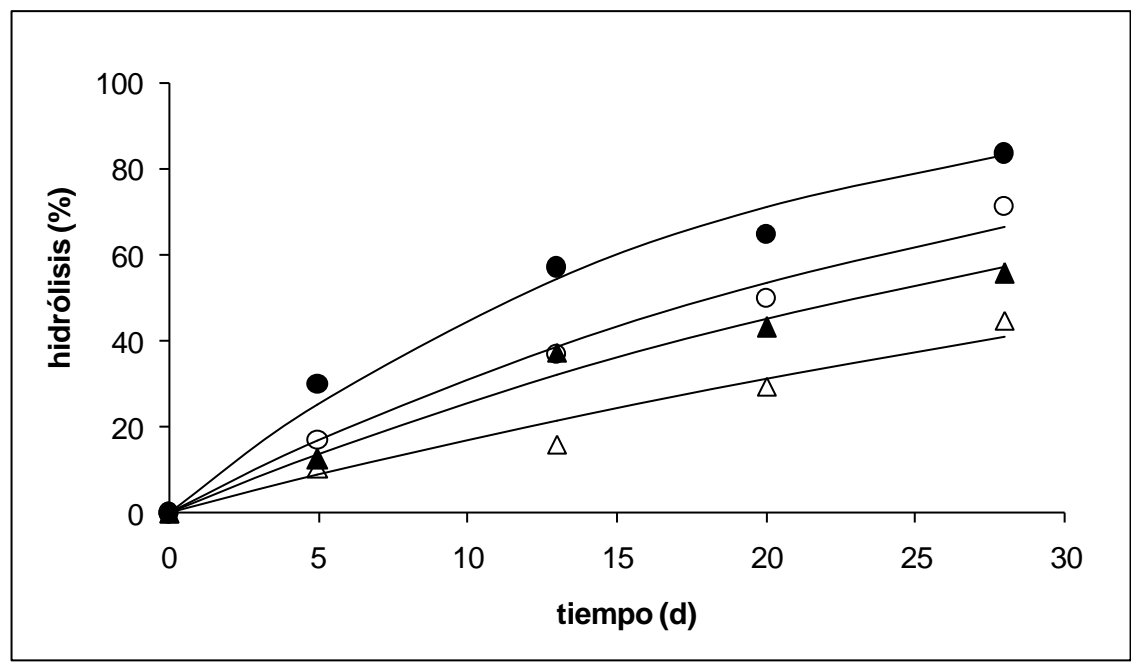

Figura 4.3. Hidrólisis de SS ajustados al modelo de superficie. $\mathrm{SS}$ mesofílico $(\Delta)$, SS termofílico $(\boldsymbol{\Delta}), \mathrm{SS}_{\mathrm{TA}}$ mesofílico $(0)$, $\mathrm{SS}_{\mathrm{TA}}$ termofílico $(\bullet)$.

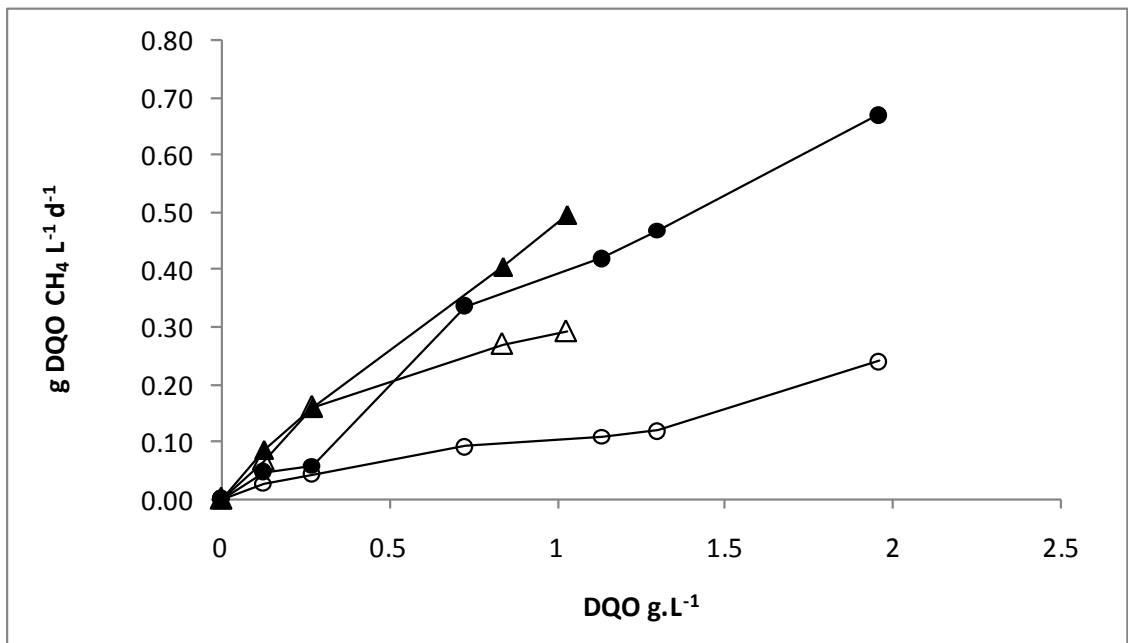

Figura 4.4. Velocidad de producción de metano como función de la DQO inicial. $(\Delta) \mathrm{SD}$ mesofílico, $(\boldsymbol{\Delta}) \mathrm{SD}$ termofílico, $(0) \mathrm{SD}_{\mathrm{TA}}$ mesofílico, $(\bullet) \mathrm{SD}_{\mathrm{TA}}$ termofílico.

\subsubsection{Cálculo de las constantes $k_{h}$ y $K_{x}$ para los SD y $S_{\mathrm{TA}}$}

La velocidad de producción de metano después de la hidrólisis anaerobia de SD y $\mathrm{SD}_{\mathrm{TA}}$ fue calculada y graficada contra la concentración inicial de DQO, Figura 4.4.

Para determinar las constantes del modelo de saturación: $\mathrm{k}_{\mathrm{h}} \mathrm{y} \mathrm{K}_{\mathrm{X}}$, la ecuación 4.9 fue utilizada.

El Cuadro 4.4., muestra que el pretratamiento termo-alcalino no mejora la hidrólisis de sólidos disueltos, el valor de la constante $\mathrm{k}_{\mathrm{h}}$ se reduce un $69 \%$ en la DA mesofílica de $\mathrm{SD}_{\mathrm{TA}}$, sugiriendo una inhibición no competitiva, debido probablemente a 
la formación de productos de Maillard (Eskicioglu et al., 2007), que participan en la formación del complejo enzima-sustrato-inhibidor.

Por otra parte $\mathrm{k}_{\mathrm{h}}$ mejora en un $14 \%$ en la DA termofílica, pero $\mathrm{K}_{\mathrm{X}}$ se incrementa hasta $134 \%$, sugiriendo que los productos del pretratamiento termo-alcalino causan una inhibición competitiva sobre la DA termofílica, probablemente debido a que se reduce la estabilidad del complejo enzima-inhibidor a $55^{\circ} \mathrm{C}$.

Cuadro 4.4. Constantes del modelo de saturación.

\begin{tabular}{cccc|ccc}
\hline & \multicolumn{3}{c|}{ Mesofílico } & \multicolumn{3}{c}{ Termofílico } \\
& $\begin{array}{c}\mathrm{k}_{\mathrm{h}} \\
\left(\mathrm{kg} \mathrm{DQO} \cdot \mathrm{m}^{-3} \cdot \mathrm{d}^{-}\right.\end{array}$ & $\begin{array}{c}\mathrm{K}_{\mathrm{X}} \\
\left(\mathrm{kg} \cdot \mathrm{m}^{-3}\right)\end{array}$ & $\mathrm{r}^{2}$ & $\mathrm{k}_{\mathrm{h}}$ & $\mathrm{K}_{\mathrm{X}}$ & $\mathrm{r}^{2}$ \\
& 1 & & & $\mathrm{~kg} \mathrm{DQ} \mathrm{m}^{-3} \mathrm{~d}^{-}$ & $\left(\mathrm{kg} \cdot \mathrm{m}^{-3}\right)$ & \\
\hline $\mathrm{SD}$ & 0.715 & 1.16 & 0.978 & 1.19 & 1.63 & 0.996 \\
$\mathrm{SD}_{\mathrm{TA}}$ & 0.220 & 0.981 & 0.962 & 1.36 & 3.82 & 0.866 \\
$\Delta(\%)$ & -69 & -15.5 & & 14 & 134 & \\
\hline
\end{tabular}

\subsubsection{Simulación con reacciones consecutivas de $\mathrm{SS} \rightarrow \mathrm{SD} \rightarrow$ metano}

Una vez obtenidas las constantes de hidrólisis de los modelos de superficie y saturación fue realizado un análisis global de la producción de metano. El modelo se estructuró utilizando las Ec. 4.1 y 4.2 y las constantes cinéticas de los Cuadros 4.3 y 4.4. La simulación de reacciones consecutivas, se muestra en la figura 4.5, combina los dos procesos: DA termofílica (5 días) y DA mesofílica (19 días), con LRS pretratados $\left(\mathrm{LRS}_{\mathrm{TA}}\right)$ y sin pretratamiento. La digestión termofílica con una concentración inicial de sólidos suspendidos de $40 \mathrm{~kg}$ DQO. $\mathrm{m}^{-3}$ produce a los 5 días un efluente de 31 y $26 \mathrm{~kg}$ DQO. $\mathrm{m}^{-3}\left(\eta_{\mathrm{SS}}=22\right.$ and $\left.35 \%\right)$ y una producción de metano de 3.7 y $3.9 \mathrm{~kg}$ DQO. $\mathrm{m}^{-3}$ para LRS y $\mathrm{LRS}_{\mathrm{TA}}$, respectivamente.

La gráfica de la DA mesofílica inicia a los 5 días (el efluente termofílico es alimentado) y después de 19 días genera un efluente de LRS con una concentración de $18 \mathrm{kgDQO} . \mathrm{m}^{-3}$ de SS y una producción total de metano de $13.7 \mathrm{~kg}$ DQO. $\mathrm{m}^{-3}$ y una destrucción total de sólidos $\left(\eta_{\mathrm{SS}}\right)$ de $55 \%$. Para los $\mathrm{LRS}_{\mathrm{TA}}$ el resultado final fue de 10

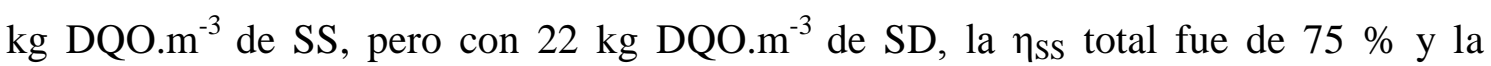
producción de metano fue de $8 \mathrm{~kg}$ DQO. $\mathrm{m}^{-3}$.

Los resultados de la simulación muestran que la destrucción de SS es favorecida por el pretratamiento termo-alcalino durante la digestión anaerobia termofílica. Por otro lado, un efecto negativo del pretratamiento termoalcalino es predicho durante la DA mesofílica de SD a metano. 
Esto coincide con los resultados de Yue et al. (1997), Roberts et al. (1999), García-Heras et al. (1999) y Ge et al. (2011), quienes reportan reducción de sólidos 38 a $43 \%$ y producción de metano de entre 0.130 y $0.420 \mathrm{~kg} \mathrm{DQO} \mathrm{CH}_{4} \cdot \mathrm{m}^{-3} \cdot \mathrm{d}^{-1}$, cuando LRS sin tratamiento son digeridos anaeróbicamente en sistemas de dos etapas termofílicosmesofílicos, con TRS de entre 12 y 24 días.

Estos resultados indican que la destrucción de sólidos y la producción de biogás no son favorecidas por el pretratamiento termoalcalino cuando la etapa termofílica es incorporada antes de la etapa mesofílica.

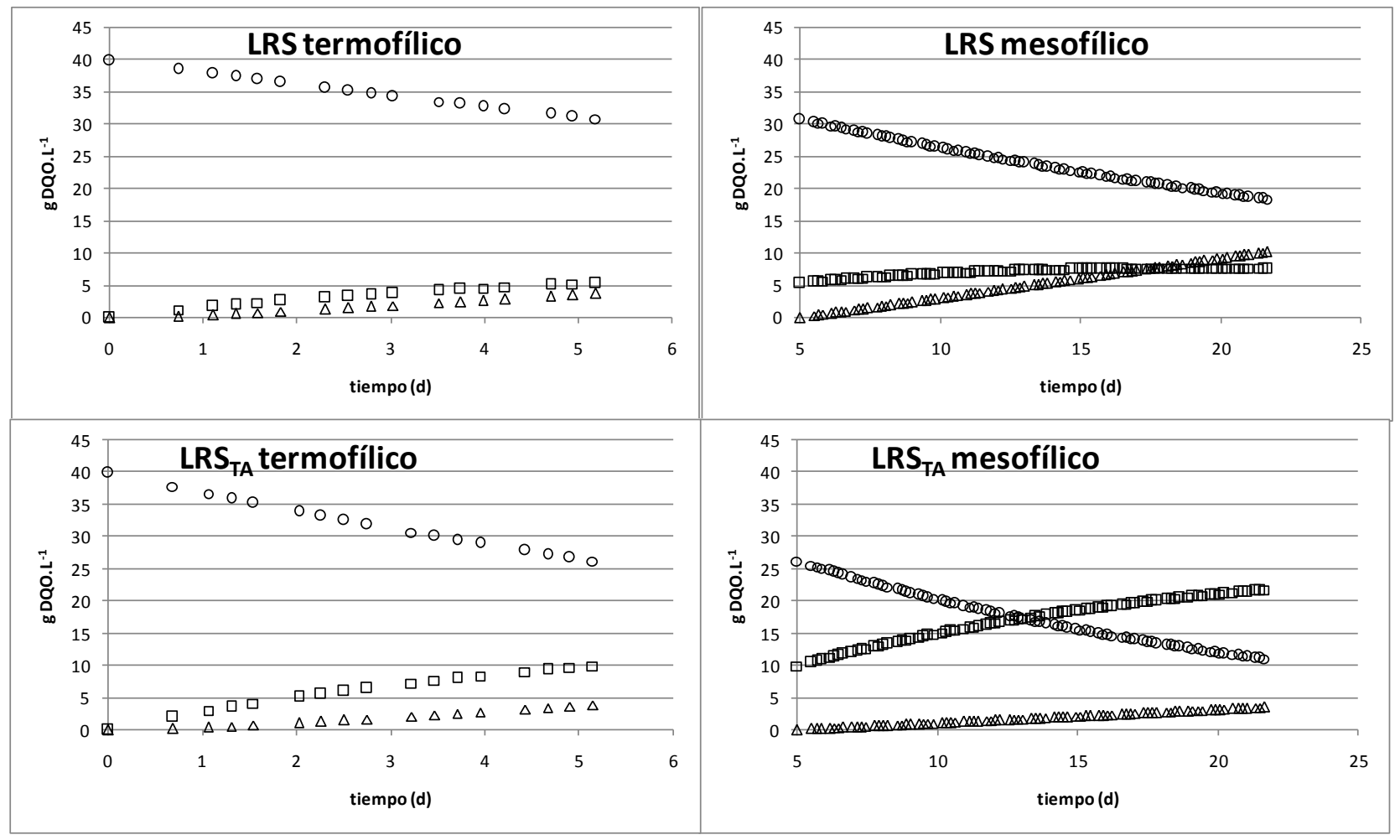

Figura 4.5. Simulación de la digestión anaerobia de LRS y $\mathrm{LRS}_{\mathrm{TA}}$ usando las constantes cinéticas de los Cuadros 4.3 y 4.4. SS ( $\circ)$, $\mathrm{CH} 4(\Delta)$, DS ( $\square$ )

\subsection{Conclusiones}

El pretratamiento alcalino tiene diferente efecto sobre la hidrólisis de sólidos suspendidos y disueltos. La cinética de la digestión anaerobia de LRS fue estudiada tomando en cuenta estas diferencias, utilizando los modelos de superficie y de saturación para encontrar estas diferencias cinéticas.

El pretratamiento termoalcalino incrementa la degradación anaerobia mesofílica y termofílica de sólidos suspendido, ya que la constante de superficie $\mathrm{K}_{\mathrm{SBK}}$ se incrementa para la DA termofílica de $0.45 \times 10^{-3} \mathrm{~kg} \cdot \mathrm{m}^{-2} \cdot \mathrm{d}^{-1}$ para SS a $0.74 \times 10^{-3} \mathrm{~kg} \cdot \mathrm{m}^{-2} \cdot \mathrm{d}^{-1}$ para 
$\mathrm{SS}_{\mathrm{TA}}$, y para la DA mesofílica $\mathrm{K}_{\mathrm{SBK}}$ se modifica de $0.028 \times 10^{-3} \mathrm{~kg} \cdot \mathrm{m}^{-2} \cdot \mathrm{d}^{-1}$ para SS a $0.47 \times 10^{-3} \mathrm{~kg} \cdot \mathrm{m}^{-2} \cdot \mathrm{d}^{-1}$ para $\mathrm{SS}_{\mathrm{TA}}$.

El pretratamiento termoalcalino tiene efectos negativos sobre la degradación de los sólidos disueltos produciendo una inhibición no competitiva para la digestión anaerobia mesofílica esto es probablemente debido a una modificación de los sitios de reacción de los polímeros (proteínas, lípidos, carbohidratos) con las enzimas de los microorganismos anaerobios, lo que provocó un decremento de hasta $69 \%$ en la constante de velocidad especifica máxima $\left(\mathrm{k}_{\mathrm{h}}\right)$. El pretratamiento termoalcalino también induce una inhibición competitiva para la digestión anaerobia termofílica por la creación de inhibidores que compiten por los sitios de los SS, reduciendo su disponibilidad, esto implicó un aumento en la $\mathrm{K}_{\mathrm{X}}$ para los $\mathrm{SD}_{\mathrm{TA}}$ hasta de $134 \%$ con respecto a $\mathrm{K}_{\mathrm{X}}$ de los $\mathrm{SD}$. Por lo tanto el pretratamiento termoalcalino (y otros pretratamientos) puede ser estudiado con los modelos de Sanders y Goel para reconocer las implicaciones que estos pretratamientos tienen sobre las reacciones de hidrólisis. 
5

CONCLUSIONES GENERALES Y RECOMENDACIONES 


\section{Conclusiones generales}

La estabilización de los lodos residuales, es una de las etapas que requiere de mayor cantidad de recursos económicos en una planta de tratamiento de aguas residuales, por lo que representa uno de los temas centrales en la investigación del tratamiento integral de las aguas residuales. Los lodos residuales secundarios tienen un carácter recalcitrante, esto hace que los sistemas de estabilización requieran de tiempos largo de tratamiento. Las sustancias exopoliméricas que forman parte estructural del flóculo son las que presentan mayor resistencia a la degradación, estas sustancias son principalmente proteínas, lípidos y carbohidratos, por lo que su carácter recalcitrante es poco entendido.

Las variables que han sido más estudiadas para lograr un incremento en la biodegradabilidad de los lodos residuales secundarios es la temperatura. Los reactores termofílicos (temperatura entre 55 y $65^{\circ} \mathrm{C}$ ) han mostrado tener ventajas sobre todo en la eliminación de patógenos y parásitos. Sin embargo, se han obtenido resultados de gran variabilidad con respecto a la producción de metano, cuando estos reactores son operados con cargas orgánicas menores a $2 \mathrm{~kg} \mathrm{SSV} \cdot \mathrm{m}^{-3} \cdot \mathrm{d}^{-1}$. En esta tesis se operó un reactor termofílico con cargas entre 1 y $8 \mathrm{~kg} \mathrm{SSV} \cdot \mathrm{m}^{-3} \cdot \mathrm{d}^{-1}$, junto con un sistema de dos etapas termofílico- mesofílico, y se concluyó que el sistema de dos etapas no representa una ventaja importante con respecto al reactor termofílico en la remoción de sólidos

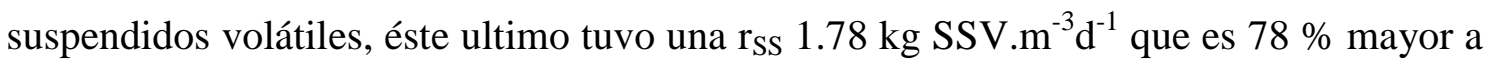
la que presentó el sistema de dos etapas.

Con respecto a la producción de metano se observó que el reactor termofílico guardó una relación lineal entre la carga orgánica y la velocidad de producción de metano, cuando la carga orgánica estuvo entre 1 y $6 \mathrm{~kg} \mathrm{SSV} \cdot \mathrm{m}^{-3} \cdot \mathrm{d}^{-1}$ y que los reactores mesofílicos (M1E y M2E) no presentaron está relación. Este comportamiento puede estar asociado a la concentración de amoniaco, ya que se sabe que el metabolismo metanogénico de los microorganismos presentes en estos reactores, se inhibe a bajas concentraciones de amoniaco (menores a $100 \mathrm{mg} . \mathrm{L}^{-1}$ ), para M1E la concentración de amoniaco fue mayor a $100 \mathrm{mg} \cdot \mathrm{L}^{-1}$, cuando la CO fue mayor a $5 \mathrm{~kg} \mathrm{SSV} \cdot \mathrm{m}^{-3} \cdot \mathrm{d}^{-1}$, mientras que para M2E la concentración de amoniaco fue mayor a $100 \mathrm{mg} . \mathrm{L}^{-1}$ para cargas mayores a $2 \mathrm{~kg} \mathrm{SSV} \cdot \mathrm{m}^{-3} \cdot \mathrm{d}^{-1}$. 
Se ha determinado que la etapa que limita la velocidad global de la digestión anaerobia de lodos residuales secundarios es la hidrólisis. En esta etapa sucede una solubilización de los sólidos suspendidos y una hidrólisis de los polímeros disueltos en sus monómeros correspondientes. Para acelerar esta etapa se han implementado diferentes tratamientos para lodo residual secundario, previos a la digestión anaerobia. Estos pretratamientos contribuyen en la solubilización de los sólidos suspendidos. En esta tesis se realizó un análisis de los pretratamientos por ultrasonido, térmico y alcalino. Se observó que para los tres tipos de tratamiento el proceso de solubilización se divide en dos períodos uno rápido, en donde se da el $70 \%$ de la solubilización total, y otro lento. También se observó que los pretratamientos ensayados requieren menos de 40 minutos para lograr la mayor solubilización. Además, se observó que el uso de pretratamientos combinados genera mayor solubilización. No obstante, se mostró que el incremento en la solubilización no necesariamente repercute en una mayor producción de metano, ya que el lodo pretratado por ultrasonido presentó el menor \% de metanización, esto quizá debido a la acumulación de propionato.

Por otro lado, también se demostró que los pretratamientos provocan que la digestión anaerobia mesofílica no sea sustentable en términos energéticos, ya que los requerimientos de energía para realizar los pretratamientos son mayores a la energía producida por la digestión anaerobia de los LRS pretratados. El balance de energía indica que se requieren $1,703 \mathrm{~kJ} \cdot \mathrm{kg}^{-1}$ SST para la estabilización de LRS utilizando álcali para el pretratamiento y hasta 261,379 kJ/kg SST para la estabilización de LRS cuando se utiliza ultrasonido-álcali para el pretratamiento.

Los modelos matemáticos ponen especial énfasis en la solubilización de los sólidos suspendidos (proteínas, lípidos y carbohidratos presentes como partículas), inclusive incluyen la hidrólisis de sólidos disueltos (proteínas, lípidos y carbohidratos solubles) como parte de esta etapa. Estudios realizados en sustratos con alto contenido de sólidos suspendidos han mostrado una independencia entre la velocidad de solubilización de sólidos suspendidos y la velocidad de hidrólisis de sólidos disueltos. El análisis cinético de la digestión anaerobia mesofílica y termofílica de lodos residuales secundarios pretratados termo alcalinamente realizado en esta tesis, concluyó que el pretratamiento termoalcalino incrementa la degradación anaerobia mesofílica y termofílica de sólidos suspendido y tiene efectos negativos sobre la degradación de los sólidos disueltos produciendo una inhibición no competitiva para la digestión anaerobia mesofílica y una inhibición competitiva en la DA de SD. 
El trabajo por realizar en la investigación de la digestión anaerobia de lodos residuales puede ser orientado, entre otras vertientes, a la identificación de las transformaciones conformacionales que probablemente sufren las proteínas, lípidos y carbohidratos cuando se aplica energía durante el pretratamiento, y que evitan que estas sustancias ya solubilizadas puedan ser metabolizadas por los microorganismos anaerobios. Además se podría verificar como contribuye la aplicación de la energía en fenómenos de refloculación, que evitan que los polímeros permanezcan disponibles en el medio. 
6

\section{REFERENCIAS}




\section{Referencias.}

Ahring B.K., Westermann P. (1987) Kinetics of butyrate, acetate, and hydrogen metabolism in a thermophilic, anaerobic, butyrate-degrading triculture. Applied Environmental Microbiology 53, (2), 434-439.

Ahring B.K., Westermann P. (1988) Product inhibition of butyrate metabolism by acetate and hydrogen in thermophilic coculture. Applied Environmental Microbiology 54, (10), 2393-2397.

Angelidaki I., Ahring B.K. (1993) Thermophilic Anaerobic Digestion of Livestock Waste: Effect of Ammonia. Applied Microbiology Biotechnology 38, 560-564.

Appels L., Baeyens J., Degréve J., Dewil R (2008) Principles and potential of the anaerobic digestion of waste-activated sludge. Progress in Energy \& Combustion Sc 34, 755-781.

Arnaiz C., Gutierrez J.C., Lebrato J. (2006) Biomass stabilization in the anaerobic digestion of wastewater sludges. Bioresource Technology 97, 1179-1184.

Batstone D. J., Keller J., Angelidaki I., Kalyuzhnyi S. V., Pavlostathis S. G., Rozzi A., Sanders W.T.M, Siegristan H., Vavilin V. A. (2002) The IWA Anaerobic Digestion Model N¹ (ADM1). Water Science and Technology 45 (10), 10-65.

Bougrier C., Carrère H., Delgenès J.P. (2005) Solubilisation of waste-activated sludge by ultrasonic treatment. Chemical Engineering Journal 106, 163-169.

Bougrier C., Albasi C., Delgenès JP., Carrère H. (2006) Effect of ultrasonic, thermal and ozone pre-treatments on waste activated sludge solubilisation and anaerobic biodegradability. Chemical Engineering and Processing 45,711-718.

Bougrier C., Delgenès J. P., Carrère H. (2008) Effects of thermal treatments on five different waste activated sludge samples solubilisation, physical properties and anaerobic digestion. Chemical Engineering Journal 139, 236-244.

Braun R., Huber P., Meyrath J. (1981) Ammonia toxicity in liquid piggery manure digestion. Biotechnology Letter 3, 159.

Buhr H. O., Andrews J. F. (1977) Review paper, the thermophilic anaerobic digestion process. Water Research 11, 129-143.

Cacho Rivero J. A., Suidan M. T. (2006) Effect of $\mathbf{H}_{2} \mathbf{O}_{2}$ dose on the thermo-oxidative co-treatment with anaerobic digestion of excess municipal sludge Water. Science \& Technology 54, (2), 253-259.

Cai M.L., Wei Y.S., Liu J.X., (2004) Enhanced biohydrogen production from sewage sludge with alkaline pretreatment. Environmental Science Technology 38, 3195-3202. 
Cheng-nan Chang, Jih-Gaw Lin, Ying-Chih Chiu y Shwu-Jiuan Huang, (1997) Effect of Pretreatment on Waste Activated Sludge (WAS) Acidification, Processes $8^{\text {th }}$ International Conference on Anaerobic Digestion, Vol. 2, pp 1-8.

Choi B.; Hwang K. y Shin B. (1997) Efects on anaerobic digestion of sewage sludge pretreatment. Water Science and Technology 35, (10), 207-211.

Carrozzi A., Steinle E. (1994) Tratamiento anaerobio de plantas municipales. III Taller y Seminario Latinoamericano "Tratamiento de Aguas Residuales" Universidad de la República, pp 200-205. Montevideo Uruguay.

Chiu Y-C, Chang C-N., Lin J-G., Huang S-J. (1997) Alkaline and Ultrasonic Pretreatment of Sludge Before Anaerobic Digestion. Water Science and Technology 36, (11), 155-162.

Comisión Nacional del Agua (CNA) Estadísticas del agua en México 2010, Ed. Secretaría de Medio Ambiente y Recursos Naturales, México D.F. 2010, pp 193.

De Baere L.A., Devocht M., Van Assche P., Verstraete W. (1984) Influence of High $\mathrm{NaCl}$ and $\mathrm{NH}_{4} \mathrm{Cl}$ Salt Levels on Methanogenic Associations. Water Research 18, 543.

de la Rubia M. A., Perez M, Romero L. I., Sales D. (2002) Anaerobic Mesophilic and Thermophilic Municipal Sludge Digestion. Chemical Biochemical Engineering Quarterly 16, (3), 119-124.

de la Rubia M. A., M. Romero, L.I. Perez, D. Sales (2006) Effect of solids retention time (SRT) on pilot scale anaerobic thermophilic sludge digestion. Process Biochemistry 41, 79-86.

Delgenès JP., Penaud V., Torrijos M., Moletta R. (2000) Investigation on the changes in anaerobic biodegradability and biotoxicity of and industrial microbial biomass induced by a thermochemicals pretreatment. Water Science and Technology 41, (3), 137-144.

Dewil R., Appels L., Baeyens J., Degrève J. (2007) Peroxidation enhances the biogas production in the anaerobic digestion of biosolids. Journal of Hazardous Materials $146,577-581$.

Eaton A. D., Clesceri L. S. y Greenberg A. E. (1998) (APHA) Standard Methods for the examination of water and wastewater, 19ava. edition, Washington D. C. U.S.A.

Elefsiniotis P., Oldham A. K. (1994) Substrate degradation patterns in acid-phase anaerobic-digestion of municipal primary sludge. Environmental Technology 15, 741-751.

Eskicioglu C., Droste R. L., Kennedy K. J. (2007) Performance of Anaerobic WasteActivated Sludge Digesters After Microwave Pretreatment. Water Environmental Research 79, 2265-2273. 
Field J., Sierra R., Lettinga G. (1986) Ensayos Anaerobios, Proc. of on Wastewater Anaerobic treatments. Valladolid Spain.

Frohlund B., Palmgren R., Keiding K., Nielsen P.H. (1996) Extraction of extracellular polymers from activated sludge using a cation exchange resin. Water Research 30 , (8), 1749-1758.

Garber W. F. (1982) Operating experience with thermophilic anaerobic digestion. Journal Water Pollution Control Federation. 54, (8), 1170-1175

García-Heras J. L., Salaberría A., Prevot C., Sancho L. (1999) Increase of organic loading rate and specific methane production by splitting phases in anaerobic digestion of sewage sludge. II International symposium on anaerobic digestion of solid waste. Barcelona España

Ge H., Jensen P. D., Batstone D. J. (2011) Temperature phased anaerobic digestion increases apparent hydrolysis rate for waste activated sludge. Water Research 45 , $1597-1606$.

Ghosh S. (1991) Pilot-Scale demonstration of two-phase anaerobic digestion of activated sludge. Water Science \& Technology 23, 1179-1188.

Goel R., Mino T., Satoh H., Matsuo T. (1998) Comparison of hydrolytic enzyme systems in pure culture and activated sludge under different electron acceptor condition. Water Science and Technology 37, (4-5), 335-343.

Goel R., Tokutomi T., Yasui H., Naike T. (2003) Optimal configuration for anaerobic digestion with ozonation. Water Science Technology 48, (4), 85-96.

Gonze E., Pillot S., Valette E., Gonthier Y., Bernis A. (2003). Ultrasonic treatment of an aerobic activated sludge in a batch reactor. Chemical Engineering and processing $42,965-975$

Guangming Z., Panyue Z., Jinmei Y., Yanming C. (2007) Ultrasonic reduction of excess sludge from the activated sludge system. Journal of Hazardous Materials 145, $515-519$.

Killilea J. E., Colleran E., Scahill C. (2000) Establishing procedures for design, operation and maintenance of sewage sludge anaerobic treatment plants. Water Science \& Technology 41, (3), 305-312.

Kim J., Park C., Kim T.H., Lee M., Kim S., Kim S-W., Lee J. (2003) Effects of Various Pretreatments for Enhanced Anaerobic Digestion with Waste Activated Sludge. Journal of bioscience and bioengineering 95, (3), 271275.

Kim J., Novak J. T. (2011) Digestion performance of various combinations of thermophilic and mesophilic sludge digestion systems. Water Environment Research $83,(1), 44-52$. 
Kim M., Gomec C. Y., Ahn Y., Speece R. E. (2003) Hydrolysis and acidogenesis of particulate organic material in mesophilic and thermophilic anaerobic digestion. Environmental Technology 24, 118-1190.

Krugel S., Nemeth L., Peddle C. (1998) Extended thermophilic anaerobic digestion for producing class A biosolids at the greater Vancouver regional distreict's annacis island wastewater treatment plant. Water Science and Technology 38, (8-9), 409-416.

Kyung-Yub H., Shin E-B., Choi H-B. (1997) A mechanical pretreatment of waste activated sludge for improvement of anaerobic digestion system. Water Science and Technology. 36, (12) 111-116.

Li H., Jin Y., Mahar RB., Wang Z., Nie Y. (2008) Effects and model of alkaline waste activated sludge treatment. Bioresource Technology 99, 5140-5144.

Li Y., y, Noike T. (1992) Upgrading of anaerobic digestion of waste activated sludge by thermal pretreatment. Water Science and Technology 26, 857-866.

Liu T. (1998). Anaerobic digestion of solid substrates in an innovative two-phase plug-flow reactor (TPPFR) and a conventional single-phase continuously stirredtank reactor. Water Science and Technology 38, (8-9), 453-461.

Mahmoud N., Zeeman G., Mizzen H., Lettinga G. (2004) Anaerobic stabilization and conversion of biopolymers in primary sludge-effect of temperature and sludge retention time. Water Research 38, 983-991.

Menert A., Blonskaja V., Vaalu T., Sokk O., Mölder H. (2001) Comparison of some physical and chemical pre-treatment methods for excess sludge. 2-6 September Antwerp, Belgium: 9th world congress anaerobic digestion 2001: anaerobic conversion for sustainability.

Metzner G., Lemmer H. (1997) Semi-continuous tests for simulation of municipal sludge digestion to evaluate anaerobic processes. International symposium environmental biotechnology part II, Ostende, Belgium.

Miron Y., Zeeman G.,van Lier J., Lettinga G. (2000) The role of sludge retention time in the hydrolysis and acidification of lipids, carbohydrates and proteins during digestion of primary sludge in CSTR systems. Water Research 34, 1705-1713.

Neyens E., Baeyens J. (2003) A review of thermal sludge pre-treatment processes to improve dewaterability. Journal Hazard Materials 98 (1-3), 51-67.

Norma Oficial Mexicana, NOM-004-SEMARNAT-2002, Protección ambiental.Lodos y Biosólidos.- Especificaciones y límites permisibles de contaminantes para su aprovechamiento y disposición final. Diario Oficial, viernes 15 de agosto del 2003.

Olalde Soto E. (2009) Dimensionamiento de un reactor (RAFA) para el tratamiento de lodos residuales secundarios pretratados (Desing UASB reactor for pretreatment 
wasted actived sludge). Tesis de maestría en Ingeniería Civil, Escuela Superior de Ingeniería y Arquitectura, Instituto Politécnico Nacional. México D.F.

Péringen P. (1999) Biomethanation of sorted Household Waste: Experimental validation of a relevant mathematical model. II International Symposium on anaerobic digestion of solid waste Vol I pp 9-16. Barcelona España.

Raszka A., Chorvatova M., Wanner J. (2006) The role and significance of extracellular polymers in activated sludge. Part I: literature review. Acta Hydrochimica Hydrobiologic 34, 411-424.

Rimkus R, Ryan J, Cook E. (1982) Full scale thermophilic digestion at the westsouthwest sewage treatment works. Journal Water Pollution Control Federation 54, (11), 1447-1457.

Roberts R., Son Le, Forster CF. (1999) A thermophilic/mesophilic dual digestion system for treating waste activated sludge. Journal of Chemical Technology and Biotechnology 74, 445-450.

Salhi M. (2003) Sludge reduction in a wastewater treatment process combining activated sludge and ozonation (Procédés couplés boues activées-ozonation pour la réduction de la production de boues : étude, modélisation et intégration dans la filière de traitement de l.eau). Ph.D. thesis, Institut National des Sciences Appliquées, Toulouse, France.

Sanders W. T. M., Geerink M., Zeeman G., Lettinga G. (2000) Anaerobic hydrolysis kinetics of particulate substrates. Waters Science \& Technology 41, (3), 17-24.

Shelton D. R., Tiedje J. M. (1984) General Method for determination Anaerobic Biodegradation Potencial. Application Environmental Microbiology 47, (4), 850-857.

Song Y. C, Kwon S-J., Woo J-H. (2004) Mesophilic and thermophilic temperature co-phase anaerobic digestion compared with single-stage mesophilic- and thermophilic digestion of sewage sludge. Water Research 38, 1653-1662.

Tanaka S., Kobayashi T., Kamiyama K., Signey B. (1997) Effects of thermochemical Pretreatment on the anaerobic digestion of Waste Activated Sludge. Water Science and Technology 35, (8), 209-215.

Urbain V., Block J.C., Manem J. (1993) Biofloculation in activated sludge: an analytical approach. Water Research 27, (5), 829-838.

Vandenburgh S. R., Ellis T. G. (2002) Effect of Varying Solids Concentration and Organic Loading on the Performance of Temperature Phased Anaerobic Digestion Process. Water Environment Research 74, (2), 142-148

Veeken A., Hemelers B. (1999) Effect of temperature on the hydrolysis rate of selected biowaste components. Bioresource Technology 69, (3), 249-255. 
Vlyssides A. G., Karlis P. K. (2004). Thermal-alkaline solubilization of waste active sludge as a pre-treatment stage for anaerobic digestion. Bioresource Technology 91 , 201-206.

Wang F., Wang Y, Ji M. (2005) Mechanisms and kinetics models for ultrasonic waste activated sludge disintegration. Journal of Hazardous Materials B123, 145150 .

Weemaes M., Verstraete W. (1998). Evaluation of current wet sludge disintegration techniques. Journal Chemicals Technology Biotechnology 73, 83-92.

Weemaes M., De Deken B., Bartholomeeusen W., Ockier P. (2001) Sludge digestión strategy in Flandres. 2-6 septiembre Antwerp, Belgium: 9th world congress anaerobic digestion 2001: anaerobic conversion for sustainability.

Wilén B.M., Jin B., Lant P. (2003) The influence of key chemical constituents in activated sludge on surface and floculating properties. Water Research 37, (9), 2127-2139.

Yub H. K., Shin E. B., Choi H. B. (1997) A mechanical pretreatment of waste activated sludge for improvement of anaerobic digestion system. Water Science and Technology 36, (12), 111-116.

Yue H., Sung S., Dague (1997) Temperature-phased anaerobic digestion of wastewater sludge. Water Science and Technology 36 (6-7), 367-374.

Zitomer D. H., Johnson C. C., Speece R. E. (2008) Metal stimulation and municipal digester thermophilic/mesophilic activity. Journal of environmental engineering 134, (1), 42-47. 
El jurado designado por la División de Ciencias Biológicas y de la Salud de la Universidad Autónoma Metropolitana, aprobó la tesis:

Digestión anaerobia termofilica de lodos residuales secundarios

Que presentó:

M. en B. Sergio Esteban Vigueras Carmona

Comité tutorial:

Dr. Oscar Armando Monroy Hermosillo

Director, UAM-Iztapalapa

Dra. Florina Ramírez Vives

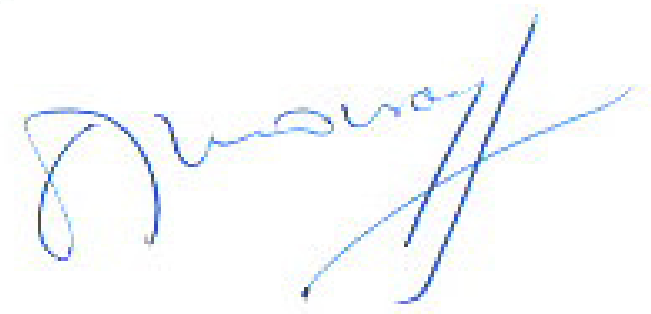

Asesor, UAM-Iztapalapa

Dr. Adalberto Noyola Robles

Asesor, UNAM-Instituto de Ingeniería

Jurado:

Dra. Florina Ramirez Vives

Presidente, UAM-Ixtapalapa

Dr. Adalberto Noyola Robles

Secretario, UNAM-Instituto de Ingenieria

Dr. Ernesto Favela Torres

Vocal, UAM-Iztapalapa

Dra. Anne Claire Texier Valentin

Vocal 